Portland State University

PDXScholar

6-16-2018

\title{
Understanding ASEAN : An Alternative Approach to International Relations Theory in Asia
}

Ryan Grimstad Driver

Portland State University

Follow this and additional works at: https://pdxscholar.library.pdx.edu/open_access_etds

Part of the Political Science Commons

Let us know how access to this document benefits you.

\section{Recommended Citation}

Driver, Ryan Grimstad, "Understanding ASEAN : An Alternative Approach to International Relations Theory in Asia" (2018). Dissertations and Theses. Paper 4436.

https://doi.org/10.15760/etd.6320

This Thesis is brought to you for free and open access. It has been accepted for inclusion in Dissertations and Theses by an authorized administrator of PDXScholar. Please contact us if we can make this document more accessible: pdxscholar@pdx.edu. 


\title{
Understanding ASEAN
}

An alternative approach to international relations theory in Asia

\section{by}

Ryan Grimstad Driver

A thesis submitted in partial fulfillment of the

requirements for the degree of

\author{
Master of Science \\ in \\ Political Science
}

\section{Thesis Committee: \\ Bruce Gilley, Chair \\ Lindsay Benstead \\ David Kinsella}

Portland State University

2018 
(C) 2018 Ryan Grimstad Driver 
Abstract

The Association of Southeast Asian Nations (ASEAN) was originally formed in 1967 by five members as a means to promote peaceful relations and prevent the spread of communist influence within their sovereign states. Since then the regional organization has doubled in size and now includes communist states amongst its membership as it seeks to establish itself as a strong economic and political hub for the greater region as two large military powers, China and the United States, vie for hegemonic influence. The American presence in the region must be governed by a firm understanding of ASEAN's unique nature and goals. When compared to other regional organizations that formed over similar time periods, such as the European Union, ASEAN has not taken a cohesive path with less of a firm timeline for integrating institutions as it instead continues to reshape its policies in small iterative steps to evolve to the changing world.

If our existing paradigms of the role of regional organizations do not match with the structure of ASEAN, we must establish a new toolset in order to guide future policies for involvement in the region. This thesis seeks to provide a clear description and thus understanding of the institutions and behavior of ASEAN as a regional organization. The questions posed include whether ASEAN conforms to the institutional and behavioral predictions of the major paradigmatic approaches to international theory, namely realism, liberalism, and constructivism. The thesis begins with a brief history of ASEAN over four distinct phases and an overview of regional organizations and international theory. The three dominant theories are then analyzed in their application to ASEAN in the areas of security, economics, and human rights. 
Conclusions are drawn that each of the three theories has its value for descriptive insight, but all fall short in creating a holistic understanding of ASEAN. Therefore, I propose a new way of describing ASEAN as a reactive, isomorphic, and anti-fragile regional organization. The potential of this approach is that it utilizes tools latent in the existing theories to examine ASEAN's nature. 
Table of Contents

Abstract....

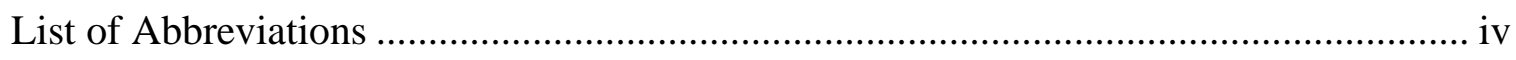

Chapter I: Shaping a Flexible Paradigm .................................................................

Chapter II: Background and History of ASEAN ....................................................4

Chapter III: Regional Organizations and International Relations Theory .......................11

Chapter IV: Questions and Research Design ........................................................25

Chapter V: Is ASEAN a Realist Security Community ..............................................37

Chapter VI: Is ASEAN a Liberal Economic Community............................................69

Chapter VII: Is ASEAN a Constructivist Rights community .....................................82

Chapter VIII: ASEAN as a Process ................................................................ 105

Chapter IX: Implications for U.S. Policy Towards ASEAN .....................................125

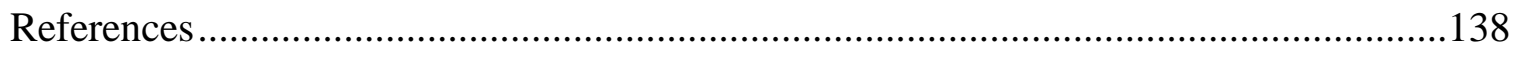


List of Abbreviations

ACCT - ASEAN Convention on Counter-Terrorism

ACSC - ASEAN Civil Society Conference

ADMM - ASEAN Defence Ministers’ Meeting

ADMM-Plus - Ten ASEAN member states, and eight Plus countries, Australia, China, India, Japan, New Zealand, ROK, Russian Federation, and the United States.

AEC - ASEAN Economic Community

AFTA - ASEAN Free Trade Area

AHA Center - ASEAN Coordinating Centre for Humanitarian Assistance on Disaster Management

AHRB - ASEAN Human Rights Body

AICHR - Association of Southeast Asian Nations' Intergovernmental Commission on Human Rights

APEC - Asia-Pacific Economic Cooperation

APF - ASEAN Peoples' Forum

APSC - ASEAN Political and Security Community

APT - ASEAN Plus Three: ASEAN, China, Japan, and South Korea

ARF - ASEAN Regional Forum

ASC - ASEAN Security Community

ASCC - ASEAN Social and Cultural Community

ASEAN Plus Six: ASEAN, Australia, China, India, Japan, New Zealand, and South Korea

ASEAN - Association of Southeast Asian Nations

AU - African Union

CSCE - Commission on Security and Cooperation in Europe

CSO - Civil society organizations

EU - European Union

FTAAP - Free Trade Area of the Asia-Pacific 
HADR - Humanitarian Aid/Disaster Relief

IGO - Intergovernmental organization

IMF - International Monetary Fund

IR - International relations

MERCOSUR - Common Market of the Southern Cone

NATO - North Atlantic Treaty Organization

NCPO - National Council for Peace and Order

NORAD - North American Aerospace Defense

R2P - Responsibility to Protect

RCEP - Regional Comprehensive Economic Partnership

RHRM - Regional human rights mechanism

RIGO - Regional intergovernmental organization

RIT - Reactive isomorphic theory

SEATO - Southeast Asia Treaty Organization

SPDC - State Peace and Development Council

TAC - Treaty of Amity and Cooperation

TPP - Trans-Pacific Partnership

USD - United States Dollar

VAP - Vientiane Action Programme

WPS - Women, Peace and Security

ZOPFAN - Zone of Peace, Freedom, and Neutrality 
Chapter I: Shaping a Flexible Paradigm

In August 2017, the Association of Southeast Asian Nations (ASEAN) celebrated its fiftieth anniversary. Over its history ASEAN has accomplished two important goals by maintaining peace between ten diverse nations and the establishment of free-trade agreements between them. Since its formation the regional organization has evolved itself and its goals repeatedly as it seeks to adapt to the everchanging regional needs, and yet when compared to more institutionalized organizations such as the European Union (EU), ASEAN remains a loose collection of states each with their own cultural identities, values, and objectives. This is not a collection of like-minded states who seek greater levels of unification with the aspiration of establishing a more cohesive union, but rather separate states that see more to gain from cooperation than competition. The benefits come from reducing risks of conflict between members, maintaining strength of sovereignty by strict rules of anti-interventionism, and increasingly greater economic benefits from free trade agreements.

The important role of the organization is underscored by the increasing level of commitment the United States has placed on its diplomatic involvement. In 2010 President Obama opened an ASEAN mission in Jakarta and followed that with hosting the ten heads of state at the first summit held in America in 2016. These efforts were to culminate in the formation of the Trans-Pacific Partnership (TPP), a multilateral free trade agreement between twelve nations that was to come to fruition in 2018 had the United States, having elected Donald Trump to office, not withdrawn leaving the region scrambling to push through a different initiative. While the enthusiasm towards the 
region has lessened under the Trump administration's more detached approach to foreign policy, the region nonetheless remains critical to global trade. Before it was eclipsed by the TPP, ASEAN had put forward the Regional Comprehensive Economic Partnership, a pact which is returning to high level talks as China, putting its weight behind the deal, is stepping in eagerly to fill the gap left by the United States in the region.

Economically and politically this region is of great significance and its priority needs to be placed higher in United States foreign policy. To do so though, policymakers need to have a greater grasp on ASEAN and what its own aspirations are. Unfortunately, academic scholarship to date has failed in this regard as the dominant international relations theories seek to impose restrictive narratives upon what role a regional organization must play. Existing work is governed by narratives without accounting for the regional cultural and political values when they do not align with the paradigms of the established theories. As realism, liberalism, and constructivism do not serve to accurately explain the whole of ASEAN's institutions or behavior, a new approach is necessary in this instance. ASEAN's reactions today do not predict future actions of the organization. It has frequently altered its scope and purpose, though it has served as an indicator of the political mindsets throughout the greater region. The theory that I will establish over the course of this paper, views the institution not as a traditional regional organization but rather as an organic entity driven by regional, state, cultural, and social values that are constantly evolving. Pushing our understanding of the association towards in new directions, avoiding the traps of being constricted into a dominant focus on security, economics, or norms as with the other schools. 
Over the course of this paper I will seek to analyze the capabilities of realism, liberalism, and constructivism when applied to the study of ASEAN, and establish that there are fundamental gaps in their application to this region. I will lay out a foundation of a potential candidate for a new approach to be used in order to gain a greater understanding of the goals and motives throughout Southeast Asia. In Chapter II I will give a brief history of ASEAN, separated over four distinct phases in its timeline. Chapter III will be an overview of regional organizations and international theory. Chapter IV will summarize how the dominant international relations (IR) theories apply to ASEAN and layout my research design. Chapters V-VII will be a deeper analysis of the existing theories when attempting to study ASEAN. Chapter VIII will seek to establish a potential new approach for the study of regional organizations. Finally, Chapter IX focuses on the value of this line of research for American foreign policy in Southeast Asia going forward. 
Chapter II: Background and History of ASEAN

Southeast Asian Organizations

The Association of Southeast Asian Nations was not the first regional organization in Southeast Asia. The Southeast Asia Treaty Organization (SEATO) was formed in 1954 as part of the United States' anti-communist 'Truman Doctrine' of creating collective defense treaties. This organization was, in comparison to the North Atlantic Treaty Organization, organizationally weak and suffered from internal divisions until its dissolvement in 1977. The Association of Southeast Asia was established in 1961, focusing on economic development, and consisted of Malaya, which included Singapore, the Philippines, and Thailand. The formation of ASEAN was at a tenuous time for the region. By 1967 Singapore had only recently separated from Malaysia, which still had tense relations with Indonesia after three years of low-level conflict; Malaysia was also at odds with the Philippines over disputed territory. The American presence in Viet Nam was ramping up significantly as the war escalated. There was skepticism from Western scholars about the durability of the association given that between the founding members there was no common language shared between them, nor any religious or cultural ties to establish a common identity. Yet the regional organization has continued to survive and the confidence in it has gradually increased.

The organization has evolved continually in the decades since its formation. Its history can be divided into four distinct phases, each with diverse goals and obstacles that the association has had to overcome. The first nine years since its creation, 1967-1976, make up the first phase in which the organization sought to assess its goals. The second 
phase lasted from 1976 through 1991, characterized by the American exodus from Viet Nam, followed by Viet Nam's occupation of Cambodia. The end of the Cold War triggered the third phase. Lasting from 1992 to 2002, this was a period of rapid expansion for the organization, seeing it double in size and the rapid economic bubble bursting. 2003 was the start of the fourth, and current, phase with the Declaration of ASEAN Concord II (Bali Concord II) that codified the formation of the three pillars of the modern institution: the ASEAN Political and Security Community (APSC), the ASEAN Economic Community (AEC), and the ASEAN Social and Cultural Community (ASCC). These communities are still in development and will play a significant role in the direction of the region going forward. The shifts between the separate phases of ASEAN were due to strong geo-political changes at the regional and international levels.

First Phase - 1967-1976

The initial formation of ASEAN consisted of five members: Indonesia, Malaysia, the Philippines, Singapore, and Thailand. There was little commonality between these states, with stronger levels of animosity than trust between its members. This period saw no meaningful actions taken by the fledgling organization. Instead, it served to maintain peace which allowed the states to dedicate their limited resources towards internal stability and development. Dewi Fortuna Anwar describes ASEAN at this time as being little more than a club for Foreign Ministers as there were no other levels of government, there were no regional cooperation mechanisms were established and no ASEAN Summits held. The most noteworthy result of this phase was the values that were taken 
that would become defining characteristics of ASEAN. Members were to respect sovereignty and boundaries, vowing to not intervene in another's domestic issues, and decision-making in ASEAN was to be done via consensus.

After the United States changed its position and normalized relations with the People's Republic of China, ASEAN released their first joint political statement in 1971. They declared that the Southeast Asian region was a Zone of Peace, Freedom, and Neutrality (ZOPFAN). Though the founding members all had anti-communist policies, they sought to maintain a neutral balance between the two large powers.

Second Phase - 1976-1991

The victory of the communist forces in Viet Nam over the American military super power stunned the members of ASEAN, which played a critical part in the dissolution of SEATO in 1977, as members lost confidence and interest. Fear built that the region would eventually fall to communism as Laos and Cambodia transformed. America was concerned that Thailand, Malaysia and Singapore would eventually fall too, like dominoes, it did not expect the ASEAN states to remain as resilient as they did. In February 1976 the first ASEAN summit was held in Bali. There, efforts towards increasing cooperation in the region were necessary towards resisting the spread of communism. The Declaration of ASEAN Concord I (Bali Concord I) confirmed the values that had been established in the preceding decade, the principles of respecting sovereignty and integrity and to not interfere in one another's internal matters. This 
meeting also led to the formation of an ASEAN Secretariat and efforts to increase economic cooperation in the region.

Another significant milestone of this period was the Treaty of Amity and Cooperation (TAC), in which the signees agree to ban the use or threat of force and that all conflicts must be resolved peacefully. This was put to the test immediately in December 1978 when Viet Nam went on the offensive after provocations by the Khmer Rouge regime, invading and occupying Cambodia. In its first major diplomatic challenge in determining how to respond, whether to accept the occupation or to diplomatically oppose it. While the Cambodian government was looked down upon by the ASEAN states, they viewed the invasion by Vet Nam as unacceptable and pushed for peace negotiations. After years of talks, ASEAN was eventually able to bring about an end to the conflict. This was a monumental diplomatic success for ASEAN, gaining it significant amounts of credibility in the international community. This phase also saw the first introduction of a new member to ASEAN with the acceptance of Brunei in 1984.

Third Phase - 1992-2002

The third phase of ASEAN was of expansion. With the admission of Viet Nam (1995), Laos (1997), Myanmar (1997), and lastly Cambodia (1999), ASEAN had doubled in size from its original roster. The integration of the new members allowed for greater economic trade and dismantling of barriers, but its policy for consensus in decisionmaking became increasingly difficult. The end of the Cold War was a turning point in 
international relations around the world, including Asia. It allowed an opening for ASEAN to shift from its anti-communist policies towards promoting its values of peace, non-interference, and integration of the region. While reluctant at first, it decided to support Asia-Pacific Economic Cooperation (APEC). It also pushed for a forum to promote diplomacy in the region, establishing the ASEAN Regional Forum (ARF). The organization also expanded its engagement in the region with membership in a series of intergovernmental organizations and forums. It also signed several bi/multi-lateral free trade agreements. Economically, this decade saw a massive flux as economies throughout ASEAN and the region's markets expanded rapidly. This growth was cut short as ASEAN faced another major challenge when the 1997 Asian Financial Crisis began in Thailand and decimated economies throughout Asia. The economic and political fallout from the credit bubble bursting still can be seen.

Fourth Phase - 2003-Present

While the third phase was a period of massive expansion for ASEAN, the fourth phase has been one of solidifying the regional organizations. In 2003 the ASEAN summit was held in Bali for the Declaration of the ASEAN Concord II (Bali Concord II), which established times for the three pillars of the ASEAN Community, the ASEAN Security Community, ASEAN Economic Community, and ASEAN Socio-Cultural Community. These are to be the foundations for more concerted development towards further integration and expand the scope for their role in the region. 
On the fortieth anniversary of the formation of ASEAN, at the $13^{\text {th }}$ ASEAN Summit at Singapore in 2007, the ASEAN Charter was signed, ratified in 2008. This Charter serves as a constitution for the association, establishing the principles of centralizing regional cooperation as well as international relations through ASEAN, promoting a regional identity, and continuing the values of sovereignty and noninterference. It also increased the number of summits to twice a year. Though it does not have any direct means of enforcement, even from the Secretariat, it has gained enough weight that the members no longer act entirely independent from it.

Though there is no titled leader in ASEAN, Indonesia has viewed itself as de facto filling that role, given its large geography and population. This has generally been informally accepted by the other members. Ralf Emmers examines how successful Jakarta has been in exercising leadership within ASEAN in Indonesia's role in ASEAN: A case of incomplete and sectorial leadership and how it has been viewed by other Asian states, in such issues as mediating the conflict in Cambodia and the South China Sea. The organization struggles trying to maintain neutrality amidst the growing tensions between the United States and China in order to keep good relations with both, even as it increases its defense ties with the United States' military. A significant embarrassment for Indonesia was when it had to renounce its claim over East Timor in 1999, the loss of territory was a deep humiliation for Jakarta. Separatist movements and sectarian violence also brought further instability to domestic politics. These were severe blows to what had traditionally represented the political center of the Association. During the Asian financial crises and burgeoning threat of international terrorism, Indonesia was very slow to respond. Its president being viewed as ambivalent and lacking the will to act decisively 
caused frustration amongst the other ASEAN members as well as friction with the United States. While previously viewed as a strong contributor to regional security, its inability to deal with domestic terrorism became a source of international concern. Indonesia had aspired for an autonomous security environment that would be unaffected by external intervention, though this is not agreed upon by other ASEAN members that have historically rejected this conception of the regional order and instead often relied upon ties with external actors to ensure security. "Most member states have not perceived the Association as a security arrangement that can replace existing bilateral links with external players, especially with the United States" (Emmers 2014, 549-550). With the role of the Secretary General being to observe discussions more so than guide them, and having no true powers of enforcement, the larger states within ASEAN will continue to act with more power. Though they remain constrained by the requirement of consensus with their fellow members. 
Chapter III: Regional Organizations and International Relations Theory

General theory and practice of regional organizations in international relations

There have been many attempts to apply theories to the mechanics of international relations. Both realism and liberalism have remained the dominant approaches, though they have gone through several fragmentations, classical, and 'neo' iterations. Alternative approaches, such as constructivism and functionalism, have emerged but have not yet reached as high of a rate of acceptance by practitioners. Intergovernmental organizations (IGOs) are predominantly classified by the organization's purpose and the size of its membership. At the highest level, there are organizations such as the United Nations and its precursor the League of Nations, seeking as inclusive of a membership as possible. Institutions this immense are multipurpose, with diplomatic efforts spanning across political, economic, military, and humanitarian needs. While the breadth and effectiveness of these efforts is continuously being debated internally and externally, the scale of these institutions has not always given them an equivalent level of influence, as the diversity of their membership leads to many divisions across political boundaries. Regional based organizations have many of the same weaknesses, but they bring with them many additional strengths.

While the proximity of the states within a region has given them a shared geographical identity and common history with which they can relate to each other, this shared history can also be filled with political or militaristic strife leading to suspicion throughout the organization. The European Union has overcome many challenges to obtain its current level of integration, but that has been an established goal; other regional 
organizations, such as the Organization of the Americas, have sought to resolve political and economic disputes peacefully, but the historic feud between the United States and Cuba has always made rifts. The African Union (AU) has had some success in its attempts to resolve some of the conflicts through multinational operations, but there are still high levels of distrust of these efforts as being invasions rather than humanitarian efforts. The degree of influence these institutions have over their members varies greatly. While some regional organizations such as the Shanghai cooperation only seek to facilitate trade and security efforts in central Asia, others such as Common Market of the Southern Cone (MERCOSUR) also seek to expand cultural and legal collaboration.

The size and goals of an IGO are fundamentally linked, but neither is static. As small multilateral organizations mature, they often develop from strictly economic initiatives into security or vice versa, which could expand the association into a full regional organization. The expanding fields of initiatives over time will bring with them new regional norms, changing the cultural identity of the region. This effect is less seen in much larger associations. Institutions that cross regions are so broad in nature that there has been little effect on the identity at the local level. While the European Union has worked to cultivate an identity of being European, more expansive organizations such the North Atlantic Treaty Organization and Soviet Union each fostered a shared sense of 'us versus them' mentality that fostered a communal identity; the globalized United Nations has not made any inroads to date insofar as a globalized identity. Rather, it has continued to strive towards the international impacts of events and the need for global response. That United Nation's personnel providing humanitarian or peacekeeping 
interventions serve under the UN's banner, instead of their homeland, demonstrates a value in international cooperation over the assertions of a singular power.

What international relations theory says about why regional organizations have proliferated and gained traction in the post-Cold War period

With the disappearance of bi-polarity, regional intergovernmental organizations gained a functional usefulness for the first time, no longer constrained by the Cold War. The end of the Cold War brought about significant changes in governance at the regional level. Before, the West and East blocs were primarily concerned with the political alignment of the region and access to its resources, fighting for influence with various overt and covert means. As the 'Iron Curtain' fell in Europe, regions around the globe gained much more control in their self-governance, the primary draw now being on opening markets under globalization. Regional shifts have emerged as a significant topic of research since then fall of the Berlin Wall. "With the end of the Cold War, the proper understanding of regional conflict and cooperation patterns assumed wider significance" (Paul 2012, 15). During the Cold War, regional conflicts were viewed by the great powers as a means to gain or maintain influence, but now states within the region have become the primary driving force behind conflict resolution, giving much more influence from regional intergovernmental organizations (RIGO) than before.

This transition has been very difficult. Many developing nations were largely reliant upon economic and security assistance from the superpowers and now must change their political and economic institutions to face the new world order. Many 
regional organizations failed to shift into a post-Cold War world as the early enthusiasm for the prospects of peaceful cooperation did not lead to tangible improvements in relations. Interregional strife that had previously been mitigated or suppressed is now surfacing, sparking an increase in small- and medium-sized conflicts along ethnic and other cultural lines. While the United Nations or other large international institutions have intervened in some instances, others have been left only to local actors; these organizations are unprepared as they lack much of the necessary equipment or training to respond. A serious concern in times of intervention is the risk that these peacemaking forces instead are viewed as an invading army, upsetting the population and furthering the conflict.

While through the North Atlantic Treaty Organization Europe has already had in place a military cooperation, it has also sought to create a regional force structure within the European Union. Given the advanced and stable nature of these states and their already capable military prowess, this would be a formidable force. As the EU has expanded its membership into Eastern Europe, it is struggling with overcoming decades of Soviet practices ingrained into the culture. Overcoming these from differing political, economic, military, and cultural practices will be crucial for integration efforts and long term regional stability.

One of the more significant examples of the changing role of regional intergovernmental organizations in the post-Cold War landscape was the approach taken by the African nations. In 1963, the Organization of African Unity was formed, promoting the cooperation of member states to remove the last vestiges of colonialism 
which had shaped the continents history for over a century, and to give a more unified resistance to pressures from the Western and Eastern blocs of the Cold War. In the 1990s, African leaders decided that the best approach going forward would be to create a new organization, an African Union, rather than undertaking the effort to remodel the existing institutional structures of the OAU. While still incorporating many of the previous union's principles of solidarity and sovereignty, the AU also sought to expand cooperation into promoting the democratic principles of popular participation, good governance, human rights, and increasing the standard of living. The new institution also includes efforts towards coordinating reginal economic communities, scientific and technological efforts, and disease eradication efforts (African Union Sumit 2002). Similar regionally independent organizations have emerged, such as the MERCOSUR, a trade bloc founded in 1991 between Argentina; Brazil; Paraguay; Uruguay and Venezuela, though Venezuela has been suspended since December 2016. A more recent effort with a larger membership is the Community of Latin American and Caribbean States, founded in 2011, which includes every country in the Western Hemisphere except the United States and Canada. This only the latest in a series of organizations that have attempted to foster a more cohesive regional institution that would not be reliant upon, or controlled by, larger powers.

The approach in Asia was instead to reform its already existing Association of Southeast Asian Nations, which had institutionalized a policy of non-interference in internal conflicts among the member states as a core principle. European colonial efforts had less of an impact in Asia as, unlike in Africa, it already had strong sovereign states. While there were strong colonial efforts, they were more focused on forced trade rather 
than exploitation and repressing efforts of resistance such as the Boxer Rebellion or the prolonged Vietnamese guerilla efforts. The long history of these states and foreign interference has led to a strong sense of state sovereignty, which has shaped ASEAN's trajectory. While it has fostered a mutual respect for self-determination, it has also left the organization incapable of effectively responding in cases of international terrorism or humanitarian crises. Its focus has remained on common security, rather than a cooperative security intuition. It's non-militaristic ethos has pushed it to rely upon diplomatic efforts to stabilize the region through inclusiveness with initiatives such as the ASEAN Regional Forum, which was established in 1994, has sought inclusiveness in its membership. This even extends to embracing strategic rivals such as China and the United States, North and South Korea, and India and Pakistan. The organization has made inroads into improving relations, even cooperation, between its members.

United Nation's affirmation of the role of regional organizations and local governments

The Cold War divisions left the United Nations incapable of responding to most regional crises, due in large part to the veto power of the rivaling Security Council members who had political or economic stakes in the region. During the prolonged conflict, the Secretaries General had to increasingly turn to regional organizations not only for their local expertise, but because their proximity to the burgeoning conflicts led to a greater willingness to prevent its spread. This method of response has continued after the collapse of the Soviet Union. In 1997 UN Secretary General Kofi Annan released a report, Renewing the United Nations: A Programme for Reform, to the General Assembly 
in which he expressed the reliance upon regional organizations due to the United Nation's inability of to respond effectively. "Under present conditions, ad hoc Member States coalitions of the willing offer the most effective deterrent to aggression or to the escalation or spread of an ongoing conflict" (United Nations 1997).

Having remained the same for the length of the institution's existence and seeming unlikely to change, there are two significant reasons for this: divisions on the security council among vetoing members and lack of resources and personnel for peacemaking and peacekeeping operations. The current conflicts in the Middle East underscore the Security Council's ability, and willingness, to respond cooperatively. This comes in part as a consequence of initial agreements being made to end growing civil strife in Libya, which had been agreed upon by the council for a limited response, but left China and Russia viewing the actions taken by the North Atlantic Treaty Organization (NATO) forces as greatly exceeding what they had agreed to in the resolution. While Russian forces have come to be directly engaged in the Syrian conflict, the Russian and Chinese governments have repeatedly blocked attempts for resolutions against the Syrian government. These divisions on the Security Council mire any potential actions in debates of rhetoric rather than logistics, negatively skewing the intuition as a whole in the public's mind.

The UN has continued to encourage greater connections with regional organizations, recently adopting ten resolutions to address global challenges, acknowledging efforts from various regional institutions as the African Union and the Shanghai Cooperation. The resolutions push for more direct interactions between the UN 
and the other organizations, "encouraging deeper cooperation between the United Nations and various regional organizations to address emerging challenges in sustainable development, fighting terrorism and economic integration" (United Nations 2016). This would include more direct consultations with the various organizations as well as establishing ties between the UN's specialized agencies and their regional counterparts to expedite logistical and financial support. As regional strife continues to spread and historical rivalries gridlock the UN Security Council, regional organizations will likely grow as the preferential instrument of the Secretary General and the General Assembly.

How regional intergovernmental organizations make states attractive vehicles for foreign policy

The practice of foreign relations becomes inherently more complicated when applied through a regional organization, following the delicate nature of discourse between member states as well as formulating external policies that can be agreed upon. "IGOs are important actors because state leaders believe they are. When state leaders deliberate over major foreign policy actions, they almost always find themselves considering repercussions that may involve one or more IGOs" (Kinsella, Russet and Starr 2013, 82). The nature of these regional intergovernmental organizations can vary dramatically depending on the political and cultural identity of its members, and thus attempting to extend that into a shared regional identity is difficult. It is upon this shared regional history that a new more expansive identity can manifest; additionally, with local and state institutions, expectations will form around the organization's responsibilities as 
it finds its role in society. The role of an IGO becomes institutionalized as the citizens within them come to rely upon, and even expect, them to act in certain ways. "They expect the United Nations to help calm areas of conflict, as it did in East Timor to keep the peace and prepare for the transition toward independence beginning in 1999" (Kinsella, Russet and Starr 2013,81). As the continued practice of these institutions goes on, they become socio-political norms, over time serving to greatly enhance the building of a larger cultural identity.

The effectiveness of these organizations is analyzed through differing views in international relations theory. The various theories differ in their views of the inherent purpose and value of states allying together. Whereas realism takes the stance that states, like individuals, are inherently homogenous self-serving and thus should only seek paths that will benefit them directly, there is no authority over the state. Liberalism asserts the centrality of domestic preferences, that the benefits of enhancing the group as a whole will create greater stability and that the larger institutions should govern over the states. Constructivism shifts the focus away from the policies of the state but rather onto the effects of historical interactions at the societal level and how those bonds of shared culture are as important in creating regional identities as the actions made at the state government level.

The major paradigms may be used causally (to explain what causes institutions or behavior) or descriptively (to describe the fundamental orientation or values of an institution or behavior) and may be applied to a variety of actors, including states and 
regional organizations. This thesis will use the paradigms descriptively and apply them to a regional organization, namely ASEAN.

\section{Realism}

A central principle in the various iterations of realism would be that a regional organization exists in an anarchic global system where other states cannot be depended upon to cooperate, and any cooperation should be ended when it is no longer advantageous. The nation-state is the fundamental actor and thus, as a rational actor, seeks to ensure its own security and prosperity over the needs of others, including through the formation of regional organizations to advance its security and power. This can result in attempts to form a hierarchical order of military and economic powers and a balance within that order. Larger states will be much more inclined to aggressively assert their influence in the region as hegemonic powers if there is no counter-balancing force, be it another large state power or by a coalition of states. It behooves smaller states to ally with larger ones of similar ideology and culture for their security or to join a strong enough collection that would dissuade potential threats. Regional organizations may thus play a role as vehicles for state ambitions. A central difference between classical realism and neorealism is that, while they both view that state as the primary actor, the classical realists view conflict as an inevitable failing due to human nature. Whereas the Neorealism views conflict as the outcome of a void in the international order, and that states will seek to assert their dominance when possible. 
The balance of hegemonic powers is critical in order to maintain peace under most forms of realism, as no state would be likely to attempt aggression without a clear advantage. Neorealism theorizes that regional order very much plays a role of the larger international system, as well as of the balance of power among the larger powers. Bipolarity at the international level maintains regional peace while multipolarity destabilizes. Neorealism views the great powers as the main caretakers of regional order. The balance between these powers serves to create stability in the region, and the security organizations that they foster can expand into other socio-economic forms. It was the Cold War competition, and within it the presence of the United States and its sphere of protection, that served to create the European Union, this security institution created the conditions without which the Union would not have been possible.

\section{Liberalism}

The primary emphasis of liberalism is on the potential capability for nations and regional organizations to institute an agency through which they can collectively prosper and externally influence to a greater degree than they would be capable on their own, due to their varied domestic preferences. This theory is such a strong counter to realism because its focus goes far beyond that of solely security, instead concentrating on the sets of domestic actors that cross borders and their interests. Under this theory, the emphasis for change is with the ability of nations and leaders to resolve their disputes through clear policies built around liberal values. Internal actors, social groups, and organizational lobbies all vie to influence the state's institutions, affecting the state's external policies. 
States with heterogenous preferences would become integrated so they would seek to create IGOs that manage this integration for their own constituency. If developed, these three actors allow for the emergences of a security community. Economic interdependence generates strong incentives towards cooperative efforts, and significant vulnerabilities that would deter in regional conflict with one another. Strong regional institutions have instilled this process by offering a means for engagement, and a venue for dispute settlement.

The notion of economic integration leading to enduring peace is a central value driving the efforts behind globalization; as state economies become more intertwined, it would be too costly to create conflict. The removal of barriers between markets will not only expand the potential for material trade but will also allow for greater cultural trade as well. The driving ideology behind globalization has been neoliberalism, which focuses on economic liberties in addition to the political liberties rooted in classic liberalism. States will seek to minimize risk in uncertain conditions of interdependence by promoting the creation of formalized rules and norms. The potential gain from this integration has been a strong force in aligning states that previously had been rivals, such as was the case with the European Union, whose economic integration after long histories of conflict has led to further political collaboration.

\section{Constructivism}


Though newer than the other two approaches to international relations, constructivism takes a more normative, ideational, and cultural-focused approach. Rather than focusing solely on the state elite to determine if a state or regional organization is perusing militaristic expansionism or economic alliances, this method factors in the cultural and normative interactions within the global sphere. Whereas realism focuses on states, and regional organizations, behaving as rational actors, this approach views states as actors with more normative behavior that reflects their distinct cultures. States interact in a social environment much in the same way individuals would. They seek friendly relations with those who share likeminded goals. The perception of goals and obstacles are developed through the history of idea entrepreneurs. Under this theory, norms and practices are considered significant towards the formation and perseverance of regional order. Norm entrepreneurs serve to create and diffuse these ideas internationally. Cultural and economic exchanges done at the local level between separate nations can influence a greater relationship.

This focus on the cultural practices gives way to much greater understanding of the how and why a state or regional organization would act counter to one from another region in a similar situation. Europe, divided for centuries of conflict, has been able to build upon the cooperation of economic and security integrations to make great strides towards a unified European identity; yet a generation after the end of the Cold War, that only scarce few interactions have taken place at the cultural level has given way to resuming tensions as both sides have not found a shared approach to engagement with each other. The establishments of new, shared norms and practices serve to create a greater cultural bond within a region. The more holistic approach of constructivism in 
international relations theory seeks to include the importance of state security, the material needs of the economy, and the social norms more deeply than the other two approaches.

The historical interactions between cultures, the 'cognitive priors,' persist as the foundation of contemporary views. These legacies passed down, such as feuds from wars fought by prior generations, can serve to prevent any social bonds from forming, even when the states wish to pursue strategic alliances. In East Asia, as Japan and the Republic of Korea governments acknowledge the need for greater cooperation for regional security, the cultural legacy from the last century makes combined efforts extremely difficult, as the citizens have held on to their grievances. In other cultures that more readily allow for change, the necessity of security alliances can lead to greater cooperative interactions and build new relationships at the local level, this serves to ward off regional conflict but can also lead towards the development of a communal identity. The design of an institution embodies the norms that caused them, as shared experiences makes the development of collective identity more viable. "In a constructivist framework the effects of institutions can be far reaching, changing actors' beliefs and identities, and hence, their definition of interests. As handmaidens of new actors, tasks, and objectives, institutions are purposive agents specifying authority patterns and allocating responsibilities" (Ganesan and Amer 2010, 6). Where realists view the weak decisionmaking process institutionalized within ASEAN, and a liberalist would focus on the failings of the economic collaboration to expand into further socio-political programs, a constructivist would view the historical and cultural developments among the diverse states in the region as a logical path to the established norms. 
Chapter IV: Questions and Research Design

Theoretical debates on "What is ASEAN"

Each paradigm of world affairs seeks to explain how the ASEAN can, or should, operate in state-to-state and regional affairs. Realism focuses on a 'security and power first' agenda driving all interaction, seeking power to control and manipulate relationships, the goal being security over all other needs. Liberalism shifts the focus to the role of diverse actor preferences, including the heterogenous preferences of domestic societies and the possibility of different cooperative or conflictual solutions (institutions and behavior) emerging depending on the shape of those preferences. Constructivism focuses more on discursive emergence of the assumptions and goals of state and nonstate actors, not the inevitable outcome of the prior theories, looking at how the social norms develop and shape institutions. The question I address here is whether ASEAN is a regional organization whose institutions and behavior conforms most closely to one of these three. While this is closely related to the behavior and policies of its member states, the two remain separate because ASEAN is a structure that supervenes upon these states but is not reducible to them. In this chapter, I will examine how various experts have examined ASEAN through the lenses of these theories and illuminate gaps in the applied logic, and lastly, propose a research design towards determining a more accurate understanding of the Asian association.

Realism 
From a neorealist perspective, the association's time of greatest power is when there is a period of equality among the large actors in the region, forcing them to seek to court influence with ASEAN to gain an advantage. During periods of regional instability, the group of smaller states would be unable to coordinate, generating negligible effect and likely being pushed aside in a larger crisis. In International Relations in Southeast Asia-Between Bilateralism and Multilateralism, Professors N. Ganesan and Ramses Amer collected contributions from several scholars to examine the interactions between states in the region since the 1970s. They view that for neorealism, institutions are linked to powerful states that can find them useful tools of statecraft, a means for exercising power. The designs of institutions are pliable to their needs and subject to change. While regional organizations can provide greater strength through larger numbers, either bolstering a hegemonic power or to provide a counter balance against one, neither of these apply to ASEAN as there is no hegemonic member, nor does it provide for a defensive security pact among its members, rather than a series of bilateral agreements, many of which with outside powers, such as the United States. This view has various critiques though, as hegemons may have incentives to organize regional institutions but so have others seeking to balance against them. To this effect, ASEAN serves as a relevant example, as weaker states may themselves seek to institutionalize in order to enhance their power within them or out of fear of being left behind. "Williams finds multilateralism to be advantageous to weaker players because it provides nondiscrimination, reciprocity, and self-restraint, which bilateral agreements generally do not" (Ganesan and Amer 2010, 5). 
Within ASEAN though the complex differences between nationalities and cultures serve to create difficulties in establishing the trust necessary for cohesive institutions that could bring security or balance power. In Why is there no APTO? Why is there no OSCAP?: Asia-Pacific security institutions in comparative perspective, John Duffield explores the characteristics missing in the Asia-Pacific community that are necessary to establish a security community that one would expect out of a regional organization under a realist perspective. A neorealist explanation would view the structure of the international system as being defined primarily by the number and relative capabilities of major powers. This view does well to explain the rapid development of security institutions in both the Euro-Atlantic and the Asia-Pacific following the Second World War. "It is much less able, however, to account for the important differences across the two regions" (Duffield 2010, 75). These include such differences as the nature of security treaties between the two regions; where the EuroAtlantic adopted multinational security community culminating in the North Atlantic Treaty Organization, the Asia-Pacific region was intertwined with a multitude of bilateral agreements. Though both efforts were fostered by the United States, another difference Duffield noted that is not explained under realism is that the Asian community lacked the degree of formalization, elaborateness, and multilateralism that was seen in Europe in the first years after the end of the Second World War, and renewal in the post-Cold War era.

Acharya refers to the works of Karl Deutsch, whose work in the 1950s explored the development of security communities. Acharya focused on the low priority placed on regional integration by ASEAN in the traditional sense by suggesting an approach to community building that is quite different from that defined by Deutsch. Deutsch viewed 
the security community as the end product of an integration process which is driven by a need to cope with the conflict-causing effects of increased transactions. These transaction, political, cultural or economic, serve to increase the opportunities for potential conflict between actors, thus forcing them to develop institutions and practices that can promote a peaceful transition. In the case of ASEAN though, regional cooperation was instead undertaken with the absence of high levels of interdependence or interaction. "ASEAN evolved as a sort of an 'imagined community', despite low initial levels of interdependence and transactions, and the existence of substantial political and situational differences among its members. In this sense, the vision of community preceded rather than resulted from political, strategic and functional interactions and interdependence" (Acharya 2001, 195).

In the absence of a strong state power to rally around, traditional theories would assert that the small ASEAN forces would seek to coordinate their defenses to create a credible deterrence from the larger regional powers. This would be justified by the long history of invasion and colonization in much of their shared history; rather, the regional norm has swung in the opposite direction in favor of firm independent sovereignty, even from allies. This avoidance of military pacts, including a multilateral ASEAN military, was a strong norm for ASEAN regionalism. Instead, a defense community within ASEAN can only be described as being an overlapping a web of bilateral defense agreements between most of its members. This approach has several severe shortcomings. These agreements are at differing stages of development, they operate under difference doctrines and lack of weapons standardization or joint weapons procurement. "Differing degrees of defence self-reliance within the region, all reflect, at 
least partly, lingering military suspicions among the members, and virtually preclude the emergence of a defence community in Southeast Asia" (Acharya 2001, 200). These regional norms defy the conventional wisdom of establishing greater levels of security and economic initiatives.

\section{Liberalism}

Classical liberalism praised the potential for intergovernmental organizations, like the expanding United Nations, to create a more stable and prosperous world, as states wound find they have more to gain through diplomacy and cooperation. This cooperation could even extend into conflict as states with likeminded values would ally together during the turbulent years of the Cold War, which used regional organizations and political blocs to gain further control and influence than their rival, power in a realist's world. Neoliberalism emerged, focusing on economic gains as a leading cause for intergovernmental cooperation, promoting reduction of trade barriers and tighter economic integration. The objective being globalization, with liberal values being a benefit rather than a goal.

This view demonstrates much of the actions taken by ASEAN, in which the majority of steps towards integration have been taken with a focus on economic cooperation at the forefront. The five founding members worked with a domestic model of economic growth through engagement in the global economy. Their uniting interest in collaborating regionally through ASEAN was to protect their model from domestic 
insurgencies and regional threats to their model's domestic dominance. Under this system there was increased per capita, high employment, and increased investments in health and education, and returns to small businesses and farmers. While the focus remained on gradual and selective internationalization, while intra-regional efforts of trade and integration were not a priority.

The strength of the ASEAN Economic Community was that it would remain separate from the political and social spheres; this would allow for a more inclusive range of members that would otherwise not come together over competing political models. The focus on economic development goals over challenging the regional powers in an economic or militaristic power struggle does follow in line with the liberalist model, but many of its actions defy the theory. Instead of seeking to fuse its governance into an overarching organizational level, many of the state governments have resisted ceding any level of sovereignty. It has not worked towards consolidating its economic programs or currencies, as has been a long-established goal of the European Union. The variations between the cultures and governing methodologies places limits on the collaborative efforts. It also shares many similarities and differences with constructivism.

"There is also a growing tendency towards analytical eclecticism, which includes both material and ideational variables of realism, liberalism and constructivism, in order to explain the dynamics of security in Southeast Asia" (Floristella 2015). When comparing to constructivism, Angela Pennisi di Floristella notes the shared emphasis of norms, principles, standards of behavior, and interactions, but the two theories have distinct divergences. Both theories highlight the importance of institutions in regard to 
regional security, but she believes that they hold differing perspectives on the reason why institutions matter. Where constructivists associate institutions with the rise of a community, and the mutual recognition of an identity, neoliberal institutions instead primarily serve to create a stable and functional environment in which all states pursue their own interests. As a result of this, the two approaches take different views of the circumstances under which cooperation among states is likely to occur or what form of institutions will result from the interstate cooperation. A constructivist focus is on shared values, which give way to the creation of a communal identity which is not defined by interests alone. Neoliberals place significant emphasis on the importance of shared interests as the driving force behind the development of interactions and the formation of a system of cooperation.

Constructivism

In recent history, constructivist approaches have been heavily utilized to understand ASEAN as a multilateral institution. One of the more ardent proponents of applying the constructivist methodology in the analysis of ASEAN has been Amitav Acharya, a professor at the American University, who over many bodies of work has championed the advantages of this new approach, such as in Constructing a Security Community in Southeast Asia: ASEAN and the Problem of Regional Order. A reason that the creation of ASEAN is significant is from the high level of divergence between its five founding states in terms of ethnic composition, socio-cultural heritage, colonial and postcolonial polities. These states also lacked any experience in multilateral cooperation. 
Absent cultural and political homogeneity as a shared norm for the basis for regionalism, the norms had to be constructed through interaction. "Such interactions could only be purposeful if they were consistent and rule based, employing those rules which would ensure peaceful conduct among the member states. To this end, ASEAN's founders over a period of a decade from its inception adopted and specified a set of norms for intraregional relations" (Acharya 2001, 47). The historical development of these norms is essential to understanding the foundational pillars of an institution, more so than basing our understanding of an organization through perceived goals from a foreign background.

Whereas other regional intergovernmental organizations such as the European Union had from a relatively early date established an 'end goal' of political unification and could work towards that over the following decades, the Association of Southeast Asian Nations did not establish lofty long-term goals, focusing instead on short-term programs that could be more viable with contemporary socio-political realities. The cultural diversity and historical distrust of foreign states prevents greater consolidation within ASEAN that would be expected to be a desired path under the liberalist theory, as does the lack of effort towards generating greater levels of strength, economic or military, in relation to its neighbors, undermine much of the realist model. Where the constructivist model succeeds in explaining this RIGO is in its embrace of the norms that have been established historically in the region, rather than seeking to shoehorn ones that are not present. The unique political culture of the region impacts its direction more than is embraced by either of the other two theories. 
An issue norm that has become increasingly important in international relations is that of human rights. As technology and communications become more prevalent, awareness of human rights on a local level has been brought to greater focus regionally and globally. Constructivist theory establishes that institutions are reflective of cultural identity of their citizens, an example being a society that values democracy will form institutions with transparency and compromise as norms. With ASEAN though, there is a significant disparity between the values of its citizens and the actions and designs of its institutions. This action-identity gap is illustrated by its response to human rights. The adoption of human rights points to those norms being used deliberately for political ends, particularly the legitimacy of ASEAN to both of its citizens and the international community. Social changes are continuously resisted until convenient to maintain stability or advantageous. The disconnect between state and cultural norms it represents critically undermines constructivist arguments.

ASEAN as a regional Institution vs. ASEAN as something else

A flaw of the three international relations schools is that each places its focus onto different aspects of the role of regional organizations, neglecting the value of the other characteristics. Too much research focuses on typecasting ASEAN into the concept of a traditional regional organization. Realism is primarily focused on security, liberalism centers on the economy, and constructivism emphasizes on society, culture, and rights. Each of these areas should be considered vital as a whole in the understanding of a regional organization, rather than sectioned off from each other. Separate, each of the 
schools only serve to provide a partial explanation of what the role of ASEAN serves for in the Asia-Pacific community. If ASEAN does not fit within the established paradigms for international relations, then an innovative approach must be considered. In International Relations of Asia, Acharya raises awareness of several Western scholars seeking to create an "Asian IR theory" (Shambaugh and Yahuda 2014, 104). Though, Acharya notes, there are Chinese scholars who reject the limited theory in search of a more universal frame, instead they view that attempts to develop a theory should not be guided by cultural specificity, rather by scientific universalism.

The classical paradigm of an international organization is the focused intent centered on a security and/or economic nature. The neorealist theory would explain ASEAN as being weaker states binding themselves to an institution to enhance their power within or for fear of becoming irrelevant. A neoliberal approach to RIGOs would be to assert that the goal for states would be to advance their interests by establishing institutions to promote interdependence and resolve collective action problems. "Institutions reduce uncertainty, enhance information about preferences and behaviour, lower transaction costs responsible for market failure, monitor compliance, detect defections, increase opportunities for cooperation, reduce the costs of retaliation, facilitate issue-linkages, and offer focal points or salient solutions" (Ganesan and Amer 2010, 6). While ASEAN has created several institutions, they are inherently weak collaborative efforts with no authority over the organization, or they are spun off into separate agencies such as the ARF and AEC. Both of the international relations theories attempt to explain how a regional organization should function, or even what its goals 
should be, but do not coincide with the historical efforts made by the Asian governments or the regional organization as a whole.

The Association of Southeast Asian Nations cannot be explicitly described through current international relations theories. There remains strong political resolve against efforts that could potentially bolster state and regional security or the lack of control over institutions created to develop economic markets. The distrust in collective institutions and unwillingness to grant any agency actual power over participant states undermines the value of the institutions, and yet the states still seek to maintain their membership to the organization. In the absence of a prevailing model, a new approach may be needed in order to explain how this RIGO functions, taking account of the local history and cultural norms, without imposing the preconceptions of existing IR theories on intergovernmental organizations.

Research design

To explore the capabilities in each of the three dominant IR theories in explaining the functions and trajectory of ASEAN, I will compare and contrast their responses in the three distinct issue areas that they would most likely be applied. Does ASEAN represent a security organization, seeking to establish a defensive stability in the region? Is it a social or economic focused institution, promoting economic expansion and increased interrelations? Or is it establishing a higher emphasis on human rights, making improvements to the quality of life of its members? Each of these areas have been core 
principles in the relations of other regional organizations and have been used as measure of analysis from the varying IR theories. I will be taking a look at how these issues are viewed across the levels of analysis of the region, the states, and the influential actors inside and outside the association. While each of the three dominant paradigms can be applied to each of the three issue areas of security, economics, and human rights, their logics are generally seen as operating most strongly in the following pairs: realism in security, liberalism in economics, and constructivism in human rights. Using these pairings to investigate the three paradigms will help to explain ASEAN as they are the issue areas most probable to prove those paradigms' intent. Methods such as analytic eclecticism, promoted by Rudra Sil and Peter J. Katzenstein in their work Beyond Paradigms: Analytic Eclecticism in the Study of World Politics, work by incorporating the strengths of focus from the various theoretical schools towards finding a meshed approach going forward. Utilizing this comprehensive approach will lead to a more transparent interpretation of what the Association of Southeast Asian Nations is and what it is not as compared to existing paradigms of international relations. 


\section{Chapter V: Is ASEAN a Realist Security Community}

What would a realist security community entail

A traditional hard security organization is institutionalized around formal political and military alliances promoting mutual defense and strategic coordination in policies. Classic examples for this form of arrangement are the North Atlantic Treaty Organization and the defunct Warsaw Pact, both displaying formidable militaristic strength and policy unity in regard to defense. Examples of strong bilateral security ties come from many of the United States' mutual defense ties with states like Canada, as the North American Aerospace Defense (NORAD), or regional bilateral ties with Asian states, such as Japan and the Republic of Korea. ASEAN is comprised of small to medium power states, militarily, and with the exception of Thailand, all have spent a period of their history under colonial rule. In a region including several medium power states, as well as the rising large power China, it would seem logical under the neorealist theory of international relations for the smaller states to either ally with a stronger state or attempt to create a collective in order to rival any hegemonic powers.

The formation of ASEAN could at a glance be seen as a step towards the latter, but the organization to date has made no significant efforts towards a true defensive alliance, instead focusing on diplomatic neutrality with foreign powers and preferring active economic engagement throughout the region. Realism is focused on the survival and security of the state and its interests, so it would follow that if ASEAN is a security organization, it would be operating in a way so as to maximize member security against large powers or external threats. This chapter will explore whether ASEAN has the 
capability and the political will to establish itself as a security community in the realist sense, seeking stability in the region or as a defensive alliance from outside aggressors. How has it responded to internal and external threats? Is there evidence that ASEAN behaves like a security community?

Evidence of realist based security community Does ASEAN reflect a realist security community

In Southeast Asia, ASEAN was established in the background of Cold War rivalry with the Bangkok Declaration in 1967 under the promise of stability offered by the American naval presence in Asian waters. Even within regional organizations, such as ASEAN, there are often efforts to maintain a degree of military parity between member states. Though there are large and medium powers in the greater Asian region, the association is comprised of small state powers that seek to avoid any potential of being dominated within the institution. ASEAN provides an example of states forming without the need of a large power to facilitate its organization. While the large American presence in the region maintained a relative peace, it was not part of the process in forming the association after the failed attempt to copy NATO in 1954 with the Southeast Asia Treaty Organization. Lack of political cooperation and little in the way of military resources or joint command structure meant the organization was handicapped from its inception, slowly being phased out by 1977 . The American forces did not have a threatening power to counterbalance as they did in Europe. It was the states within the region that took the initiative to establish ASEAN as the central regional institution for cooperation. At least 
initially, then, ASEAN did not operate to provide some form of military balance or bandwagoning with existing or rising great powers. From a bandwagon perspective, ASEAN is intrinsically flawed, as it lacks a dominant power that can effectively guide the group as a whole. The balance between the Asian states mandates an agreed upon approach to policies. This results in slow and limited responses as the regional organizations seek to find a consensus, which remains difficult given the significant political and cultural diversity between its members. The requirement of consensus remains a foundational principle within ASEAN and many of its regional associations, serving to build trust through cooperation rather than imposition, but has prevented significant resolutions to many of the regional issues such as fishing rights in contested waters. ASEAN does not serve to create a balance of power against other strong actors within the region.

From its inception, many of the foundational principles of ASEAN follow the tenants of realism.

1. Mutual respect for the independence, sovereignty, equality, territorial integrity, and national identity of all nations

2. The right of every state to lead its national existence free from external interference, subversion or coercion

3. Non-interference in the internal affairs of one another While these principles follow many of the central designs of classical realism and its various iterations, such as sovereignty and the importance of independence from external influence, and non-interference on other states, the next two are more restricting. 
4. Settlement of differences or disputes by a peaceful manner

5. Renunciation of the threat or use of force

These principles place restrictions that violate a state's sovereign path, placing artificial limitations on its actions, especially in regard to potential threats.

6. Effective cooperation among themselves

While this final principle is not necessarily non-realist, the lack of having any political or power-based hierarchy leads the organization to be viewed as an immobilized community.

While it may not have a collective security clause, ASEAN might still be considered a security community if its secretariat had the authority to mobilize members in the face of threats. The Secretary General of ASEAN does not have the capacity to establish agendas; rather, it is an administrative role, serving to facilitate agreements made by the council. The flat hierarchical power between states necessitates a consensus in its policy decisions to move forward. In the past larger members have reversed their state policies in order to coincide with the organization's will in maintaining consensus. In comparison, the Secretary General of NATO chairs vital decision making military bodies, the Defense Planning Committee and the Nuclear Planning Group, guiding policy, as well as leading diplomatic discussions in the Euro-Atlantic Partnership and the Mediterranean Cooperation Group. Neither Secretaries General are in the military command structure. That power remains with the member states. Given the weak institutional structure, is ASEAN capable of effective governance or response in times of crisis as NATO? Can the organization serve to provide stability in the region? 
Indications of a hard security community

The ASEAN Regional Forum has served to raise discussion of nonmilitary security matters, such as transnational crime, environmental hazards, and illegal population movements. First meeting in 1994, the forum has since grown to include twenty-seven members. Similarly, the ASEAN Plus Three (APT) summit, which includes China, Japan, and South Korea in addition to the ASEAN states, seeks to promote efforts towards a Free Trade Agreement. There are also the more focused ASEAN-US, ASEANRussia, and ASEAN-India summits, which serve to promote ASEAN as a central hub for diplomacy in the region. However, the ASEAN Way has been that of slow incrementalism, it does serve towards building a stronger notion of an ASEAN identity, which is key towards the establishment of a strong security community. Though ARF's focus on security has skirted from military matters, a more collective ASEAN could see that hurdle crossed. That the organization seeks to assert itself as the platform for regional dialogues elevates its position, which bolsters recognition politically. A more unified ASEAN, with an established cultural identity, would have an amplified voice in the global community that could garner greater levels of international support.

The gap created from the absence of an inclusive effort has led members to increase their military spending, and for some to establish their own defensive ties. From 2006 through 2015, Viet Nam has increased its defense budget by $258 \%$, from 1.3 to 4.6 billion (USD) after value adjustment (Abuza and Nhat Anh 2016). Though this is one of the fastest spending increases in the region, it is still behind Indonesia, Singapore, and 
Thailand in overall spending amounts. This surge has been in direct response towards the increasing tensions with China, an issue many members are having to face but have yet only done so separately, an approach that benefits China. Viet Nam and the Philippines held their third confidence-building meeting between naval leaders, proposing increasing the levels of communication and information sharing between their respective coast guard and navies. These bilateral connections serve to build stronger bonds that serve to establish greater trust within the community, including the establishment of working groups towards cooperative policies.

In August 2017, the Philippines and Thailand signed the terms of reference for a Joint Committee on Military Cooperation. This is a significant step in a long series of military cooperation efforts dating back to 2012. Both states have been causing distress in the ASEAN community. Thailand's military junta came to power through a coup led by Prayut Chan-o-cha in 2014 and sought to firmly establish its control. While Filipino president Rodrigo Duterte was democratically elected, he has run a brutal crackdown against the drug trade within his country, promoting vigilantism and the mass killing of traffickers and users alike. While the United States and the Philippines have been historic allies, signing a mutual defense treaty in 1951, including the periodical stationing of United States military forces on the islands, on 4 October 2016 President Duterte vocally confronted then-US President Obama after he had expressed concern over the killings (Durando 2016). In the following months he expressed his intentions to politically shift away from America and towards its rivals China and to a lesser extent Russia (Blanchard 2016), both states which do not take a stance against strong authoritarianism and would politically and strategically gain from the slight against the United States. 
Thailand is not unfamiliar with coup d'états, having gone through twelve since 1932. Growing political unrest over corruption and unpopular reforms escalated into widespread protests after then-Prime Minister Yingluck Shinawatra pushed for pardoning former politicians charged with corruption and an attempt to amend the constitution. Both efforts were struck down by the Senate and Constitutional Court respectively. Though both efforts failed, this fueled the anti-government protests, sparking violence that led to the death of 28 and over 800 injuries (Olarn 2014). On 7 May 2014, the Constitutional Court removed Yingluck from office. This only exacerbated the violence and on the $20^{\text {th }}$ the Royal Thai Army declared martial law. Two days later a coup disbanded the government and established a junta system titled the National Council for Peace and Order (NCPO) under the leadership of General Prayut Chan-o-cha. ASEAN states, in keeping with their tradition of self-determination, responded positively for the most part, promoting a peaceful transition. Viet Nam's ambassador showed support for the new regime while Singapore issued a statement of concern over the coup.

The public claim by Filipino President Duterte to shift alliance towards China has upset fellow members of ASEAN and shaken the organization's claim of neutrality. Though this seems hypocritical given the Philippines existing pact with the United States, political partnerships such as this have been 'grandfathered' after the creation of ASEAN. If the Philippines were to end its alliance with the United States, it could lead to a massive shift as other ASEAN states seek to realign themselves for greater stability. Seng Tan, a Professor of International Relations and the Deputy Director of the Institute of Defence and Strategic Studies at the Sinnathamby Rajaratnam School of International Studies expressed concern over the ramifications. Singapore had increased its allowance 
of American forces after base closures in the Philippines during the early 1990s as the United States shifted its Cold War positioning. "It could also compel countries like Vietnam to deepen their security ties with the U.S.” (Kuo 2016).

Despite President Duterte's call for separation from the United States, he has not formally altered the alliance. Joint efforts between the militaries continue, including quarterly discussions between their respective air forces, including one held on the $16^{\text {th }}$ through the $25^{\text {th }}$ of August 2017 (Parameswaran 2017). These meetings discuss tactical cooperation and joint exercise drills. Duterte has also sought military aid from Japan and South Korea, seeking training and equipment. The Philippines has also pursued the purchase of two frigate class ships to be made in South Korea; this is the first time the country has acquired new naval vessels. It has traditionally stocked its fleet with ships decommissioned from the United States Navy and Coast Guard (Cruz de Castro 2016). There has been a diplomatic whiplash as the Philippines has attempted to garner concessions from the Chinese regarding fishing rights, at the same time making statements with Japan agreeing to the continuation of freedom of navigation in the South China Sea, something that China has been aggressively thwarting. Still, the Filipino leader states that the Philippine and Chinese friendship is unbreakable.

The actions made by Myanmar, Thailand, and the Philippines to maintain their identity and independence are rational actions by a state from a realist perspective. The focus on power, in various forms, and its effective use by neorealist views posits a poor view on the regional organization. The lack of strength of individual member states and the unwillingness to pool defensive resource efforts hamper their impact on regional 
actors. Instead, it is influenced by the larger powers such as China, India, Japan, and the United States. Without a stronger, rules-based, infrastructure to implement policy, ASEAN will remain an ineffectual loose association that does not deliver on the goal of creating regional balance. It would dedicate the effort or resources if the institution's focus was on that of security. Instead, it remains moderately dependent upon external powers to maintain a balance for stability. Between its members is a stark lack of trust in each other, too much to allow for an agency to gain authority that would impede on state sovereignty.

Indications of a soft security community

In the 2017 ASEAN Defence Ministers' Meeting (ADMM), the minsters agreed upon the goals of increasing senior levels of dialogue, transparency and openness, as well as to pursue the establishment of an ASEAN Security Community (ASC), per the Bali Concord II (ASEAN Defence Ministers' Meeting 2017). While the main objectives of the ASC are to promote intra-regional peace, this is in contrast to Indonesia's policy to sink foreign fishing vessels in its waters. This continued drive towards a unified effort, though slow, does advance the efforts of a security community.

While the United States has maintained strong bilateral defense ties with many of ASEAN's members for decades, the foreign policy of the American government has become increasingly more erratic. Many of America's partners around the globe are becoming less dependent upon it, and this is true throughout Asia where President 
Trump's posturing towards North Korea has been viewed as a dangerous escalation, made without notice to or support from regional allies (Rapp-Hooper 2017). In contrast, in the 2016 ASEAN-US summit, the second ever held and the first taking place within the United States, then-United States Secretary of Defense Carter proposed expanding on the existing bilateral security exercises into more multilateral maritime domain awareness efforts (Parameswaran 2016). The shift to region-wide efforts is significant towards building cohesive training and cooperation practices, as is the pervasive presence of the United States in leading these initiatives. The unpredictable nature of this relationship makes it progressively more unreliable, but in the short-term ASEAN can use these naval exercises to establish stronger norms and practices internally as it builds its own foundations for greater strategic independence in the region as a security community.

Large regional actors wield considerable influence that can help shape a region around it or serve as a catalyst for unification to oppose it. "Security concerns link the states to the extent that national securities cannot realistically be considered apart from one another. A great power active in a region may be part of the regional security complex by imposing or receiving negative and positive security externalities" (Paul 2012, 17). The networked influence gives smaller states much greater capability as well, as with the case in Southeast Asia where ASEAN, comprised of small to medium powers, has proven capable of entangling great powers and attaining a "complex balance of influence.' In a region of medium powers, Japan and South Korea, a large power, China, and the significant presence of the United States, the only remaining super power, attempts at achieving a peaceful and cooperative balance are critical. ASEAN's location in the middle of an area with contested overlapping territorial claims, in addition to its 
principle of neutrality throughout the Cold War that has continued in its relations between the United States and China, places the network of smaller states in the vital position of needing to broker a peaceful collaboration with its larger neighbors. “ASEAN's approaches to conflict were not geared to external threats but rather to helping its members achieve regime security vis-à-vis their neighbours through confidence-building via consultations" (Ganesan and Amer 2010, 37). This approach is in contrast with U.S. bilateral security arrangements in Asia, which are primarily limited exclusively to external threats. The diplomatic strength of the organization significantly strengthens the diplomatic capabilities to levels much greater than would be possible by any single member. A region with a past of nearly continuous war between comparable powers, the European continent has become a testament towards the benefits of a security community. The devastations of the conflicts have been left behind for mutual prosperity and through the European Union and the North Atlantic Treaty Organization. The continent has worked hard to shift all disputes to diplomatic negotiations. All threats to peace are now external; its collective military might would give any would-be aggressor a moment of pause.

Failure to emerge as an Asia-Pacific Treaty Organization The historical and structural influences

One of the strongest rationales for adopting a regional organization is to ally with other states to ensure greater security for oneself; the security from threats within a community is as critical to stability as external threats. Military alliances have been a 
perennial staple of international relations, as it is a force multiplier not only in times of war, but as one of the strongest deterrents against a conflict from starting. Extending this beyond a bilateral alliance into a regional community extends this deterrent effect greatly, as few states would be willing or capable of going rogue against their surrounding region, and serves to shape a greater communal atmosphere of prosperous relations that the community can build upon to expand economic and cultural relationships as well. In time, this could potentially foster a more unified identity for the region. That is not to say that the process would be linear or smooth; finding a stable balance upon which to build a true peace takes time, as with the case of the Association of Southeast Asian Nations seeking to choose a direction for the organization going forward. While there are periodic and historical tensions between members, no ASEAN state has actively considered direct conflict with its neighbors, there are periodic spikes in defense spending as states seek to maintain moderate degrees of military parity amongst one another. "Even Malaysia's suggestion for establishing an ASEAN peacekeeping force based on the experience of several ASEAN state's armed forces in Cambodia, East Timor, and the Balkans, were shelved, partly because it might be seen as an attempt to turn ASEAN into a military alliance" (Ganesan and Amer 2010, 40).

Two approaches are raised towards the lack of a hard security organization. In the first article, Why is there no APTO? Why is there no OSCAP?: Asia-Pacific security institutions in comparative perspective, John Duffield contrasts the creation of the North Atlantic Treaty Organization in Europe to the reluctance by ASEAN's members to collaborate defense. In ASEAN and its Security Offspring: Facing New Challenges, Sheldon W. Simon examines the threats and difficulties experienced in the region and the 
attempts that have been made to overcome significant incapability. Both pieces serve to illustrate the shortcomings of the association when viewed as an organization for security purposes.

When compared to the Euro-Atlantic institutional security architecture, AsiaPacific is fragmented and sparse. While both regions are covered by large numbers of security ties, European efforts have been focused more on greater levels of multilateralism and formalization, whereas Asia is a loose network of less institutionalized bilateral agreements. "Such differences have been emblematic, moreover, of both externally-oriented collective defence ties and inclusive collective security arrangements at the regional level" (Duffield 2010, 70). One view taken is that due to the rising tensions between the United States and the Union of Soviet Socialist Republics after the Second World War, America's primary focus remained in Europe reducing its capacity, and will, to foment obligations in another region. The Truman administration was apprehensive about establishing further security obligations but accepted the necessity of multilateral solutions. Initially there was some modest consideration for a multilateral Pacific Pact that would comprise the United States, Japan, the Philippines, Australia, New Zealand, and possibly Indonesia, though this was never implemented. The caustic effects of Japan's actions during the war also persisted longer than Germany experienced in Europe, erecting high obstacles to post-war cooperation with potential regional partners, obstacles that in many ways have still not been overcome. A significant factor in the change of perception of Germany was due to the multinational authority that governed it in the post-war years. While tensions would rise between the western powers and the Soviet Union during this arrangement, the 
perception of German threat was retarded by perception of subjugated rule being split between its former enemies. In contrast, Japan was unilaterally administered by the United States, limiting complications of the transitionary period, especially given the complexities arising in Europe. Middle powers such as Britain and France were able to guide the region together, while the lack of involvement by other Asian powers in regional reconstruction served to maintain the political/cultural divide throughout the Pacific.

A strong characteristic that distinguishes the two regions is the geographic proximity between the states, Duffield notes that many Euro-Atlantic states share borders with or lie only a short distance from their former enemies. Thus, the fear that imminent military threats could materialize quickly after the post-war occupation forces have left remained high. In contrast, in the Asia-Pacific theater, there was enough distance between most states and Japan that there was less of a prevalent fear. Japan had lost its ability to project power across the sea, and any effort to rebuild that capability would take more than adequate time for the United States Navy to intervene. This resulted in less of an incentive to establish institutional security structures, outside of bilateral ties with the United States, to ward off a resurgent Japan. The assessment that the American level of involvement and geography were central issues continues to be a fundamental explanation, but the author does expand on other possible reasons, stressing the absence of potential counterbalances to Japan, and the relative distance between Japan and other states provided it with higher degree of security in comparison with West Germany which resulted in fewer incentives for security cooperation during the early post-war years. These factors serve to reinforce regional characteristics, such as enmity toward 
Japan, distrust of the former colonial powers, and varying levels of development, led to additional obstacles to the construction of strong multilateral security institutions in the region.

Regional engagement

While the neorealist model and its focus on power struggle in a competitive world fit with many regions, the consolidation of power by joining inter-government organizations that would fit into this theory does not seem to apply to ASEAN. It has not sought to deter potential threats by establishing a defensive pact. Instead, many members have established bilateral treaties with non-member states before and after joining the regional organization. Though a core goal has been to bolster its economies, it has not leveraged its initiatives, such as the AEC or the ARF, to bolster its position. Its efforts to date have focused on remaining economically pertinent in the globalized market.

The notion of economic market integration leading to stability and dialogue was expanded further throughout the region with the ASEAN Regional Forum, with the objective to establish relations, explored by Andrew T. H. Tan, of the University of New South Wales, in East and South-East Asia - International Relations and Security Perspectives. The ASEAN Regional Forum emerged as a system to engage more powerful states and other external actors was established in 1994. The role this forum was to build confidence between states, offering a medium for preventive diplomacy, and for the resolution of conflict between. In its early years, ARF increased in standing as a 
pro-engagement forum, but it was also sidestepped when high stakes issues needed to be addressed due to the ASEAN norm of non-interference. One of the most significant examples of this was when the Democratic People's Republic of Korea (North Korea) withdrew from the Nuclear Non-Proliferation Treaty in 2003. When the Six-Party Talks were established, ASEAN was not admitted, even though all parties at the talks were ARF member states. "While the ARF aims to focus on terrorism, maritime security and disaster relief, it remains a difficult area for states to navigate and there is little optimism that it will generate the necessary capacity to provide robust responses to current and emerging" (A. T. Tan 2013, 308). To coordinate its foreign policy goals, ASEAN works to keep the forum active as a focal point by focusing on broad discussions of regional concerns over issues such as maritime exclusive economic zone rules. Although it is an issue needing to be addressed, ASEAN also desired to create a body that would acknowledge its institutional status. To achieved this, ASEAN ensured that its states would be the venue for the ARF's annual meetings. "ASEAN would dominate the agenda; that inter-session study groups, each composed of two states, would always include an ASEAN member; and that the ASEAN consensus principle would prevail in ARF decisions" (Ganesan and Amer 2010, 49).

The continued significance of ASEAN and its many collaborative efforts such as ARF, are hinged on the value that its governments and society place on their capability to produce results. While economic prosperity remains a central focus, security from terrorism and other regional crises are becoming increasingly expected. There has been a notable shift in Southeast Asians that believe their security is best maintained by not isolating the region from great power activities, as originally envisioned in the RIGO's 
creation, but rather by engaging them in multilateral efforts, such as the ASEAN Post Ministerial Conference, ASEAN Plus Three, and the ARF. Though these measures were originally intended toward keeping the United States and China involved in the region's security, little progress has been made on multilateral issues outside of economic discussions, especially in regard to security in the region and sovereignty disputes.

What shape would a theoretical ASEAN security institution take

There are significant similarities between the North Atlantic Treaty Organization and the Warsaw Pact. Both security organizations are comprised of members that share a separate layer of alliances, often economic or political, within the greater organization as well a larger state that guides the policy objectives. The majority of NATO's European members are also part of the European Union and pursuing greater levels of economic and political integration. The United States is by a large margin the biggest military power within NATO. It is not a member of the EU. Instead, it maintains significant trade relationships throughout the region. Within the Warsaw Pact there was the Union of Soviet Socialist Republics, both of which were governed to varying degrees by Russia. The common bonds of political and economic ideologies served to unite members of these organizations and serve as the catalyst of division between NATO and the Warsaw Pact. The threat of invasion that many Europeans felt by the large presence of Soviet forces in Eastern Germany was a driving force in the creation of NATO, which in turn led a threatened Soviet Union to seek to expand its buffer of satellite states from the western military alliance. 
In contrast, ASEAN does not contain a military or economic power that is significantly large enough to assert its policies over the rest, nor does it possess commonalities that served to unite other regional organizations. One commonality between the regional organizations that is paramount to a security community is the elimination of the use of force in disputes between members. Building off this principle, the region needs to shift socially towards the establishment of a common identity. This is critical for the successful formation of a community. Though European states have a history of centuries of conflict between each other, the fact that they share many core liberal values served extensively towards the establishment of a European identity. There remain significant degrees of tension between ASEAN states over border security. That institutions within the organization have successfully maintained peace in attempts to broker solutions is a great start towards establishing norms. Unlike either of the other two regional organizations, ASEAN does not face a direct existential military threat. It could be argued that China is a significant danger to many individual members, that the association as a whole maintains a principle of neutrality, prevents a coordinated response. States instead turn to outside actors for bilateral security assurances, most significantly the United States, which has a defense pact with the Philippines. If the Asian states were seeking to mimic the other organizations, it should pursue to incorporate a large regional power like Japan, India, or South Korea. All three of these are strong militarily and economically, which would bolster the organization. Currently many of the member states seek to maintain parity between each other out of rivalry but accepting in a much stronger member would serve to greatly reduce the threat of inner conflict and instill the capability to coordinate forces to respond to crisis faster than parallel members. 
While many states already share military and economic ties with the United States, inviting it to join ASEAN would counter the possibility of establishing a common identity, unlike the United States' alliances with European states as they share more cultural common values.

An alternative to incorporation would be to expand upon the bilateral security ties many of the ASEAN members have with outside powers, such as India and the United States, to encompass the organization as a whole. This would allow it to benefit from a greater range of partner states to work with, while maintaining its internal composition as is. The challenge of this though is that without a more dominant partner to guide the institution, the consensus-based planning will impede decisive initiatives. Maintaining its membership roster to existing states that are in close proximity helps towards the necessary establishment of the cultural identity; this has only progressed slowly to date.

Not having the United States serving as a key arbiter for the formation of a multilateral union was certainly a strong possible factor for any association to exist earlier on in the beginning years after the Second World War. However, the Association of Southeast Asian Nations did eventually form in the following decade, though with little arrangements in the way of security, lending weight to the view of the geographical proximity between states in the region, especially when compared to that of Europe, creating a lack of need for mutual defense. This has changed significantly with the advances in military technology and force projection in the region. This could lead to significant changes in the perception towards security needs, "the regional distribution of power remains highly skewed in favour of Japan and, increasingly, China. Consequently, 
the smaller countries may well continue to fear the possible domination of regional security arrangements by those countries" (Duffield 2010, 87).

Division also holds back policy cohesion, but efforts to maintain peace in the region have formed much of the core principles for the association. The 1971 declaration of Southeast Asia to be a Zone of Peace, Freedom, and Neutrality served to constitute the framework in which Southeast Asia declares itself to be free of nuclear weapons. This move was made in part to maintain a non-aligned position during the Cold War, as well as to prevent any member from allying with an outside power to increase their strength in the organization; though bilateral defensive arrangements with external states predating the declaration were allowed to continue. From its creation, ZOPFAN was a reaction to two separate visions for security in the region. Malaysia had proposed that the continued neutrality between the great powers guaranteed the region security. Indonesia countered that the Southeast Asian states themselves should provide the region's security. "Jakarta was concerned primarily about China, and Kuala Lumpur ultimately acquiesced. The Indonesian neutrality plan was also acceptable to Thailand, Singapore, and the Philippines because it was sufficiently vague that a continued American balancing presence was tacitly accepted" (Simon 2007, 13). This division about the organization's own role in its security is a central issue that has led to the existing shortcomings with domestic terror.

The inability for governments in the region to control groups within their own borders stands out as one of the largest threats to regional security. While no ASEAN government supports insurrection against a neighbor, governments have been unwilling, 
or unable, to suppress groups that take shelter within their borders. Thai separatists have fled to northern Malaysia; large numbers of Karen are located inside the Thai northern border; Philippine Moros are found in Malaysian. In the aftermath of the Bali bombings, police forces representing ASEAN gathered in Jakarta in January 2003, proposing an antiterrorism task force to be established in order for each state to strengthen regional antiterrorist collaboration. This joint effort enabled the Indonesian National Police and its contemporaries in their efforts towards several terrorist networks. This was not a straightforward process, as the sovereign governments differed on how far they were willing to open jurisdictions. Indonesia and Malaysia requested that legislation should be passed by each state to make terrorism an extraditable offense. Singapore refused, protesting the different legal systems within ASEAN, “though Singapore's primary concern is probably the safety of large numbers of wealthy ethnic Chinese who fled from Indonesia to Singapore in the wake of anti-Chinese riots in 1998" (Simon 2007, 9-10). Slowly governments are making modest efforts to combat terrorism, but even with the rise in bombings in previous years, it was not until the 2007 summit that ASEAN agreed on the ASEAN Convention on Counterterrorism, an ongoing effort that takes years often for member states to ratify. Despite the existing threats, governments are apprehensive to take actions that would relinquish any amount of state sovereignty. The issue of sovereignty and state's jurisdiction is a handicapping issue for the region to coordinate efforts on issues such as piracy. Though Japan put forward a call for a regional coast guard, the ongoing disputes over territorial claims at sea, as well as the historical fears of Japan, blocked the effort from adoption. Many Southeast Asian states have shown to be disinclined to prosecute those detained in their waters for crimes committed in other 
countries, preferring to deport them instead. Individual members are making modest efforts to upgrade their own capabilities; they are wary to do so though as members within the association struggle to vie for military parity between each other rather than seek mutually beneficial efforts.

In 2006, the first ASEAN Defence Ministers' Meeting was held. The stated intent was: to promote regional peace and stability through dialogue and cooperation in defence and security; to give guidance to existing senior defence and military officials dialogue and cooperation in the field of defence and security within ASEAN and between ASEAN and dialogue partners; to promote mutual trust and confidence through greater understanding of defence and security challenges as well as enhancement of transparency and openness; and to contribute to the establishment of an ASEAN Security Community (ASC) as stipulated in the Bali Concord II and to promote the implementation of the Vientiane Action Programme (VAP) on ASC (ASEAN Defence Ministers’ Meeting 2017). This initial meeting was marred though by the absence of the Myanmar minister, an action that has become a continual act of revolt from the organization. In an act of protest, the Myanmar government did not attend ASEAN's inaugural Defence Ministers' Meeting, its leaders have often given greater cooperation to the UN than to ASEAN. The Myanmar government, the State Peace and Development Council (SPDC), "maintained a practice of making embarrassing announcements at highly sensitive moments for ASEAN - such as announcing the continuation of Aung San Suu Kyi’s (a political dissident) detention just days prior to the ASEAN Summit in Kuala Lumpur” (Roberts 2012, 185). Christopher B. Roberts, of the Australian National University, looks at the motivations and challenges of regional integration in ASEAN Regionalism-Cooperation, Values, and 
Institutionalization. The capability of a single government to flex its individual will within the organization illustrates the anarchic view of states being the primary actors of realism, and that they view the association as a means to an end for their own gain. This behavior is best explained by the realist paradigm. The political elite of Myanmar do not identify with ASEAN and thus the regime continues to conduct its relations without regard to regional. The political stability and credibility of Myanmar's government reached the United Nations Security Council under the auspice of the Responsibility to Protect, despite ASEAN's protests that the regional organization could handle the matter internally and fearful that this could establish a larger precedent of external influence over the RIGO and its members. "The apex of this frustration was reached when Myanmar asked ASEAN to defend it from UN action and Singapore's Foreign Minister responded that ASEAN has lost both the 'credibility and ability' to do so" (Roberts 2012, 187).

Incompatibilities latent in the institution

While there is strong support for the ASEAN Regional Forum, it has been unable to settle many critical issues in the region, such as unresolved territorial disputes, conflicting maritime jurisdictions resulting from the 1982 UN Law of the Sea, and nuclear weapons proliferation, all of which have been addressed in discussion but remain unable to be resolved. Unlike a pact of mutual defense in a hard security organization, the forum has long held a strong principle promoting peaceful treaty resolution between its members, ASEAN's 1976 Treaty of Amity and Cooperation, that calls for renouncing 
force to settle disputes. Members of the forum have signed on to respect the treaty regarding non-aggression towards members of ASEAN. ARF was instrumental in promoting the ASEAN Convention on Counter-Terrorism (ACCT) of 2007 effort after the series of bombings throughout the region in the early $21^{\text {st }}$ century.

ASEAN has used regional incorporation, mainly through efforts of economic integration, as its main focus towards bringing internal and external stability. Since ASEAN's introduction, it has established a preference of non-aggression pacts rather than forming militaristic alliances. The first meeting of the ASEAN Regional Forum in 1994 seeking to expand diplomatic efforts in the region was not the organization's only initiative. ASEAN Plus Three (China, Japan, and South Korea) held its first meeting in 1997, and ASEAN Plus Six (Australia, India, and New Zealand) in 2005, with the goal of expanding cooperation through economic trade. These efforts culminated with the creation of the East Asia Summit in 2005, which in addition to the existing members expanded to include the United States and Russia as well, though ASEAN Plus Three still exists as a separate institution. In its meeting in June 2017, APT ministers pledged strengthen cooperative efforts in both traditional and non-traditional security areas including "terrorism and violent extremism, transnational crime, cyber security, maritime security, climate change, disaster management, sustainable water resource management, food security, energy security, and pandemic diseases and trade-related building” (ASEAN Secretariat Information Paper 2017). Similar pledges have been made in the past but have seen little progress. The work of organizations like the ASEAN Plus Three Food Security Information System have shown commendable efforts to increase crop yields. The overall regional political security is deteriorating from low trust levels 
between members. While China's economic rise did not initially disrupt the region, as it has sought to use its position of strength to leverage its will over maritime rights and seek hegemonic power, it has created a schism with the existing dominant influence of the United States. APT has not been able to abate these concerns, and ASEAN seeks to maintain its neutrality.

While the inclusion of large powers will grant potential for expanded economic and diplomatic avenues, the combative nature of many of these states dampers multilateral efforts towards regional issues, such as natural disasters, climate change, and fishing rights; it will also prevent any form of security institution being shaped within these forums. Simon notes the influence that external state preferences have had on the role with which ASEAN should proceed for ARF. While China's reserve reflects a concern towards basic national security issues such as its the future of Taiwan to not be subject to ARF deliberations, in contrast Canada, Australia, Japan, and the United States would like to see ARF's role strengthened. While the United States in particular hope that the forum will come to serve as an antiterror cooperative mechanism, ARF's consensus rule, an extension of ASEAN values, has proven an obstacle in addressing tensions that arise from diverging interests. Yet, the rule of consensus was as significant for encouraging states to adopt membership in ARF just as it was with the establishment of ASEAN. Caught between the competition of China and the United States, both seeking to expand their power in the region, ARF will have increasing difficulty moderating discussions and conflict resolutions. 
The Treaty of Amity and Cooperation in Southeast Asia was established by the founding members of ASEAN to promote peaceful resolutions to disputes and to build stronger relationships through collaborative efforts. Since the signing in 1976, many states outside ASEAN and some outside of the regions have signed. In 2003 during the Bali Concord II, the treaty was amended for the third time to form the High Council. The role of the High Council, consisting of a minister from each signatory party, not only member states within ASEAN, is to seek a peaceful resolution to disputes compared to a judgment arbitration system such as the Permanent Court of Arbitration in The Hague. An ASEAN principle ingrained into the process is the requirement for consensus. This is significant as it makes larger states more willing to come to the table, with China and India both signing in 2003 and the United States in 2009. Many of the members of the treaty have contentious relations with other members, so establishing an additional diplomatic channel acts as a potential positive step towards resolution. However, to date the High Council has not been utilized. "ASEAN needs to upgrade itself into a more effective regional organization with a more powerful High Council so as to ensure the legacy of its continuing existence. Without modifying its policies and bureaucratic procedures, ASEAN will fail not only in settling the South China Sea dispute, but also in future challenges" (Tong 2016). Another attempt to change ASEAN's regional diplomacy methods was made in 1999 with efforts to create an ASEAN Troika, an impromptu assembly of foreign ministers in response to urgent matters of regional peace and stability. The intention was to formulate recommendations to ASEAN Foreign Ministers, operating in accordance with the core principles of the association, consensus and non-interference. Indonesia and the Philippines rejected the Troika as a means to 
address secessionist conflicts, nor was it activated regarding the border clashes with Thailand. Lacking actual implementation of the Troika, and without any institutionalized obligations, ASEAN's secretariat will continue to remain constrained by national secretariats. Meanwhile, states have still not resorted to the TAC's High Council. Without being more willing to assert its institutional agencies and risk shifting away from the ingrained tradition of requiring a consensus for all actions, ASEAN will not be able to effectively establish its own priorities.

Regional challenges such as terrorism, exploitation of oceanic natural resources, and maritime security all require multinational cooperation. Unease remains between members as they continue to seek military parity between each other, maintaining a balance in the region. Several members maintain bilateral cooperation with external states, such as the United States and Australia, for support on issues such as counterterrorism "Security services appear to compete more than collaborate, as domestic politics (such as concerns with Muslim constituencies in Indonesia) and obsessive concerns with national sovereignty foil both bilateral and multilateral regional security strategies" (Ganesan and Amer 2010,10). This is showing some signs of change though as, after repeated efforts endeavored by the United States, ASEAN members have agreed upon increasing levels of cooperation, including the 2007 Convention on Counterterrorism. As ASEAN continues to transition away from its concept of a ZOPFAN, there remains little intent to wield any traditional hard power policies within the organization as the lack of interoperability between armed forces in the region, entrenched suspicions regarding the motivations in neighboring states, as well as an unwillingness to coordinate effective strategies to address transnational challenges have 
led to security efforts to bilateral arrangements by default. The Association of Southeast Asian Nations possesses neither the political will nor the capability to constitute a hard security organization.

The institutional difficulty of the organization is apparent from the association's regional turmoil in the late 1990s. ASEAN experienced severe difficulty in its attempts to respond to the financial crisis as well as the secession of East Timor from Indonesia, the public health issues across the region caused by the annual forest fire haze from the Borneo island of Indonesia, and the coup in Cambodia that overturned an ASEANendorsed election. The source of the organization's inability to respond effectively is rooted in the principle of noninterference in its members' domestic affairs. This has made crisis response more difficult, for example when attempting to organize humanitarian response after Cyclone Nagris devastated Myanmar in 2008. The organization had neither the logistical integration to respond in a timely manner nor the will, unless accepted by the Myanmar government, which had been very reluctant for international intervention, despite the desperation of its people.

Moving to rectify this weakness has been a main effort for ASEAN in the early 21 st century. The institutionalized principle of noninterference is at the core of the organizational inability to deal effectively with these issues. Since its establishment in 1967, ASEAN has been grounded in the values of consultation, consensus, and noninterference when it comes to its member's internal affairs, as well as any disagreements between each other. The preservation of sovereignty has been a significant factor among the states; requiring consensus in decisions was a way to reassure members 
from the fears of being compelled into unwanted policies, and to defuse tensions without conflict. "ASEAN's approaches to conflict were not geared to external threats but rather to helping its members achieve regime security vis-à-vis their neighbors through confidence-building via consultations" (Simon 2007, 2-3). The rise of extremism in the region found the governments incapable of responding to the rising security threats with a bomb plot in Singapore in 2002, the bombings of Bali in 2002 and Jakarta in 2003, followed by the 2004 bombing of the Australian embassy in Jakarta, and a second bombing in Bali in 2005. Only after this escalation in violence was an increased effort placed on coordinating law enforcement efforts undertaken in the region. The unique threat created by terrorism could push the organization towards a more integrated and cohesive security agenda as non-state actors that can operate transnationally necessitate a greater degree of collaboration than the institute has previously been willing to adopt.

Though the efforts towards increasing the levels of integration within ASEAN have made marked progress over the last four decades, numerous hurdles remain. Several qualities are necessary for separate agents to see integration such as basic underlying preferences, willingness to share sovereignty by the leadership, internal demand for increased economic incorporation, or an external threat to the region and its continued growth. Min-hyung Kim explores in Theorizing ASEAN Integration, that unlike the European Union which made steady steps towards economic cooperation from the beginning, ASEAN did not see any significant development until the 1990s. This article reviews existing research into this slow process and provides a strategic-preference theory that analyzes the focus of individual members in the organization and placing them within the context of the global political economy. The core theory is that existing 
accounts that merely apply insights of general international relations theories on to ASEAN integration are limited in explaining this process. By not factoring the unique regional and country circumstances these accounts only serve to highlight various systemic variables. Thus, they do not factor in the strategic preferences of ASEAN members that are essential towards understanding political forces of regional integration. Pressure for integration will have to come from multiple actors across multiple political and economic levels, "successful integration requires not just demand from market actors but also supply from political actors - the existence of an undisputed leader among the group of states seeking closer ties" (Kim 2011, 413). Indonesia has been filling the guiding position within the organization, though as mentioned before, this is not a designated position, much in the same way that Germany has been a driving force behind the integration efforts within the European Union.

Even recent accounts that stress the economic and political issues at the domestic level do not show the complete picture. Kim hypothesizes that strategic preferences within ASEAN states, resulting from both their domestic politics, specifically concerns by the elites' over sovereignty and regime security, and their degree of economic interdependence, should be a significant variable in the explanation of the ASEAN integration process over its history as well as recent agreements to deepen integration. While free trade efforts in North America and Europe are indicative of their long history of heavy intraregional trade efforts, the Southeast Asian states do not share a similar history, instead focusing primarily on trade efforts with more developed Western powers. This is a lasting impact of the colonial history in the region. Another lasting effect of colonialism is a deep-rooted protection of state sovereignty, which from the inception of 
the regional organization has been a constant hurdle during every negotiation as members have been unwilling to cede any degree of their sovereignty to any regional institution. This is in keeping with the tradition of the 'ASEAN Way,' promoting the ideals of respect for national sovereignty and non-interference in domestic affairs, a value that has been reaffirmed in many of the association's declarations and even in the 2007 Charter. Though ASEAN leaders share, to varying levels, the perception that deeper integration could serve to invigorate ASEAN's economy by improving efficiency and promoting complementarity efforts among ASEAN members which would increase the level of intraregional trade, the lack the political will for it will not materialize if it is perceived to threaten the survival of their regime. It is uncertain if ASEAN will be able, or willing, to make the necessary steps that would be required for further integration. Efforts by individual members for bilateral trade agreements undermine the political strength of the association as its own entity. Efforts such as ASEAN Plus Three/Six, which pursued economic cooperation with larger regional powers, has instead hindered ASEAN integration by pushing regional trade and investment away from Southeast Asia and toward China. Though some progress towards that has been made as they have recently outlined clearer goals for a unified market system and arranged to delegate some policy authority to a regional institution by adopting a more rules-based system, including enforcement mechanisms to ensure the implementation. The largest hurdle though is having members give up their sovereignty for a collective security outside of economics. This could change in the presence of a significant external threat.

What we have learned from a realist perspective analysis of ASEAN is that it functions under the principle of neo-contingency. The institution is intrinsically reactive, 
contingency driven rather than conceptually driven. The member countries have used ASEAN not so much to engage in hard or soft security building, but as a site of information and signal gathering. Continuing to iterate policies and plans from lessons learned more than strategizing future scenarios. 


\section{Chapter VI: Is ASEAN a Liberal Economic Community}

What would a liberal economic community entail

The sixth principle in the ASEAN charter, 'effective cooperation among themselves,' illustrates the advantages seen in collaborative efforts between member states and throughout the region in order to advance the socio-economic needs at home. The strong emphasis on diplomacy over military strength, a core tenant of liberalism, has served to make ASEAN an intermediary between many of the larger actors in the region, giving the group considerably more clout. With ASEAN, the pursuit of economic gains has remained a core principle within the organization. Through cooperative efforts, such as the Asia-Pacific Economic Community, ASEAN Regional Forum, ASEAN Free Trade Area, ASEAN Plus Three/Six, the organization has made contentious efforts to expand economic integration throughout the region, and with it, enhanced stability for all. Economic and social communities are traditionally established in order to coordinate fiscal strategies and efforts, establishing trade agreements such as liberal practices like free trade pacts that give economic advantages to regional economies while handicapping external products. This is in opposition to protectionism, which utilizes tariffs and strict import quotas so as to disadvantage foreign goods in domestic markets. Regional free trade pacts, the Mercado Común del Sur and the North American Free Trade Association or more intertwined initiatives such the African Union and the European Union, give the trade partners an advantage over other states which can serve to bolster the region's stability as a whole. 
Liberalism focuses on the gains to be made through increasing levels of institutionalization of inter-governmental cooperation, for instance, the establishment of regional organizations that create free trade areas. Its focus extends from economics to political and religious liberties as well. Neoliberalism emphasis remains on the economic gains to be made through the removal of barriers through globalization efforts, such as deregulation and increasing privatization. This chapter will examine ASEAN's stated intentions and efforts towards establishing itself as an economic community. Have its member states universally approved these efforts or has there been uneven adoption? Have non-member states in the region embraced ASEAN as an economic hub, or is it viewed more as a rival power?

Evidence of liberalist based economic community Economic-community

In addition to security alliances, trade and economics are among the most significant motives for states to seek joining regional organizations. Imports/exports can bring much needed supplies and capital into an economy, as well as allow for more focused manufacturing efforts if a market is not closed off and needing to provide all products 'in house.' A major hindrance to trade is wading through the myriad of bilateral trade laws between all participating nations; an example of this is the 'Noodle Bowl Syndrome,' where if you were to place the hundreds of overlapping trade deals of the East Asian countries onto a map, it would resemble a massive mess of noodles. A free trade agreement that is region wide would substantially reduce the amount of time and 
finances that states and companies would have to spend getting through the "noodle bowl.' Singapore and Thailand have been strong supporters of increasing the utilization of free trade agreements within and outside the region, signaling a potential bilateral alliance on economic policies. "This bilateralism—based on both the deeper strategic intentions embedded in their foreign economic policies and wider international political economy considerations - is underpinning region-divergent outcomes within Southeast Asia" (Ganesan and Amer 2010, 18). Regional free trade agreements, such as the North American Free Trade Agreement or the European Union Free Trade Agreement, each bring with them their own regulations and requirements, but changing industry laws for an overarching system is less taxing than those of a myriad of smaller systems. The market access that comes with these agreements can help states' economies, but it does come with political and economic risks.

With the economic transactions comes cultural trade as well. These exchanges will help cultivate a regional identity as the separate cultures increasingly overlap. Shared experiences within the region create sympathetic bonds, though depending on that history also risk high levels of animosity. These common bonds serve to foster a sense of community that is essential for long-term cooperation. This community would be demonstrated by strong social networks that are capable of bridging national boundaries as well as strategic thinking that recognizes shared security interests, and importantly a regional identity that is capable of superseding national identities. The historical nature of the regional order in East Asia leads to this form of consolidated regionalism to remains highly problematic. The difficulties of navigating a region towards a more united cultural identity cannot be overstated; the hurdles of overcoming decades if not centuries of 
history, both positive and negative, into a sense of trust will take substantial time and effort. "The challenge of constructing a South-East Asian community (identity) was evident in a survey of 100 elites from all 10 ASEAN nations, wherein $59.8 \%$ of the respondents indicated that they could not "trust their neighbours to be good neighbours"' (A. T. Tan 2013, 454). Many members of ASEAN still rely upon outside states, specifically the United States, for support even with domestic issues such as insurgencies. While there is potential for greater integration, there is little political or cultural will to support it.

ASEAN Free Trade

While improving economic conditions has been a stated goal of ASEAN from its initial inception, its efforts towards this were scattered at first and have only gained momentum in the last several decades. The 1976 signing of the Treaty of Amity and Cooperation in Southeast Asia at the first ASEAN summit, held in Bali, established the initial foundation for later economic integration efforts, initially between ASEAN members and then later allowed for inclusion of non-Southeast Asian states after being amended in 1987 and again in 1998. Though primarily focused on political cooperation, it promoted greater economic collaboration, under the notion that economic integration promotes stronger deterrence from conflict. Within the Bangkok Declaration of 1967, economic cooperation was positioned as one of the organization's pivotal objectives with several efforts made towards shifting the organization towards this goal. One of the first steps was tariff reduction to promote trade and improve economic ties but the 
negotiations were drawn-out. Only in 1977 did ASEAN produced its first preferential trading arrangement. "The Cambodian crisis of the late 1970s and the following decade strengthened ASEAN's habit of consultation and co-operation. The perceived common threat rallied the ASEAN countries into joint actions to secure peace and stability, from which economic prosperity was derived" (Lee 2011, 87).

Efforts towards establishing the Asia-Pacific Economic Cooperation were initially resisted by ASEAN, which counter-proposed an East Asia Economic Caucus, seeking to exclude non-Asiatic states, including traditionally strong bilateral trading partners such as the United States, Canada, Australia, and New Zealand (Ganesan 1999). The caucus, which was to be made up of ASEAN states as well as China, Japan, and the Republic of Korea, was rejected by Japan and criticized by the United States. While this initiative floundered, never officially starting, it in many ways served as a precursor for the ASEAN Plus Three organization.

The first meeting of APEC was held in November 1989, with the first annual APEC Economic Leaders' Meeting beginning in 1993. The membership of APEC has expanded from the original twelve states to the current twenty-one, with several potential candidacies on the horizon. Significantly, India was denied membership but granted observer status. The role of APEC has been to enable smoother transactions between Pacific states, including the creation of the APEC Business Advisory Council in 1995, and has worked to promote free trade with the 2006 proposal of the Free Trade Area of the Asia-Pacific (FTAAP). The goal of the FTAAP was to untangle the massive amount of separate free trade agreements in the region. By 2012 ASEAN Plus Six alone had three 
hundred thirty-nine separate overlapping and conflicting agreements creating a 'noodle bowl' effect, with hundreds more proposed throughout the Pacific (Brilliant 2007). Efforts are still ongoing to improve the situation. For a while the Trans-Pacific Partnership was seen as a possible step in the right direction though its fate is currently unclear.

The ASEAN Free Trade Area (AFTA) was established in January 1992 (Association of Southeast Asian Nations 1992) by the six member states at the time but now includes all ten current members. The four states that joined ASEAN after AFTA was established, Viet Nam (1995), Laos and Myanmar (1997), and Cambodia (1999), were allowed longer periods to implement the required tariff reductions with the original states to meet the obligation of zero tariffs in 2010 and the new members in 2015. Though a partial extension was given on some tariffs, "flexibility was accorded to the four newest members to have three more years from 2015 to 2018 for keeping some of their tariffs at the $0-5 \%$ tariff rate instead of reducing all the Inclusion List tariffs to zero by 2015" (Lee 2011, 109). This system, the Common Effective Preferential Tariff, only requires the tariff limitations on trade between ASEAN members. Foreign trade is subject to tariff rates dictated by individual governments. The ASEAN Secretariat only has the authority to monitor compliance of AFTA. All enforcement and disputes are handled by national government's trade and custom authorities; a symptom of states' unwillingness to cede any authority. Disputes are commonly handled informally as the protocols for Senior Economic Officials Meetings require resolutions to be resolved through unanimity between all ten members, including the affected parties. Alternatively, states have taken 
disputes to the World Trade Organization or the International Court of Justice for arbitration.

Complimentary efforts to AFTA have been made in the institution to create an internal common market to capitalize on the exchange of goods, services, and labor. Improving trade and keeping capital within ASEAN will give it greater abilities for investment. This will be a significant shift from the contemporary foreign exchange efforts which predominantly involve trading to states outside of the associations. As of 2010, only Laos and Myanmar had a majority of their exports going to ASEAN members with $80 \%$ and $50 \%$ respectively, while as a whole the association's members' exports to foreign countries is $80 \%$ (ANTARA News 2011). ASEAN currently has separate free trade agreements for China, India, Japan, Korea, and one for Australia and New Zealand together. Talks have recently begun towards establishing free trade agreements within APT. Since 2012 there has been an ongoing effort made for launching the Regional Comprehensive Economic Partnership which includes all six states with which ASEAN already has free trade agreements as well as the East Asia Summit, which has been working towards a trade agreement under the title Regional Comprehensive Economic Partnership for East Asia. These efforts are gaining more traction following the United States' withdrawal from the Trans-Pacific Partnership. "RCEP will boast a population of 3.4 billion people - more than half coming from India and China - with a total gross domestic product of $\$ 49.5$ trillion or about 39 percent of the world's GDP” (Hunt 2017).

From a liberalist perspective, ASEAN has made efforts towards establishing itself as an economic and political hub, but its institutions remain effectively weak in their 
current implementation with little means of control or enforcement. A neoliberalist standpoint, focusing on efforts to bring closer economic cooperation through capitalism, shows prospect. The establishment of free trade areas has increased overall levels of income in the region, but the 'noodle bowl' of overlapping trade deals creates barriers to trade and migration. It has also exposed the region to greater market and societal risks.

Evolution of regional economics Asian Financial Crisis

The 1997 Asian Financial Crisis has been one of the toughest tests of ASEAN's abilities to respond to prolonged emergencies. Most members of ASEAN were hit, with Indonesia and Thailand suffering the worst of the effects, with Laos, Malaysia, and the Philippines taking a moderate hit, while Brunei, Singapore, and Viet Nam were less affected. Outside of ASEAN, other states within the region were impacted as well. While South Korea was significantly affected, China, Hong Kong, and Taiwan suffered more from decline in demand for trade as the crisis went on. Japan held the world's largest currency reserves at that time and was able to stave off the more serious problems and recovered quickly (Yamazawa 1998, 342).

Preceding the economic bubble bursting, attempts by finance ministers at the third meeting of APEC in March 1996 to negotiate an increase to the quantity of sums available for the Emergency Finance Mechanism failed. The $30^{\text {th }}$ ASEAN Ministerial Meeting, held in July 1997, issued a joint declaration that expressed growing concern and called for increasing cooperation to safeguard economic security (ASEAN Ministerial 
Meeting 1997). The inability for ASEAN to adequately institute policies and safeguards to stave off risks that were becoming increasingly apparent is symptomatic of the entrenched value of non-interference in domestic policies.

As the crisis began to unfold, domestic governments sought to prevent a potential currency collapse due to flight of capital by raising domestic interest rates and purchasing back high volumes of domestic currencies at fixed exchange rates. These were costly short-term efforts that did more harm than good. As central banks were being drained of reserves, the flow of capital out of the country could not be stopped, thus governments conceded to let their currencies float, which led to rampant depreciation and wide-spread bankruptcies, expanding the crisis. As domestic currency values dropped, loans pegged to the United States dollar grew increasingly unpayable leaving many businesses and municipalities to default. Investor panic led to an increasing exodus and trade in the region plummeted.

The International Monetary Fund (IMF) had to step in with a series of aid packages to the states most at risk of defaulting. The economic aid was provisional on the requirement of significant reforms to government oversight of the market systems. While some of the larger economic powers in the region have returned or surpassed their former market levels, many of the smaller states remain below pre-1997 levels. Given the failure of domestic and regional powers to stave off the worst of the crisis, it is arguable that the involvement by the IMF was necessary, but it was still resented by many as interference by foreign powers, especially Western former-colonial nations. 
One result of the financial crisis was the creation of a currency swap agreement between the members of ASEAN Plus Three at the $33^{\text {rd }}$ annual meeting of the board of governors to the Asian Development Bank in May 2000. The meeting was held in Chiang Mai, Thailand, to establish bilateral agreements in order to prevent a future financial crisis, titled the Chiang Mai Initiative. This effort would also serve to complement international financial institutions, such as the IMF. The Chiang Mai Imitative Multilateralism agreement was signed in 2009 and went into effect on March 2010. The reserve pool was originally set at a level of 78 billion (USD), but it was agreed to be elevated to 120 billion in 2008, then doubled to 240 billion in 2012 after launching (Ministry of Strategy and Finance 2010). At its current levels, members can collect up to 30 billion from the reserve pool.

Integration via regionalism instead of bilateralism/multilateralism

The strong push for multilateralism and open markets, through efforts such as the General Agreement on Tariffs and Trade and its successor, the World Trade Organization, have been at the forefront of the North American and European initiatives to promote a global integration through economic trade. Globalization aims to create a unitary political and economic space, but in the vast global community many smaller states feel their value lessens as their individual relative impact diminishes. This incentivizes the formation of regional blocs to strengthen their position through collective bargaining. While membership in multilateral organizations such as the WTO grows, so too does the expansion of its biggest obstacle, regionalism through smaller economic 
blocs. "Industries at a comparative disadvantage globally might nonetheless enjoy a comparative advantage within their region; their governments would thus encounter less domestic resistance to regional arrangements" (Paul 2012, 139). The comparatively small membership of a region bloc does give smaller powers the chance for a larger voice, but it does not necessarily remove the risk of being pressured in to unfavorable agreements by larger states; for example, when forming the North American Free Trade Association, the strength and solidity of Canadian and United States economies allowed them leverage when negotiating terms with Mexico.

Persisting rivalries

The continuing efforts to implement free trade agreements within ASEAN, allowing for lenient timelines for the newer members, as well as broader bilateral and multilateral agreements throughout the region serves as a strong indicator of neoliberalism. These trade agreements with states such as China, Japan, and South Korea individually, as well as increasingly through regional treaties, demonstrate the acceptance of regional powers embracing ASEAN as an economic hub. Yet the position of the AEC to maintain a strong division between economic policies and political ones serves to illustrate a high level of distrust throughout the economic community of outside influences.

Viet Nam serves as an example of strained relationships within the ASEAN community. Viet Nam has faced ongoing trade deficits with Thailand that have led to 
some tensions. "In January 2008 alone, Vietnamese exports to and imports from Thailand were recorded at USD \$109 million and USD \$372 million respectively, a 58.0 and 45.2 per cent increase as compared with 2007 figures" (Ganesan and Amer 2010, 80). Additionally, the two states appear to compete in some areas such as rice export and foreign investment. However, they may not necessarily engage in direct economic competition due to Thailand being more developed than Viet Nam and some view efforts of depicting Viet Nam as a potential economic rival has been mainly for domestic consumption in Thailand. Viet Nam has also had political disputes with Cambodia, with many still bitter from its invasion to dislodge the Khimar Rouge government. Two persisting matters remain at the heart of disputed issues, territorial disputes and the situation of ethnic Vietnamese remaining within Cambodia. There has been notable progress towards improving bilateral relations in recent years, such as with the managing of border disputes. Talks at high-levels have shown that the current governments are willing to move relations forward. The main desire of both states has been increasing economic relations. Disputes over maritime rights remain, but there is growing potential for cooperation to develop the relationship, if the efforts can be sustained.

What we have learned from a liberalistic perspective analysis of ASEAN is that it functions under the principle of institutional isomorphism. ASEAN does not conform to a binding interdependence that a liberal approach would adhere to. Instead member countries have used ASEAN in an opportunistic and heterogenous manner, changing preferences towards free-trade, whether they favor bilateral or multilateral agreements. Liberal interdependence marches along a path defined by the previous two steps, not by some lofty goal in the distance. Progress towards liberalization has happened gradually as 
organic reaction to events, rather than long-tern planning efforts. Results of these steps are inherent unpredictably. 
Chapter VII: Is ASEAN a Constructivist Rights community

What would a constructivist rights community entail

The shared rich cultural history of the Asia-Pacific has served to create the institutions built upon by ASEAN. The interactions throughout the region develop their own inertia in the behavioral development of a state. A constructivist explanation of Southeast Asia's diversity states that each of ASEAN's norms are shaped to generate an institution uniquely suited to solving the region's specific problems. "While states initially cooperate to fulfil individual motives - for example, because certain goals cannot be pursued unilaterally - this can only explain initial, short-term cooperation. It does not account for long-term collaboration" (Parekh 2014). China's implementation of a tributary system throughout much of the region, an extension of its internal practices with its provinces, still influences its perception of other states and how interactions are meant to be performed. An interaction most Asian states have gone through in their history is that of foreign powers claiming to be more advanced and imbuing their culture onto the indigenous populations. This not only alters the cultural and technological levels of the society, but also shapes its view towards future interactions with other powers, as well as a cultural understanding with other subjected Asian states. This commonality is a leading factor behind the formation of ASEAN, that the smaller states have more to gain when they work together, even if they do not necessarily like one another. The behavior of ASEAN and its members are a product of their history. The region's history is full of periods of colonization, from actors within and outside the region, as well as oppressive rule and authoritarian governments. The member states continue to seek moderate levels of military parity even though the foundations of the organization prohibit any military 
action against another member. Even when members may have tensions between each other, they still participate in summits and have continued seeking to resolve differences nonviolently.

"Norms not only establish expectations about how particular actors will behave, they also 'teach' states, which are exposed to norms, new interests and identities" (Acharya 2001, 24). The high levels of cultural interaction and trade have served to form stronger norms at all levels. The continuous interactions between the states and their cultures has served towards the establishment of a shared identity, 'the ASEAN Way.' This identity has taken on several forms, from the social effort to create a stronger unified culture to the political form, characterized by the informal approach that aims at preventing conflict and is often not carried out in public. As ASEAN states continue to practice regional norms between one another, it serves to reaffirm the identity of the member and its collective. Through this process of socialization, states have been able to gloss over many of the historical disputes of the region. "In the post-Cold War era, ASEAN's norms have nevertheless been tested and frayed over issues such as membership expansion, non-interference in matters of political economy, and human rights and democratization debates" (Acharya and Buzan 2010, 139).

The constructivist approach emphasizes the importance and interactions of norms, values, and identities, seeking to analyze what practices have become regional norms, serving towards shaping that shared cognitive identity. Long standing norms have been difficult to change rapidly, thus if ASEAN were to be viewed through a constructivist lens it would have challenges developing historical norms to evolving issues. This 
chapter will analyze how the association's rules have changed to answer social issues, specifically the increasing global awareness towards human rights, as well as how the established norms have responded to handle crises. How have the established political norms reacted to the involvement of inter-government and non-governmental organizations or the creation of civil society organizations throughout the region?

Evidence of constructivist based rights community Bangkok Declaration

At a ministerial meeting of Asian states held in Bangkok in March to April in 1993, the representatives walked a fine line in creating what became known as the 'Bangkok Declaration.' The meeting, which included states as far west as Iran, solidified a statement that would represent Asian views before the coming World Conference on Human Rights to be held that June in Vienna. The declaration promoted the notion of human rights but at the same time objected to the concept of universal rights without recognizing cultural and regional backgrounds. "[They] recognize that while human rights are universal in nature, they must be considered in the context of a dynamic and evolving process of international norm-setting, bearing in mind the significance of national and regional particularities and various historical, cultural and religious backgrounds" (The Ministers and Representatives of Asian States 1993, 1). While the ministers did recognize the Charter of the United Nations and the principles of human rights, they stressed the importance of sovereignty and respect for 'Asian values' in their application. The global response to the Bangkok Declaration has been tepid. While the 
acknowledgment of the need for human rights has been viewed positively, the concern raised over the issue of the universality has been subdued by the position of strength in the negotiations the Asian states gained by fortifying their position before the World Conference.

Human rights and equality

In 2000, the United Nations Security Council passed Resolution 1325, its first policies for protection for Women, Peace and Security (WPS), to show its commitment to promoting practices that enable women to participate in all affairs of peace and security. Over time, seventy-four countries have adopted similar plans, but only two of the ten members of ASEAN signed (Peace Women 2018), despite the many claims from states in the region to uphold women's rights. In Women, Peace and Security as an ASEAN Priority, Sara E. Davies, Kimberly Nackers, and Sarah Teitt argue for the need of ASEAN to adopt policies pertaining to women and how ASEAN implementing policies to uphold women as central agents will enhance peace and security in society, as well as future policy proposals. In their view, the region has made significant institutional statements regarding the protection of women's human rights and preventing violence against women. However, it still does not address these in relation to regional security.

In members of ASEAN, there continues to be high levels of violent crimes against women, despite claims by local governments towards their growing value in society. "The poor scores of ASEAN countries concerning the economic empowerment, health 
and political status of women may be explained, in part, by its membership's violent history" (Davies, Nackers and Teitt 2014, 336). Though they are continuing efforts for political transition and restructuring, women are typically not included in these processes beyond a supportive role. Indonesia and the Philippines are among the nations who have WPS policies implemented, but the low number of women in state government inhibits change from happening at a quicker pace and being implemented as nations rebuild, making transition easier for the future. In 2009 ASEAN developed and passed a declaration against violence on women and children which includes a survey to see how extensive the problem is. This was a strong step in providing women the opportunity to gain access to economic independence and greater contributions to society. However, despite this policy ASEAN has done little beyond its creation to uphold the rights they state they want their nations' women to enjoy.

The $21^{\text {st }}$ summit of the Association of Southeast Asian Nations in 2012 brought the adoption of the ASEAN Human Rights Declaration. This was viewed as a significant shift for the region as member states were not affiliated with the existing international human rights institutions that have increased in significance over the last forty years of ASEAN's existence, though many of its members lacked the internal laws and policies to safeguard human rights that have come to prevalence throughout many other regions. Nicholas Doyle concludes in ASEAN Human Rights Declaration and the Implications of Recent Southeast Asian Initiatives in Human Rights Institution-Building and StandardSetting that these efforts have not only fallen short, but in fact are hurting human rights efforts in Southeast Asia. While there seems to be much to celebrate in ASEAN's efforts toward safeguarding rights, however, there are indications that these new initiatives may 
instead be a distraction and in fact a backwards for human rights protection in the region. By appearing to address the concerns of international and national bodies regarding human rights in ASEAN States yet they amount to little more than political rhetoric.

The recommendations from Women, Peace and Security as an ASEAN priority suggest an ASEAN joint workshop within its communities to discuss engagement in WPS policies, "by committing to support member states to implement the WPS agenda, regional arrangements send a strong normative message that success of regional peace and security institutions will be judged by their responsiveness to the perspectives and priorities of women" (Davies, Nackers and Teitt 2014, 347). Since current ASEAN policies only go so far as to bolster women's economic status, these workshops could help identify ways women can be political facilitators and providers of regional security. Dialogue between the United Nations and ASEAN can be constructed after these workshops to see what the nations' next steps should be to involve women in ASEAN peacekeeping efforts. Then ASEAN can collaborate to write guidelines for regional institutions and branches in implementing and following better WSP policies and advance women into peacekeeping matters. By implementing regional treaties, as is the case with the ASEAN Human Rights Declaration, states gain the positive attention from the international community without having to submit any authority to adopting international standards and observance. Pulling from Hathaway's 2002 report Do Human Rights Treaties Make a Difference? By ratifying treaties, counties experience a drop in external pressure for tangible improvement, thus leading to an actual reduction in the pace of real improvement. It is unclear what levels of external attention and domestic pressure will aid in furthering adoption and implementation of greater equality practices. 
Rights groups must remain determined, careful from being distracted by placating resolutions that serve for positive attention from foreign press. Having women's representation in all levels of government is the most definitive pursuit for there to be long term structural change.

Three years after the Thai military overthrow of the government, the country still suffers from accusations of rampant human rights abuses. Human Rights Watch claims that thousands of dissidents have been imprisoned and undergone 'reeducation' in military prison camps. The junta National Council for Peace and Order has continued to prolong its strict authoritarian rule despite pledges to restore democratic rule and respect human rights. "Key constitutional bodies set up by the NCPO - such as the National Legislative Assembly - are dominated by military personnel and other junta loyalists, meaning that there are no effective checks and balances on military rule" (Human Rights Watch 2017). A newly proposed constitution would safeguard members of the government from being accountable for any human rights violations since coming to power as well as further strengthen the military control over the government. Social forums and academic panels related to human rights are frequently cancelled by authorities including political gatherings of more than five people. The newly imposed Computer Related Crime Act has been viewed as a thinly veiled effort to establish sweeping surveillance and censorship mechanisms.

ASEAN's response to the coup d'état was poignantly muted. The December statement by the ASEAN foreign ministers was to express confidence in the resilience of Thailand to overcome the hardship and their willingness to extend all appropriate support 
based on the principles provided of the ASEAN charter. The most significant statement came from Indonesia's Foreign Minister, Marty Natalegawa who said that with respect to the principle of non-interference in a state's internal affairs, in regard to the ASEAN Charter and its emphasis on democratic principles and constitutional government, "the developments in Thailand merit Indonesia's and ASEAN's attention." No further actions or statements were made by the RIGO as political unrest and claims of human rights abuses have continued to persist in Thailand. Non-ASEAN states have had mixed responses, with China wishing for a return to order, Australia and Japan speaking out of the need to return to the constitution and rule of law. While the United States stated it would review its military links to Thailand and has reduced joint training exercises, as of 2017 it is still selling arms, including helicopters.

Since being elected as Philippine President, Rodrigo Duterte has vocally pushed for stronger actions to be taken to combat the growing drug epidemic. After a bombing on 3 September 2016, he declared a state of emergency and authorized the armed forces and national police to prevent the spread of violence. He has also publicly encouraged citizens to kill those suspected of being criminals or addicts. Previously, while serving as mayor of Davao City, he was accused of being involved with vigilante death squads and has even boasted of personally killing. Since launching his 'War on Drugs,' he has also accused and imprisoned several political rivals, including Senator Leila De Lima.

While ASEAN has attempted to thwart the increasing drug problem in the region, the thirteenth meeting of the ASEAN Inter-Parliamentary Assembly's Fact-Finding Committee to Combat the Drug Menace, held from the fourth to the sixth of July 2017, 
focused on information sharing and intelligence gathering. The issues of human rights or high numbers of deaths were not discussed. Isra Sunthornvut, a legislator from Thailand stated, "The drug menace is a problem for us all. But we're not here to judge anybody. Everybody has different methods of dealing with the drug menace. So what we're trying to do is we're trying to learn from one another" (Cepeda 2017). The delegate from the Philippines reasoned away the existence of 'collateral damage' as a result occurring in any war, having previously stated that over seven thousand drug related suspects had been killed, with over four thousand of those occurring outside of police operations by vigilantes. Criticism from outside nations and NGO/IGOs, notably from the United States under the Obama administration, led to a souring of relations involving personal attacks.

The most significant crisis in modern times for ASEAN has been the brutal ethnic cleansing of the Muslim Rohingya minority group by the Burmese Armed Forces and the mass exodus that ensued. Long been discriminated against, an attack by Rohingya extremists on 9 October 2016 was all it took to justify a massive operation to sweep through the countryside detaining Muslims and burning down entire villages. Brutal mass executions and rape have been reported (Slodkowski, et al. 2017). As of September 2017, neighboring states have seen an influx of over 600,000 fleeing refugees, with the Burmese government claiming to have killed over a thousand. ASEAN has not taken any actions to censure the involved governments. At the $30^{\text {th }}$ ASEAN summit on 26 April 2017, the ongoing crisis in Burma was not on the agenda. With little to no enforcement mechanisms from ASEAN, the power of implementation remains under the sovereignty of the individual members. Doyle summarizes with a final critique, that while it is often viewed that some degree of international regime 'is better than nothing.' In the case of 
ASEAN though, its initiatives towards human rights might be worse than having none as the current norm is obstructive. "If the 'ASEAN Way' is itself a 'regional particularity,' it is a perverse one in the context of a regional human rights initiative. Like any international organization, ASEAN is no more than the sum of its parts and it falls to ASEAN leaders to see that national standards at least achieve parity with international benchmarks" (Doyle 2014, 98).

Disaster relief

The United Nations Resolution 1674 by the Security Council unanimously reaffirmed the institution's support for the Responsibility to Protect, one of the largest shifts to the notion of state sovereignty since the adoption of the Westphalian System. It states that it is the responsibility of the state to protect its populace from genocide, war crimes, ethnic cleansing and any crimes against humanity, and that it is the international communities' responsibility to make timely and crucial decisions through peaceful means and only uses more forceful means consistent with the UN Charter if the former fails. What has long been the international relations standard of non-interference in domestic issues, this resolution mandates that it is the duty of the state to safeguard its own people, and when it is incapable of protecting, or actively involved in threatening its citizens, it is the duty of the international community to intervene upon their behalf. These changes have been met with trepidation within the Asian community. The long historical influence and occupation by European powers raises deep-seated concerns of foreign intrusion, as ASEAN members are currently concerned more with domestic security than 
expanding their reaches of humanitarian efforts globally. In addition, since many nations have more authoritarian governments, such as China, there is little political will to expand into international humanitarian issues.

In The Responsibility to Protect in Southeast Asia: Can ASEAN Reconcile Humanitarianism and Sovereignty? written by Alex J. Bellamy and Mark Beeson and in The Responsibility to Protect in Southeast Asia: Between Non-interference and Sovereignty as Responsibility, also by Bellamy with Catherine Drummond, they review how the Responsibility to Protect has been a policy of some contradiction for ASEAN as it has institutionalized around the sovereign rights of state boundaries and regulation, even in times of humanitarian crises. The ASEAN Charter adopted a compromise between traditional non-interference policies and a more flexible model towards achieving the organization's collective goals. The charter maintains the norm of noninterference and consensus-based decision-making, protecting members from interference as they can effectively block any action; however, the acceptance of the ASEAN-minus$\mathrm{X}$ method, which allows states that are not in agreement to opt out of collective decisions in regard to economic matters, is a significant shift in the voting system that creates an opening for new policies.

"There was consensus that R2P must not be used to legitimise unilateral coercive interference in the domestic affairs of states, with Singapore adding that the R2P does not in itself create any additional legal obligations" (Bellamy and Drummond 2011, 194), and yet Singapore has later gone on to state that, "narrow notions of sovereignty no longer hold today" (Bellamy and Drummond 2011, 196). A strong case for the need to reform 
was the devastation and slow response following when the Cyclone Nargis hit Myanmar in 2008. With over 100,000 dead and roughly 1.5 million left displaced, the Myanmar government was unable to effectively respond on a significant scale. While international bodies, states, and non-governmental organizations offered to assist the government's relief efforts, the authoritative regime was sluggish in accepting aid. The French administration sought to invoke R2P, it was rejected by China as well as members of ASEAN currently serving on the United Nations Security Council, Indonesia and Viet Nam. Their position was that natural disasters were not covered under the R2P and maintained that Myanmar should not be pressured into accepting humanitarian assistance, rejecting the possibility of forcibly delivering supplies without consent. An emergency meeting of the ASEAN assembly was held and ten days after the cyclone had passed, the organization sent a small, hastily formed, group as an Emergency Rapid Assessment Team with consent from the Junta to gain access and coordinate the international relief and rehabilitation effort. "Despite the lengthy delays in delivering aid supplies and assistance, the much predicted second round of deaths due to disease and malnutrition was avoided" (Bellamy and Drummond 2011, 193).

While ASEAN was slow to respond to the crisis, members did deliberate as they recognized they had an obligation to the people of Myanmar since it was a part of the RIGO and that the aid that had channeled to the area should have come through ASEAN. At the 2009 General Assembly, ASEAN gave their endorsement for many of the elements of the Responsibility to Protect, particularly the promotion of a nation's sovereignty while upholding human rights to their citizens, but ASEAN did find dispute with the third pillar's requirement of response to crisis regarding interfering in 
international affairs in order to prevent other nations from committing crimes against humanity. However, the change in tone from complete rejection of the R2P protocols to willingness for adoption of some of its principles shows an inclination on ASEAN's part to accommodate humanitarianism alongside upholding its value of non-interference and a nation's sovereignty. "We need to consider the possibility that organizations like ASEAN will filter and reconstitute apparently universal ideas or impulses in ways that reflect and accommodate local conditions" (Bellamy and Beeson 2010, 269).

Lessons taken in the aftermath of Cyclone Nargis have resulted in the establishment of the Emergency Rapid Assessment Team, whose role is to assess the disaster and recommend appropriate actions for relief. The ASEAN committee on Disaster Management in 2011 formed the ASEAN Coordinating Centre for Humanitarian Assistance on Disaster Management (AHA Center) with the creed, 'One ASEAN, One Response.' The role of the center is to collect and provide an up-to-date information database of natural disaster reports within the region as well as conduct joint civilian and military training for disaster management (Wey 2016). The AHA Center played an important role in managing responses to the 2013 Typhoon Haiyan in the Philippines and the 2016 Banda Aceh earthquake. In 2017, the role of the center was expanded to include coordinating efforts with the United Nations and other international organizations relief efforts both in and outside of Southeast Asia. Though much of the attention was focused on the U.S. Army plans to coordinate stockpiles of equipment in several ASEAN countries for future Humanitarian Aid/Disaster Relief (HADR) efforts, "less so, to efforts by the United States to provide ASEAN with advice as well as software and hardware to improve the capabilities of the AHA Center" (Parameswaran 2016). 
Environmental governance

Despite the growing importance given to the environment and the effects that climate change will have throughout Southeast Asia, given the geographical disposition of the members being predominantly coastal if not islands, there has been very little attention given to researching governance policies' impacts in the region. Lorraine Elliot seeks to fill in some of this void in her paper ASEAN and Environmental Governance: Strategies of Regionalism in Southeast Asia. Southeast Asia faces a range of environmental hazards that need to be addressed effectively with degrees of cooperation in order to avoid the redundant pattern that has occurred previously. Transboundary problems such as air or marine pollution necessitate shared policy in order to reduce transaction costs in dealing with them. Industrialization in the region has led to higher efficiency in crops but the level of concentration has made them more susceptible to soil pollution from increasingly dense urban and commercial areas with few oversights on pollution control efforts. A new study published in the journal Environment Research Letters in 2016 documented the fatalities associated with air pollution caused annually by forest fires in Indonesia that cover the region for months at a time. "Researchers from Harvard and Columbia universities estimate that exposure from pollution from last year's fires killed 91,600 people in Indonesia, 6,500 in Malaysia, and 2,200 in Singapore in 2015 and 2016" (Parameswaran 2016), though all three governments dispute these numbers. The Indonesian government records specify only 19 deaths due directly to the forest fires in 2015, and 500,000 suffering minor health conditions. 
Internal and external policy factors work together to inhibit efforts towards shifting norms from caustic programs to ones more promoting environmental stewardship. Domestic structures with states within the region have been predominantly vertical structures with political and industrial elites at the top able to use their weighted influence to shape public opinion to favor policies that promote economic expansion with little oversight. The 1977 adoption of the Treaty of Amity and Cooperation has institutionalized the policy of non-interference in the internal affairs of other members, making it much more difficult to attempt regional steps for environmental policy change. The creation of the ASEAN Ministerial Meeting on the Environment in 1981 gave the organization an agency towards developing policy recommendations and the ASEAN Senior Officials on the Environment for promoting regional cooperation. The limit of cooperation and effectiveness of these offices to control policy was quickly apparent as it was up to individual states to implement and enforce policies due to them being protected by the Treaty of Amity and Cooperation as internal policies. Mounting pressure for governmental change in regulation has risen at the social and elite levels, which has forced slow changes on the way ASEAN members respond to and govern environmental problems. Increasingly since the late 1980s, the rising levels of international negotiations towards environmental protectionism has taken place as a backdrop for the regional political importance placed on the impact by environmental degradation. In response to grassroots activism and the growing presence of regional NGOs, "the rule systems of environmental cooperation expanded from soft-law declarations and resolutions to include plans of action, issue-specific programs, and two binding multilateral 
environmental agreements. In turn, these changes brought into question ASEAN's dominant political norms and practices" (Elliott 2012, 44).

Complex regulatory structures and regional initiatives have been formed in order to extend control of the existing power structures. The shape of the multilateral environmental cooperation efforts, reflecting its result from the ASEAN Way, is a complex association. With each member forming their own internal policy, multilateral efforts regarding environmental challenges has seen moderate progress comparatively, including the inclusion of some nongovernmental organizations. Future efforts to expand cooperation or open policy initiatives to social discussion is uncertain as these efforts have not been the historical norm. The inclusion of NGOs and the partial flattening of environmental governance in some trans-governmental arrangements still raises speculation about whether networked forms of governance will server to increase transparency. "The counter-argument is that, depending on their form and actor constellation, transnational networks run the risk of privileging technocrats and experts, that they can replicate or mask power relationships of various kinds (including those that blunt the voices of the vulnerable and marginalized), and that they can distort policy objectives" (Elliott 2012, 53). While the ASEAN regional regime created to address problems such as the transboundary haze pollution has many positive features, it is still handicapped by a number of matters, namely the requirement of consensus and preference towards soft law approaches, making this effort to be unlikely to be successful in practice. 
Development of rights organizations

Role of IGO/NGOs

As a regional intergovernmental organization, ASEAN has sought to maintain itself as the central hub for an increasing number of IGOs. The formation of ASEAN Plus Three, East Asia Summit, ASEAN Economic Community, and the ASEAN Regional Forum all represent the association's method of using IGOs to further its goals. Nonregional entities are not treated so amicably but still are found to be useful. The International Monetary Fund stepped in with aid packages for several states during the 1997 financial crisis but with the aid came steep restrictions and regulations over fiscal policies. Some perceived that Asia had lost face by submitting the region to what could be essentially viewed as 'Western' institutions like the IMF and World Bank, that frustration was compounded by the fact that Western countries on the region's periphery did not suffer much of the economic downturn. The IMF was even accused of deepening the crisis due to its sudden and strict demands to restricting the economy and financial reforms.

The World Bank provides reports to aid its members on efforts that should be taken to improve and expand their economies. The October 2017 release of the Migrating to Opportunity report cited the need to ease barriers of migration throughout the region that lead to expensive and long recruitment processes and strict quotas on foreign workers accepted to immigrate. It stated that workers faced mobility costs that were several times the annual average wage. The improvement of the migration process would help countries respond better to changing labor market needs. The report shows simulated 
returns of a $10 \%$ increase to low-skilled migrant workers resulting in $1.1 \%$ increase to the nation's GDP. Though foreign calls to change domestic or regional policies have often been met with much skepticism, those that can demonstrate fiscal advantages have gained greater traction. Even when policy changes can be seen as advantageous, stark political shifts in historical and cultural views are very difficult in the region and must be taken gradually.

For most of its history, ASEAN has been very hesitant towards the presence of NGOs in the region. Due to the wide range of issues and agendas platformed by NGOs, ASEAN placed strict guidelines on activities within the region, granting access to those focused on business and medicine, while blocking ones working in pro-democracy or human rights fields. ASEAN has been actively courting multinational corporations into the region, but it has only more recently begun to allow a wider range of organizations to operate in the region, possibly a result of the series of natural disasters it has suffered. These organizations, such as Direct Relief, a humanitarian aid organization that is active in seventy countries worldwide, which recently signed a memorandum to provide prepositioned emergency medical supplies for ASEAN's collective response to regional disasters in coordination with the AHA Center (Parameswaran 2016), have served to augment ASEAN's capabilities and assist in areas that have traditionally been difficult to create cooperation. These network-building efforts have been accompanied by a more institutionalized engagement with NGOs. The actions by non-governmental organizations have become increasingly relied upon in supporting ASEAN programs as well as in facilitating dialogue and sometimes regulations on which governments come to rely. 
“This apparent willingness to work more closely with NGOs and civil society groups in a formally structured way is new" (Elliott 2011, 63).

Civil society organizations

Abdullah Ahmad Badawi, the Prime Minister of Malaysia from 2003 to 2009, once stated that, "the ultimate measure of the ASEAN Community's success depends on how well the organization has brought change to its 600 million people in the region" (Hooi 2017). The diverse political structures throughout the Southeast Asian community, coupled with the varying economic levels, has made it difficult to implement a comprehensive social outreach to the communities feeling disenfranchised with government efforts. Rather, it seems more apparent that the states instead are seeking minimal efforts to placate these groups, if not outright ignore them.

Throughout its early history, ASEAN has sought to repress social activism and most left-leaning efforts to prevent any undermining of state authority. It was not until the economic transformations of the 1990s and the devastation of the 1997 economic crisis that forced change. The crisis obligated the states to seek appeasement to the social upheaval to prevent a greater collapse of the system. Civil society organizations (CSOs) were given tacit acceptance, but little official acknowledgment until 2005, which was seen as a strong step forward for CSOs within ASEAN, as the regional organization announced recognition of the ASEAN Civil Society Conference/ASEAN Peoples' Forum (ACSC/APF) as the formal platform for CSOs to meet with ASEAN leaders at the annual 
summits. While originally stating that CSOs were an important role in the sociocultural community, in the 2007 ASEAN Charter and its blueprint to 2025, CSOs were not mentioned. In practice, ASEAN views the role of CSOs as to assist in the implementation of the already established government policy agendas. The meetings with the state officials takes place at the end of the summit, after policies have already been discussed and decided upon, furthermore the meeting is only allocated for fifteen to thirty minutes (Tadem 2017). States hold authority over approving which CSOs can attend the meeting. An internal evaluation of the ASEAN Civil Society Conference/ASEAN Peoples' Forum found that over the ten years of engagement with ASEAN from 2005 to 2015, individual member states have consistently resisted civil society participation.

Leading up to the 2015 ASEAN Summit in Malaysia, Lao CSOs came under pressure to not raise concerns related to human rights under threat to their safety. Speaking anonymously, an official stated, "[The CSOs] will talk mostly about gender roles only, but not other issues such as land rights, the impact of hydropower dams ... and enforced disappearance, because they are afraid for their safety" (Souksavanh 2015). The majority of Lao CSOs did not attend the forum, especially to those pertaining to human rights, in their place the Lao Ministry of Foreign Affairs and Ministry of the Interior brought other organizations that were 'irrelevant' in their place. During the 2017 summit in the Philippines, demonstrations were suppressed while both the police and the activists claiming the other used violent tactics while they maintained peaceful efforts. In the end, fifty-six protestors were injured, four seriously, while six police officers were reported to be hurt (Patag 2017). 
Current leading concerns raised by civil society organizations are inclusion in the decision-making process, growing levels of inequality between member states, the decline of democratic values and subsequent rise in authoritarianism, abuses of human rights and lack of sanctions against violating governments, economic growth centered around elites, ASEAN states' focuses on trade competition over complementary investments, absence of a regional identity, little social protections for residents as well as migrants; and the continuing inequality between genders.

Based on tradition, mired in the past

While ASEAN has steadily worked towards greater levels of economic integration in the region and levels of globalization, the individual member states still seek to retain full levels of sovereignty, not wishing to relinquish control or power. There have been small steps towards intergovernmental cooperation in regard to issues such as counter-terrorism and small efforts towards environmental protection as well as notable efforts by non-governmental organizations in the region. The long standing political and cultural divisions prevent ASEAN from being considered as having a coherent encompassing identity throughout the organization as long as the states remain unwilling to seek higher levels of cooperation. It will take time to determine what levels of compliance and initiative the individual states take having signed the Paris Agreement in 2016 and what impact this could have on the organization's internal governance practices. Allowing signees to set their own 'nationally determined contributions' encourages states to take more feasible approaches while still encouraging strides 
towards combating climate change; this self-determined standard will be more palatable to the developing states that have traditionally rejected foreign imposition on their policymaking.

When compared to how other RIGOs respond to internal crisis, it is clear just how non-intrusive ASEAN is in regard to domestic events. In the African Union any memberstate that undergoes unconstitutional changes in power is automatically suspended from AU activities and given six months to restore constitutional law. Unlike ASEAN, where the Secretary General is given no true authority to impose influence over sovereign states, the chairperson and the secretary general of the AU have responsibility to condemn coup d'états as well as the power to impose sanctions. A comparative analysis of the two RIGOs shows that regional civil society engagement, supported by democratic governments and an institutionally strong secretariat, make for more proactive institutions that are less restrained by the competing interests of individual member states. Active civil society in Africa, coupled with a network of indigenous lawyers and a strong secretary general to form its progressive document on democracy and human rights. It is important to note that, like ASEAN, AU member-states are a mix of authoritarian and democratic regimes. "Apparently, democratic member-state regimes are not necessary for a democratic regional IGO” (Li 2016).

What we have learned from a constructivist perspective analysis of ASEAN is that it functions under the principle of an adaptive organization, a strong antifragile resilience. Southeast Asian regimes have maintained stability throughout periods of great change in the world, and those that have exchanged forms of governances have shown 
the ability to do so in smooth transitions of power. Southeast Asia is not a region that conforms to liberal democratic norms, but instead its form of modernizing is as sufficiently adaptive authoritarianism, slow moving on environmental governance, women's rights, civil society organizations, but still semi-tolerant and foreseeing enough to be non-confrontational. While ASEAN Human Rights Mechanism is institutionally weak, its very existence shows acknowledgment of the issues growing importance. The focus remains on economic social rights as the means of raising standards across the board, alleviating other issues. 


\section{Chapter VIII: ASEAN as a Process \\ Insufficiencies}

Realism, liberalism, and constructivism are considered the foremost paradigms towards understanding international relations, and yet none of them can adequately explain the intentions or reasoning and thus describe the contemporary institutions and behavior of ASEAN. The fact that segments of each do, to a degree, accurately apply promotes the notion for a more complex approach in the research. In this chapter I will examine a paradigm-shifting method for utilizing tools from across the separate theories. I will highlight some of the stronger signs of internal change. A strong factor in the difficulty of studying ASEAN has been that the nature of the organization has evolved consistently since its formation. Finally, I will put forth the notion of applying a multitheoretical approach that factors in the methodology for change used by the various governments and societies within the region that have promoted their resilience.

\section{A holistic approach}

While the three dominant paradigms of international relations each have their strengths, their inherent biases and focuses of study limit their applicability for cases such as ASEAN, which does not line up with what either of the three theories state should be the goals of the regional governments. More recently there have been researchers proposing a more expansive scope of study. Rudra Sil and Peter Katzenstein propose the notion of analytic eclecticism in their work Beyond Paradigms in which they describe a 
more coherent and systematic approach that integrates existing scholarship across the theoretical scope. Promoting pluralism and tolerance in the academic debate and policyoriented research, the analytic eclectic approach is about making usable connections among clusters of analyses that are functionally related but normally formulated in to separate paradigms. "It rests on a pragmatic set of assumptions, downplays rigid epistemic commitments, and focuses on the consequences of scholarship for concrete dilemmas" (Sil and J. Katzenstein 2010, 2). This effort seeks to create more cohesive explanations, as well as diminish the gap between academia and the policymakers with more actionable studies. This approach is reliant upon the work that is generated within the existing paradigms and research approaches. It does not seek to supplant them. Rather, it seeks to establish the potential relevance of, as well as connections between, various narratives created using what would otherwise be considered discrete and incompatible approaches.

The concentration of each of the traditional theories limits their scopes, creating blind spots, which is what the goal of analytic eclecticism seeks to overcome. This approach examines how the various mechanisms used in the competing paradigms could interact with each other and where it would be possible to combine efforts for practical and scholarly use. Analytic eclecticism takes the approach of addressing problems as they are experienced by political actors, rather than limiting the scope of the subject to fit within the academic boundaries established by any one traditional paradigm. Previous studies fall short in that they only examine the ontological and primary causes of mechanisms while minimalizing other factors. This method differentiates itself from other efforts, such as multi-method research or methodological triangulation, which 
primarily focus on complimenting results through various methods, instead concentrating on the diversity of connections between different mechanisms and theories normally studied in separate research methods. The approach promotes the construction of theories that generate 'pragmatic engagement' towards the contemporary social conditions in which world politics have emerged. Having a multi-methodical approach also serves to bring awareness to the external environmental factors that influence an actor's interests and methods for their studies and to what degree does that impact manifest in their findings.

In that it uses methods and tools from the other paradigms, eclecticism was not created to replace any of them. Rather, it serves as a useful heuristic that offers more expanded flexibility for applicable analyses than any one paradigm would be able to. This focused goal of pragmatism towards creating actionable research requires there to be a direct cause or issue of some import. "In the absence of a concern for framing one's research in such a way, eclectic scholarship will fare no better than paradigm-bound scholarship" (Sil and J. Katzenstein 2010, 22), risking becoming overly concentrated with the study rather than the utility, "academic theorizing will say more and more about less and less."

A new theory

ASEAN has gone through several milestones of development since its foundation in 1967, a significant one being the signing of the charter in 2007. The adoption of more 
members and the formation of several regional political and economic forums, as well as the internal and external pressures towards liberal efforts of democratization and human rights, have altered the course of the RIGO from seeking to maintain economic and regional relevance to now hosting some of the fastest growing economies in the world. For much of its existence it was grounded around creating a modestly cohesive resistance against the spread of communism in Asia, and now it hosts several communist members including Viet Nam, whose fall to communism and subsequent invasion into Cambodia, who has also since become a member, paralyzed the RIGO. Many scholars doubted the organization's longevity after its formation in 1967, and yet again questioned its resilience after the end of the Cold War and the perception of an American withdrawal from the region followed by the economic bubble bursting leading to a devastating financial crisis. Though ASEAN has shown its fortitude in its adaptability to evolving within a changing region, market, and political landscape. With the adoption of the ASEAN Charter and the gradual establishment of the APSC, AEC, and ASCC, ASEAN now appears more robust than ever.

In order to produce a better understanding of this unique regional organization we must move away from the existing paradigm bound theories, which rely upon concepts, foundational assumptions, and analytic principles to simply complex social phenomena, and adopt a more pluralistic reasoning. "Such simplification can be fruitful and is often unavoidable in light of practical research constraints, especially in relation to phenomena on which there is little existing research" (Sil and J. Katzenstein 2010, 19). Grounded in the methodological approach established with Sil and Katzenstein's Analytic Eclecticism, I propose the reactive isomorphic theory (RIT) as an analysis tool for a new approach to 
studying ASEAN. As I have established in previous chapters, ASEAN continues to defy what the nature of a regional organization ought to be when governed through the lens of international relations theories. Moreover, the institution continues to evolve and change course. To what extent the direction is being led by states, social and political elites, or if the cultural communities are driving the region needs to be further analyzed. If we are to comprehend ASEAN, we must accept that it might not be fixed on a predetermined course. Instead, we must come to the understanding that the fluidity of the organization can serve as an indicator for the contemporary values throughout the greater region.

The hybridization of imitating foreign concepts into the various levels of society while morphing them to be adoptable to existing cultures, mimetic isomorphism, and how that progresses out on the local versus regional level, neo-contingency approach, is the concentration of the reactive isomorphic theory that necessitates further study. A central focus of RIT is the evolving nature of ASEAN over time, the adaptation process that has led to its durability. The organization has shown at times that it could have, and possibly still could, go down the road towards establishing a security network with mutual defense agreements analogous to that of NATO, as one focused on the security aspects of realist theory to show predisposition for, and yet it has not. The collectivizing efforts created through free trade agreements and ARF have shown an indication of some liberalist tendencies. There remains a lack of commonalities between governments and cultures within the organization, highlighted by the admittance of communist states, as well as the continued trepidation over implementing regional institutions and interdependence that would potentially diminish sovereign powers. Constructivism serves to observe the cultural interactions that have shaped the 
region but does little to create an actionable theory of institutional mechanics within ASEAN that would serve policymakers.

What is ASEAN's current trajectory? What are the goals of its members for the association and the greater region? Are these goals compatible with those of the United States, and regardless how best can the United States interact with ASEAN itself and as a regional hub? Are there indications towards changing values that could alter ASEAN's efforts established in its charter? Given the absence of an accurate model, RIT seeks to apply the multi-methodically tooled approach of analytic eclecticism towards promoting a pluralistic view of ASEAN that could account for the shifting politics of the region driven in often differing directions at the various social and political levels. The goal of this new theoretical approach being to create a more cohesive understanding of the dynamics of the organization, serving to facilitate foreign relations with Western policymakers. Continuing efforts towards regional integration will play a large part towards increasing the support for human rights as a new norm. That said, while democratization is an essential support for human rights in the region, the presence of any external pressure on Asian states to democratize would be drastically counterproductive, leading to state collectively resisting such pressure. This occurred during the 1990s 'Asian values' debate. "A better policy is to quietly assist ASEAN members in developing civil society and NGOs as well as support ASEAN with its effort to deepen regional integration and advance the ASEAN community" (Ryu and Ortuoste 2014, 377378). The developing approach to issues such as human rights, opening economic markets, and regional security illustrate an evolution within the Association of Southeast 
Asian Nations that is not captured through the fixed prisms of realism, liberalism, and constructivism.

Acknowledging inconsistencies with paradigms

Security: neo-contingency \& information signaling

The neo-contingency approach by Katsunori Sato and Michael Roy in their article, Further Limits to Institutional Isomorphism? Introducing the 'Neo-contingency Approach' to the Field of Community-Led Social Ventures, highlights the roles that, "local contingencies, such as the external environment, leadership, and social capital, play a role in influencing organizational culture in community-led social projects and, in fact, the form that the social project takes" (Sato and Roy 2015). The neocontingency approach breaks from the notion that a single approach for an organization works universally. It illustrates how organizations must adapt as needed in response to current stimuli. The organization's structure is always adapting, shifting policies in the face of dilemmas on an as needed basis. The Association of Southeast Asian Nations has maintained a loose cohesion; though formed in the 1960s, it was thirty years later that a series of treaties and initiatives had pushed towards a more formative international structure. The ASEAN Charter, the ASEAN Economic Community and the ASEAN Political-Security Community have served to transition the assembly away from being a non-binding political association to a more rules-based institution, establishing a more effective organizational structure, the so-called 'ASEAN Way.' 
ASEAN has reoriented itself many times over its four distinct phases. As with the slow evolution towards the European Union, the first step was aimed more directly at preventing conflict between its members than from external intrusion. One of the largest shifts in the region during this period came from the United States normalizing relations with mainland China, which lead to ASEAN beginning to reorient itself as a neutral entity during the Cold War. It was the American withdrawal from South Viet Nam, and its subsequent fall to communist forces sending ripples of fear throughout the region, that spurred the next phase of development. The Bali Concord I and the TAC were significant diplomatic milestones that led to the formation of the ASEAN Secretariat and reaffirmed the commitment to non-interference and peaceful resolution of disputes. Almost immediately these ideologies were put to the test as Viet Nam invaded neighboring Cambodia and sought to overthrow the Khmer Rouge regime. The Paris Peace Conferences signified a substantial diplomatic victory for ASEAN as it was able to bring the conflict to an end without resorting to military intervention.

The end of the Cold War and the spread of globalization required ASEAN to once again reinvent itself. No longer a collection of states, unified in response to a potential communist incursion, the RIGO now opened itself up to membership for states such as Viet Nam that are still communist and had antagonized unrest in the region, resulting in the association doubling its original size. This phase was focused on diplomatic engagement, primarily through the creation of ARF, and the rapid economic expansion in the region. When the economic bubble burst, each of the states struggled to find their own solution to the crisis with little cooperative efforts succeeding, and the eventual need 
for outside economic support from the IMF resulting in significant internal loss of pride. The regional organization failed to be self-sufficient.

The lessons from these events have culminated into the current phase where we see ASEAN slowly formalizing its structure under the ASEAN Charter and the gradual creation of its pillar communities for security, economics, and cultural needs. This is a period of solidification after its rapid growth as it seeks to politically adapt to the new social and international expectations. While not a security community from a realist prospective, with few indications of a cohesive RIGO-wide security establishment, there are growing indications towards more serious defensive treaties being formed throughout the region, a 'noodle bowl' of security pacts. While in some regards ASEAN has attempted to mimic certain aspects of other regional organizations, when it comes to security matters the organization remains limited to reactionary measures. Where the European Union has gradually increased levels of inter-service cooperation, including joint operations and procurement programs, ASEAN has fixated around non-aggression pledges both between member and non-member states. Previous efforts to organize a security pact, namely the ill-fated Southeast Asian Treaty Organization, or other efforts to formalize a structure within ASEAN, such as Malaysia's motion to create a peacekeeping force for the region, have all failed due to lack of interest and commitment in the region to allow foreign forces on their soil. The potential for an intra-ASEAN conflict is crippling to get any initiative beyond mere theory.

Since the ASEAN Defence Ministers' Meeting, beginning in 2006, there have been slow efforts made towards frame working for future humanitarian assistance and 
disaster relief operations. The results of these efforts continue to be criticized though after lackluster and delayed responses in the wake of natural disasters. While there have been some efforts to coordinate faster reactions in response to widespread public criticism, the difficulties over multinational efforts interfering with sovereignty remains an extremely difficult issue. Recent moves to pre-position supplies will help local aid groups while larger relief efforts can be formalized. With the increasing risk posed by climate change and sea levels rising, these initiatives will be tested. This neo-contingency approach to handle each event as a unique occurrence leads to an often delayed and muted manner from the lowest effective level of governance possible. There has been minimal effort placed on creating overarching strategic planning. Joint training between coast guards have occurred, again between member and non-member states, but these efforts are more diplomatic than tactical.

Where the RIGO has improved its coordination is through information sharing. At the $8^{\text {th }}$ ADMM in 2014, the Direct Communications Link was adopted, its role to promote response coordination in emergencies, principally with maritime security. This has come in response to the increasingly inter-state responses required from violations of territorial waters from fishing vessels, growing levels of piracy, and the expanding presence of the Chinese naval and maritime fleets. This communication link will serve as a confidence building measure between the states that could foster some cooperated responses in time. Communication between members is critical, not only for security, but also to maintain diplomatic cohesion in the region. Information sharing leads to clear signalling for states in the region. 
The requirement of unanimity in ASEAN puts great stress on members to maintain agreement with one another, even when it goes against their individual preferences. But that self-restraint can only be stretched so far, as with the case of the Philippine's very vocal distancing from the United States and shift towards China, a move that broke the group's norm of neutrality and led to great friction amongst the members who were not used to division. Political shifts within ASEAN's position signal throughout the region. Uncertainty about its goals and direction can disrupt diplomatic efforts. ASEAN's future actions are based off previous efforts, more so than any longterm objective goals. This is a slow-moving organization; big shifts do not happen quickly without cause.

Economics: Institutionalized isomorphism

'Isomorphic adaption' is a strategy used when the call for change is strong, so the state will choose to mimic a foreign government that's values and structure resemble the prevailing system, with many of the changes being drawn out over time and mostly ceremonial. 'Localization' is a controlling effort towards influencing the implementation of new systems, attempting to retain existing values and orthodoxy while still adapting to a new system. A 'transformation' represents a complete change of the norms and identity; this usually happens after a significant crisis that highlights the failings of the existing paradigms. ASEAN has shown extents of mimetic isomorphism at the institutional level, as shown by Hiro Katsumata in Mimetic adoption and norm diffusion: 'Western' security cooperation in Southeast Asia? Mimetic isomorphism is the behavior of an organization 
to mimic external institutions as a means of garnering legitimacy, though this behavior should be distinguished from policy emulation, which is used to resolve specific problems.

A central mission of ARF was to promote preventative diplomacy in the region, to establish a forum to resolve disputes before they escalated. This collective approach was inspired in part by European programs. "The Southeast Asians had been inspired by 'common security' thinking, developed in the CSCE (Commission on Security and Cooperation in Europe) process. Such thinking is based on the view that regional security is indivisible and can be achieved only through cooperative undertaking" (Katsumata $2011,570)$. In the 1990s there were several discussions on the official level of implementing an Asian form of the CSCE, put forward by Australia and later security cooperation based off the lessons learned by European efforts was explored by Singapore.

ASEAN has often looked to the European Union for inspiration, but its goals have never been so entwined as the EU's efforts towards integration. Whether this reflects the craving of European's economic achievements or due to lasting effects on institutional direction left over from the colonial imprinting is open to interpretation. This is repeated on the socio-cultural level as Western trends remain popular in Asia, not only in entertainment but to an extent liberal values towards gender equality and human rights have begun to take hold. From my own experience interning in the Quang Nam province of Viet Nam, one of my tasks was to teach English lessons to city officials or when visiting local universities. I was frequently questioned by women over the role of women 
in the United States regarding the balance of gender roles between both the household labors and presence in business, much to the obvious chagrin of their male counterparts. Though this is a small sample size, the desire to replicate Western practices was near universal in this regard as there was a desire for change that will butt up against conservative traditions.

Just as the European Union has expanded to become not only a central hub of the region but a global economic powerhouse, ASEAN has made timid efforts towards similar goals while maintaining restrictions on sovereign integration. The achievement of the Euro currency led to similar aspirations with a potential Asian Monetary Unit, though this effort has gained little traction. Efforts towards integration have been extremely slow as, unlike the Europeans, there has never been a true long-term plan towards that level of cohesion. The organization adopts practices as needed in response to changing demands, and if successful those efforts are shared to the rest of the members, though adoption comes in a localized form if at all. The most significant coordinated effort though has been the efforts of regional diplomatic and economic forums, seeking to firmly cement their position as the central hub, as has the EU for Europe. With the Declaration of ASEAN Concord II (Bali Concord II), ASEAN stated its intent to establish three communities that would be the pillars of the organization based on political and security cooperation, economic cooperation, and socio-cultural cooperation. These three institutions resemble those of the EU: The Pillar of Common Foreign and Security Policy, the Community Pillar, and the Pillar of Police and Judicial Cooperation. Regional values in East Asia prevent the possibilities for regional courts comparable to the 
Europeans, but its members have been accepting of the role of more international judicial systems, such as the International Criminal Court or the Permanent Court of Arbitration.

Acharya explores ASEAN's role in the region's institution-building efforts, including the ASEAN Regional Forum, ASEAN-Plus-Three, Asia Pacific Economic Cooperation, and the East Asia Summit. While ASEAN does act as the role of a 'hub' for relations with other organizations, it does not seek nor have the structural capability to take a leadership role of a wider regional institution. That many efforts and initiatives have failed, such as with the defunct SEATO, gives weight to the argument that the organization does not have the capability for greater cohesion. "Yet in reality, the biggest blow to the ASEAN Way ... comes from the ASEAN members themselves. The damage to the ASEAN Way is deliberate and self-inflicted act, a fact little recognized in the academic writings on ASEAN" (Acharya 2009, 493). As recognized by Jurgen in The limits of democratizing interest representation: ASEAN's regional corporatism and normative challenges, states have resisted the persistent international and domestic pressures for democratizing regional governance through several strategies that include rejection, isomorphic adaptation, and localization. The resistance to new ideas is influenced by the region's 'cognitive prior,' the region's existing norms and values in the collective memory, which mold what is expected of the state and society from established tradition. This creates a degree of permanence that can make it very difficult for new norms to take hold without prolonged enforcement. "During its term as ASEAN Chair, the Indonesian government has practiced greater participatory openness than most Chairs before, but with the Chair passing over to less democratic member countries, this momentum may get lost" (Rüland 2014, 256) While change is possible, it will have to 
come from internal pressure and not solely external influence. The multiple strategies being utilized have largely kept intact its cognitive prior, which rests in a blending of imported European and older local ideas from the region. Given the pervasive resilience of this cognitive prior, the prospects for a significant shift towards a liberal-pluralist transformation of ASEAN's institutions remains unlikely.

ASEAN has adopted many similar traits of European regionalism that have served to create legitimacy as an international actor seeking to solidify its status as a central hub throughout the region. At the state and local levels though, governments have maintained distinctly local cultural values and practices and to date have either repressed or mitigated many social efforts towards adoption of western liberal practices. As Katsumata notes, "local actors may voluntarily adopt external norms for the sake of legitimacy, even if the new norms compete with existing ones" (Katsumata 2011, 576). These are methods commonly practiced by ASEAN as it slowly develops, even in the absence of great power politics or transnational struggles that normally define periods of normative change.

Norms and values: adaptiveness \& antifragility

The antifragile theory by Nassim Taleb distinguishes between a robust system and an antifragile one. Where a robust system might be able to weather many events or crises, inevitably it faces a large enough hurdle that will force a significant shift to overcome. The advantages of an antifragile system are that its multifaceted approach takes small 
diverse steps towards evolution. It can adapt faster to failure than more singular efforts, whose failures could prove significantly more detrimental. In Antifragile: Things That Gain from Disorder, Taleb illustrates an antifragile as the mythical Hydra, which responds to decapitation by growing two new heads in its place. "Some things benefit from shocks; they thrive and grow when exposed to volatility, randomness, disorder, and stressors and love adventure, risk, and uncertainty. Yet, in spite of the ubiquity of the phenomenon, there is no word for the exact opposite of fragile" (Taleb 2012, 2). Taleb terms this antifragile, a trait which goes beyond resilience or robustness. Where a resilient system resists shocks and stays the same, an antifragile system improves. An antifragile system responds well to the randomness of the world. It can adapt to the uncertain. It is a living organism that evolves to meet the world around it rather than stay inert and resilient to change.

Regional governments have displayed several methods to placate the populace. Since its original formation, ASEAN has evolved through several distinct phases as it adapts to the changing global norms. The end of the Cold War and the rise of globalization have required significant shifts in the direction of the RIGO, but at its core the foundation has remained solid, fixed in place. One of the more significant indicators of ASEAN's ability of adaptiveness in the last few decades has been its response to the growing call towards human rights. This is a slow-moving organization that shifts just enough to placate social unrest without uprooting the underlying foundations of the institutions. In doing so, ASEAN has remained remarkably adaptable. 'A tongue but no teeth?': The emergence of a regional human rights mechanism in the Asia Pacific region by Andrea Durbach, Catherine Renshaw, and Andrew Byrnes explores how the 2007 
signing of the Charter of the Association of South East Asian Nations, was intended to "strengthen democracy, enhance good governance and the rule of law, and to promote and protect human rights and freedoms" (Durbach, Renshaw and Byrnes 2011,212) in its members and throughout the region. Yet they find that efforts towards safeguarding human rights have come with much resistance as many member states are hesitant towards changes in social values and policies that lessen their state sovereignty. While there have been modest moves towards the establishment of regional mechanisms, these efforts shift between resistance and hesitant endorsement. Debates over values and sovereignty, strong governance and individual rights, have continued to frustrate any comprehensive effort towards implementation of a regional body since the inception of the in 1996. "At the same time, there has been significant growth in the number of national human rights institutions across the region" (Durbach, Renshaw and Byrnes 2011, 212).

The establishment of the Association of Southeast Asian Nations' Intergovernmental Commission on Human Rights (AICHR) was a strong step towards embracing what are increasingly becoming international norms and values through the establishment of multiple regional human rights mechanisms (RHRM), such as the ASEAN Human Rights Body (AHRB). Given the history of poor human rights records in many of the members, though, it is a surprising move for the organization. From its origin in 1967 through the 1990s, no mention of human rights as an issue existed within the institution's priorities as most ASEAN members opposed the universal application of human rights. Some policymakers viewed the suppression of domestic dissent provided the socio-political stability needed for economic development. The established norms of 
state sovereignty and non-interference blocked any significant development of human rights. A strong rationale for these changes has come from both the regional and domestic levels with the increasing stages of regional integration coupled with democratization in several states. The increasing regional integration has led to the erosion of old norms, allowing for modern values of good governance and increased accountability. This created the context for human rights issues and institutions to be discussed and begin to develop. The authors, Yongwook Ryu and Maria Ortuoste, assert in Democratization, regional integration, and human rights: the case of the ASEAN intergovernmental commission on human rights that while democratization efforts continue in ASEAN and the region, the efforts remain tentative. Events such as the 2006 military coup in Thailand have made some actors in the region hesitant to press for further democratization. While previously many had considered the march towards democratization a fixed path, the events in Thailand and the reversal of democratization serves to show just how tenuous foundations are for democracy in the region. Some still doubt if a democratic form of government is indeed necessary for political stability and economic development, leaving many questions over human rights role in the region. "Further development in regional democratization would likely lead to a strengthening of the AICHR and improvement of human rights" (Ryu and Ortuoste 2014, 377). Historically democracies can take several generations before truly solidifying to a culture that had heretofore not been practiced, and with the recent economic events, instability will weaken fledgling efforts. It is unclear though whether the organization as a whole wishes to advance these efforts.

Though there was an effort by Indonesia, Malaysia, the Philippines, and Thailand to create a regional commission, potentially even a human rights court, this was met with 
strong trepidation by other states and to date no ASEAN institution has been established. This fueled growing fears that the ASEAN Charter's promotion of human rights was more into political rhetoric than any real transformation. The strongest prevailing effort has come from the APF of National Human Rights Institutions, but even those efforts are viewed with skepticism. There are concerns that this effort will be implemented in a way as to evade the application of universal human rights in favor of regional and national values. Simon Tay, Chairman of the Singapore Institute of International Affairs and CoChair of the Workshop on the ASEAN Regional Human Rights Mechanism emphasized several key points of contention within the association which continue to undermine efforts towards the establishment of the ASEAN Human Rights Body. He acknowledges the concerns over whether the AHRB should be comprised of governmental officials who may not pursue changes that risk friendly relations as opposed to independent experts who could be critical of human rights violations. Whether the body should have investigative powers into complaints throughout the region or to serve as a monitoring tool. And to what degree can a minority of ASEAN states push for this initiative given the lack of full support. The efforts by Indonesia towards democratization have been very influential though, as it has been seen as the 'informal leader' within ASEAN. In the early 2000s, Indonesia began to strongly promote for the creation of a regional human rights mechanic as being critical for the future of the greater association. The president at the time, Susilo Bambang Yudhoyono, had been a strong proponent for the AICHR. "Indonesia was so insistent on ASEAN promoting human rights and democracy that it signed the ASEAN Charter on the condition that such activities will be implemented by the organization" (Ryu and Ortuoste 2014, 369). 
This acknowledgment of the public call towards human rights with the creation of the AICHR serves to raise further awareness of the issue, and yet through the limited capability and resources given to it indicates that for now this is serving more to pacify discontent. Institutions like this within ASEAN are indicative of the association's antifragility in response to changing times. By taking small diverse iterative steps it remains structurally sound and yet capable of changing itself when necessary. Despite repeated proclamations of its imminent demise or obsolescence, ASEAN continues to adapt and evolve just enough to remain a prominent fixture of the region. It does not evolve to thrive but to continue on in the face of new challenges. This is causal to the unpredictable nature, it will respond as needed to each new stimulus. 
Chapter IX: Implications for U.S. Policy Towards ASEAN

Cold War mentalities do not fit this institution

The 'Pivot to Asia' for the United States proposed by President Obama early in his first term has, in fact, made the Western Pacific more unstable and given false assurance to America's allies and partners. In Rebalancing or De-Balancing: U.S. Pivot and East Asian Order, Wei Ling posits that, while originally intended as an effort to open the possibility of a greater cooperation initiative between the United States and China, it instead has become "a balance-of-power, especially military power, situation" (Ling 2013, 148). With a growing mistrust towards China, the Association of Southeast Asian Nations finds its neutrality being tested, pressured into siding with the United States, a move which could further destabilize the region. While the organization as a whole has long claimed neutrality as a central tenant, many of the members of ASEAN have bilateral defensive ties with Western powers such as the United States, which were 'grandfathered' in and thus remain in effect.

The change in policy has served to reinvigorate America's involvement in the Indo-Pacific discussion, and its added military presence has reassured many of its allies. Yet this effort to balance the region with China has brought bilateral relations to a new low and forced many of the smaller powers into picking sides, a dilemma that has "disrupted ongoing regional processes" (Ling 2013, 152). A significant risk to peace is the fear that a smaller power will take on a strong stance against China under the assumption that the United States will stand by it, even militarily. While neutrality has been a strong principle in the RIGO's identity, to ASEAN countries, the pivot by the 
United States to counterbalance China's influence in the region has forced them into a position of having to take sides. ASEAN has sought to balance its relations between the regional powers well enough to remain institutionally central and has benefited enormously from regional integration efforts. "Once it had to take sides between China and the United States, not only would the balance be tipped, but ASEAN itself would lose its identity and value" (Ling 2013, 152). Taking a more liberal power-sharing view on the region, T. J. Pempel shows in More Pax, Less Americana in Asia that there are great possibilities from cooperation and mutual benefit to participating parties. While this may come at the expense of American policy dominance in the region, that does not automatically mean the new values would be counter to Washington, and certainly not necessarily hostile. The region would be self-reliant for security and stability, and no longer reliant upon the United and its priorities. The regional economic and political systems that were established by the United States after the Second World War are still in place but going forward the regional actors may be able to take hold of it themselves. "The final result may not be a 'Pax Americana' in its most unilateral form, but it would represent an order that would be highly compatible with America's long-term interests" (Pempel 2010,484). Though shifting values in Washington only serve to create unease amongst its Asian partners as concern over a more isolationist America would have sweeping repercussions throughout the region. The current administration's declaration of an 'America First' policy and withdrawal from the proposed Trans-Pacific Partnership has led to anxiety of a greater American withdrawal. The multilateral trade agreement was reshaped without the United States, with China taking the role as the dominant proponent. 
The United States' efforts to create a stronger community between states in the region, the intent being to balance China's growing power, has justifiably given the Chinese government the impression that America's policy is that of containment, as was the political policy with the Soviet Union during the Cold War. ASEAN states seek to maintain their claim of neutrality, in part due to fear of economic reprisals from China, yet they still seek to ensure American assistance. "Ideally, ASEAN would have the United States Navy steam in force into the South China Sea to maintain the peace, while ASEAN then clucks disapprovingly from the sidelines and reassures the Chinese that it had nothing to do with it. Intellectually, of course, ASEAN knows that it has to do better than that" (Dillon 2011, 61).

The United States has been a strong advocate for both regionalism and multilateralism. After the Second World War, it was a supporter of efforts to coordinate defense and economic integration through the Treaty of Brussels, later with the North Atlantic Treaty Organization and the European Economic Council; these efforts laid down the framework towards the European Union. This has served the United States well as over time the tensions defused in Europe, uniting against a common enemy during the Cold War, leading to an increased economic production that would benefit Americans through trade. In East Asia, the United States' approach was through a series of bilateral relationships to gain influence throughout the region, instilling a 'hub and spokes' model with Australia, Japan, South Korea, the Philippines, and Thailand. "Bilateral arrangements to be easier to arrange than multilateral ones; stronger and more resourceful countries find them preferable because they tend to gain better terms than those of multilateral forums, with their checks and balances" (Ganesan and Amer 2010, 16). 
Regionalism and bilateralism/multilateralism each have their weaknesses. States must weigh heavily on which agreements give them the most gains, politically and economically, and if the risks of collectivizing are worth the threat of shared burdens. ASEAN is in a truly unique positions, as an amalgamation of ten small states that operate by consensus and have pledged non-violence offers a degree of stability in a region with multiple big power rivals. "ASEAN will never be a titan like China, Japan, India, or Russia. But its weakness in the traditional power sense allows ASEAN to play a vital and irreplaceable role. Only ASEAN can call all the big powers to the table for the yearly East Asia Summit meetings" (Hachigan 2017).

\section{U.S. policies towards ASEAN in future}

With faults being evident in past policy efforts by the United States in the region, as well as the theories applied towards creating our conception of how ASEAN should function, it is clear that new approaches need to be made going forward to shape future American efforts. As the United States continues to evolve its policy goals for East Asia, having a clearer understanding of ASEAN's role in the region is critically advantageous. Under the Obama administration efforts were made to enhance relations with ASEAN, becoming the first non-member state to open a mission dedicated to ASEAN in Jakarta. The United States has also expanded its advising role in ARF, as well as continuing efforts to enhance the region's institutional preparedness for disaster management. These are good, positive steps to raise America's presence in the region, but it must understand the slow-moving nature of politics on the ground. Yet there have been major setbacks, 
including the sudden spat between the Obama and Duterte administrations' regarding human rights and combating the narcotic epidemic. The TPP was an overly ambitious project and the abrupt withdrawal by the Trump administration left Asian partners confused and shaken. The United States must be slow and methodical going forward to repair its relationships, and principles need to be considered.

Security

Since its creation ASEAN has taken a non-confrontational approach to conflicts, seeking to use diplomatic pressures to resolve disputes. The TAC demonstrates both the commitment to peace between Southeast Asian states as well as the association's diplomatic outreach. As of 2018 the treaty has extended beyond the original five members of ASEAN to now include thirty-four states and unions. While this has served to improve relations between many states, most of this has been between ASEAN members. Outside of the RIGO there are many members to TAC who demonstrate increasing levels of friction if not outright hostility between each other. Few, if any, view North Korea and the United States' pledges to peace in the region as binding constraints that will stave off hostilities. The same could be said of India and Pakistan. This treaty serves as a pledge, or hope, rather than any form of enforceable pact.

There is no elaborate security agreement in place or any greater agenda for a regional security organization planned out, instead ASEAN responds to each event as they occur. Through neo-contingency we see that to date member states have responded 
to events individually, or when absolutely necessary they form local agreements for interstate cooperation in order to address only the specific issue. This is an as needed ad-hoc policy with only the most extreme of circumstances requiring greater levels of cooperation and planning, as we are starting to see with the increasing costs of postdisaster HADR efforts leading to the formation of the AHA Center. The association learns from prior efforts in order to enable better responses in future events, but that does not mean they actively seek preparations or arrangements between states for security needs outside of initiatives such as the ADMM, and more recently the ADMM-Plus, which again focuses more on improving diplomatic relations over strategic planning for regional security.

ASEAN navies are modernizing, and the confidence building efforts from the ADMMs have value in establishing greater levels of cooperation but without stronger trust and leadership there will not be a shift towards security agreements. The failings of SEATO were numerous. Chief among them was lack of commitment by all parties. It was clear that the United States was placing its weight behind NATO and the EU with its Pacific focus aimed at Japan, the Korean Peninsula, and for a time Viet Nam. While the organization needed far more than just stronger support from a great power state, it was too early into the establishment of ASEAN to extend that cooperation into a military alliance. There remains a lack of will towards recreating one. It does not currently fit into their contingency based paradigm. If the United States seeks to control the direction of these events, it needs to play a more active role. Going back to SEATO and the earlier phases of ASEAN, an American presence was reassuring towards regional stability as long as its Asian partners could believe it to be a long-term commitment. Even though 
ASEAN maintains neutrality, they need to be made aware of the American commitment to the region, even in the face of near-competitor challengers. I am not proposing a confrontationality policy, but an active engagement in the region and with ASEAN as events manifest.

Successful efforts, such as the powerful imagery of American response to Typhoon Haiyan's devastation in the Philippines in 2013 can shape lasting impressions in the region. "About 50 U.S. ships and aircraft have been mobilized in the disaster zone, including $10 \mathrm{C}-130$ transport planes, 12 V-22 Ospreys and 14 Seahawk helicopters airdropping supplies from an aircraft carrier" (Mogato and Belford 2013). The American vehicles were more capable than those used by local government forces, able to reach farther and faster to remote villages. In addition to the military response, other agencies such as the U.S. State Department and the U.S. Agency for International Development also contributed their resources. Demonstrated proof of American capability and more importantly commitment will serve to gain traction in being factored into ASEAN planning. ASEAN will continue its ad-hoc efforts, but if United States involvement continuously shows positive results it will become increasingly relied upon.

Washington needs to establish a firm policy of active engagement and strong lines of communication with ASEAN. Responding to crises serves to win the hearts and minds, but if the United States wants to direct the region's trajectory it needs to place itself in the region. When the Philippines won its legal dispute with China, it did not seek to actively enforce it. This could be rooted in lack of capability or in political policy shifts under the incoming Duterte administration. The active presence of the United 
States Navy, acting in the role of maintaining international law of the sea through Freedom of Navigation missions served to show that it was dedicated to the region. That the Trump administration temporarily suspended these operations in early 2017 only serves to raise doubt from ASEAN.

Economics

The Trans-Pacific Partnership was too lofty of a goal based on ASEAN's iterative isomorphic nature. While it has increasingly adopted multilateral over bilateral free trade agreements, slowly expanding its noodle bowl, the scope of the TPP was too aggressive for it to instigate. American guidance was a driving force for the initiative, and the near collapse of the agreement after the United States withdrew highlights the need for a strong advocate. In this instance, China was eager to step in and overtake the trade talks and usurp America's position. It was predictable that in the absence of a great power another would step in and seize the reigns. China has made its position clear that it is strategically ready to replace the United States in regions it is withdrawing. Left to its own devices, ASEAN will restrict initiatives to smaller iterative efforts that have near term objectives, those that will advance its position without opening it up to unnecessary risks.

Over the last decade China has undertaken increasing economic initiatives throughout the developing world. Their motives are clear. They are securing access to economic resources by building up local infrastructure, and their policy of non- 
interference with local government policies that the West finds off-putting puts it at a strong advantage in gaining access over the United States. Throughout Asia, China's One Belt One Road Initiative is going to establish far greater economic efficiency through these often massive investments in local infrastructure. These investments win over local support because they can see direct tangible benefits, whereas the TPP was so abstract that even within the United States the public was confused and apprehensive to the agreement. That cannot be the case if America wants to gain stronger support in the region.

Heavy investments are an easy solution. They create a perception on the local level of American support, like the photos of U.S. Marines airlifting in food and medical supplies. The gains from local projects must be clear and direct. Gaining support for larger investments overseas is a difficult proposition and becoming increasingly more contentious. Smaller projects, though not as impactful, in greater amounts would allow for a greater reach through various communities and would keep with the small iterative approach preferred by ASEAN governments. The United States was willing to compete with the Soviet Union for ideological control of many regions, but now it finds itself competing with a large power state that does not seek to only do business with states that share like-minded politics, and so to meet this new world order the United States cannot afford to be so particular. That said, the United States has a long history of supporting governments only because of their anti-communistic positions, when we should have taken a much harder glance at their own domestic practices instead. An American presence can serve to steer political directions at the local level, pushing for gradual iterative changes over time. 
Human rights

The same approach is applicable in regard to ASEAN's position on issues of social norms. It will continue to make gradual steps as it seeks to accommodate imminent social changes while stopping short of instigating further changes or confrontations when at all avoidable. A steady American presence in the region can serve to sustain pressure on governments of the value of adopting liberal norms. The United States has had notable success in this regard throughout East Asia, most notably with the evolutions in Japanese and South Korean societies. ASEAN governments will maintain policies that continue the region's antifragile nature, and so a guiding hand seeking to promote the advantages of change need not focus on economic growth, but over the long-term resilience of Western liberal practices.

It is important to note that the ASEAN governments are not necessarily resistant to normative changes, but they seek to do them in the same gradual iterative nature seen in other policy making processes. The nature of antifragility is the adoption of small diverse changes, this allows successful ones to be found and adopted while minimizing potential risks of failed changes. There have been inroads made towards giving a greater voice to CSOs on issues such as human rights, but given the tumultuous social and political uprisings throughout much of the Middle East, in part linked to civil liberties, governments within ASEAN are apprehensive on the best approach to the issue. They seek a slow but steady trickle of changes to prevent the dam from bursting. Foreign involvement to bolster the CSOs will likely cause them to be alienated from their local 
governments, a more direct communication directly with the governments towards the capabilities of these CSOs to resolve social issues on a local level without needing to expend provincial resources through funds or personnel. Giving local teams the permission to address issues will allow for the greater ASEAN to view which efforts are, or not, successful, thus continuing its antifragile practices.

An American presence serves to facilitate cultural exchanges of ideas and values. Through the Viet Nam-to-Oregon Initiative, I have experienced firsthand the eager curiosity towards Western values. This program is also serving to advance economic trade and educational opportunities. Cultural exchanges will continue to increase the curiosity and eventual call for normative changes, and so exchange programs through local and state officials will serve to raise awareness of the advantages of adoption and the risks of ignoring the call for change. There are many programs such as this already operating, they need to be given greater funding in the U.S. and given greater access within ASEAN.

\section{A Final Thought}

The goal of this thesis has been to demonstrate the value in expanding involvement in the region. ASEAN redefines the paradigms of what the role of a regional organization is, and while each of the existing dominant international relations theories do bring significant levels of knowledge to bare, they each suffer from their own inherent limitations. I propose the reactive isomorphic theory as a tool to incorporate the lessons 
learned from these theories by bringing awareness of these gaps. From the realist's notions of establishing a security infrastructure, to liberalism's emphasis on relying upon integrating infrastructures for expanding economic trade, or constructivist's promotion of a cultural identity for the greater region, none of these archetypes resemble the organization that ASEAN has evolved into. Focusing on ASEAN's policies and actions has demonstrated a behavior of neo-contingency, institutional isomorphism, and adaptive antifragile through which the regional organization has continued to evolve into a vastly different organization than what it originally was when the original five members focused more on securing peaceful relations amongst each other and the prevention of the spread of communism, into the economically minded inclusive institution it is today.

Meaningful programs that give tangible benefits to locals have a strong impact on lasting sentiments, such as expanding the efforts to remove toxins left behind after American involvement in Viet Nam. These initiatives not only serve to improve bonds with locals, but it also raises accountability levels for government cleanups throughout the region. This should go hand-in-hand with the infrastructure change initiatives. Promoting cleaner practices and renewable energies can be a costly and complicated transition, often ignored until absolutely necessary. By seeking to sponsor these shifts, it will aid local economies and put an American face on something they see directly benefiting them. The crucial theme is to maintain a visible and positive American presence within Southeast Asia. Promoting ideas without forcing change will allow the ASEAN governments the ability to adapt and adopt normative changes. Some practices will serve better in some provinces than others as the separate governments attempt various alterations. The continued involvement by the United States, through trust- 
building efforts and economic initiatives, will serve to establish a durable value to its message in the region. 


\section{References}

Abuza, Zachary, and Nguyen Nhat Anh. Vietnam's Military Modernization. October 28, 2016. http://thediplomat.com/2016/10/vietnams-military-modernization/ (accessed October 28, 2016).

Acharya, Amitav. "Arguing about ASEAN: what do we disagree about?" Cambridge Review of International Affairs, 2009: 493-499.

-. Constructing a Security Community in Southeast Asia: ASEAN and the Problem of Regional Order . London: Routledge, 2001.

Acharya, Amitav, and Barry Buzan. Non-Western International Relations Theory. New York: Routledge, 2010.

African Union Sumit. Transition from the OAU to the African Union. May 2002. http://www.au2002.gov.za/docs/background/oau_to_au.htm (accessed March 18, 2017).

Allen-Ebrahimian, Bethany. This Village In Vietnam Is Holding A Dozen Police Officers Hostage. April 17, 2017. http://foreignpolicy.com/2017/04/17/this-village-invietnam-is-holding-a-dozen-police-officers-hostage/ (accessed April 19, 2017).

ANTARA News. ASEAN feared to become multinational companies market only. November 10, 2011. http://www.antaranews.com/en/news/77403/asean-feared-tobecome-multinational-companies-market-only (accessed October 18, 2017).

Anwar, Dewi Fortuna. Indonesia, ASEAN and Regional Stability. Brief, Jakarta: ASEAN Studies Program, 2017.

ASEAN Defence Ministers' Meeting. About the ASEAN Defence Ministers' Meeting (ADMM). February 6, 2017. https://admm.asean.org/index.php/aboutadmm/about-admm.html (accessed April 15, 2017).

ASEAN Ministerial Meeting. "Joint Comminuque The 30th ASEAN Ministerial Meeting (AMM)." Association of Southeast Asian Nations. July 25, 1997. https://web.archive.org/web/20151117090931/http://www.asean.org/index.php/co mmunities/asean-political-security-community/item/joint-comminuque-the-30thasean-ministerial-meeting-amm-2 (accessed October 23, 2017).

ASEAN Secretariat Information Paper. "Overview of ASEAN Plus Three Cooperation." Association of Southeast Asian Nations. June 2017. http://asean.org/storage/2017/06/Overview-of-APT-Cooperation-Jun-2017.pdf (accessed September 3, 2017).

Association of Southeast Asian Nations. "Agreement on the Common Effective Preferential Tariff Scheme for the ASEAN Free." ASEAN. January 28, 1992. http://www.asean.org/storage/images/2012/Economic/AFTA/Common_Effective 
_Preferential_Tariff/Agreement\%20on\%20the\%20Common\%20Effective\%20Pre ferential $\% 20$ Tariff $\% 20$ Scheme $\% 20$ for $\% 20$ the $\% 20$ ASEAN $\% 20$ Free $\% 20$ Trade $\% 2$ 0Area.pdf (accessed October 16, 2017).

-. Association of Southeast Asian Nations. n.d. http://asean.org/ (accessed October 3, 2016).

—. "Declaration of ASEAN Concord II (Bali Concord II)." Association of Southeast Asian Nations. May 11, 2012. http://asean.org/?static_post=declaration-of-aseanconcord-ii-bali-concord-ii (accessed August 26, 2017).

Aung, Nyan Lynn. Why ASEAN stays quiet as the Thai military seizes control. June 23, 2014. https://www.mmtimes.com/national-news/10777-why-asean-stays-quiet-asthe-thai-military-seizes-control.html (accessed November 12, 2017).

BBC. Philippine President Duterte's son denies drugs role. September 7, 2017. http://www.bbc.com/news/world-asia-41189557 (accessed September 8, 2017).

—. Rohingya crisis: UN sees 'ethnic cleansing' in Myanmar. September 11, 2017. http://www.bbc.com/news/world-asia-41224108 (accessed September 11, 2017).

-. Rohingya 'extremists' trying to build stronghold - Myanmar army. September 17, 2017. http://www.bbc.com/news/world-asia-41300247 (accessed September 21, 2017).

Bearak, Max, Laris Karklis, and Tim Meko. The 'ethnic cleansing' of the Rohingya. September 18, 2017. The 'ethnic cleansing' of the Rohingya (accessed September 21, 2017).

Behm, Allan. Why the Showdown in the South China Sea Is Far From Over. July 29, 2016. http://nationalinterest.org/blog/the-buzz/why-the-showdown-the-southchina-sea-far-over-17180 (accessed September 28, 2016).

Bellamy, Alex J., and Catherine Drummond. "The responsibility to protect in Southeast Asia: between non-interference and sovereignty as responsibility." The Pacific Review, 2011: 179-200.

Bellamy, Alex J., and Mark Beeson. "The Responsibility to Protect in Southeast Asia: Can ASEAN Reconcile Humanitarianism and Sovereignty?" Asian Security, 2010: 262-279.

Blanchard, Ben. Duterte says U.S. has lost, aligns Philippines with China. October 20, 2016. http://www.reuters.com/article/us-china-philippines-idUSKCN12K0AS (accessed October 20, 2016).

Brilliant, Myron. A Free Trade Area of the Asia-Pacific: An Idea with Merit, but Is It Feasible? January 2007. 
https://web.archive.org/web/20110920100958/http://www.brookings.edu/opinions /2007/09northeastasia_brilliant.aspx (accessed October 22, 2017).

Caballero-Anthony, Mely. "Understanding ASEAN's centrality: bases and prospects in an evolving regional architecture." The Pacific Review, 2014: 563-584.

Cabuenas, Jon Viktor D. World Bank: Easing restrictions in ASEAN labor migration to improve regional economy. October 9, 2017.

http://www.gmanetwork.com/news/money/economy/628793/world-bank-easingrestrictions-in-asean-labor-migration-to-improve-regional-economy/story/ (accessed November 18, 2017).

Cepeda, Mara. Human rights not discussed in ASEAN lawmakers' anti-drug meeting. July 7, 2017. https://www.rappler.com/nation/174912-human-rights-not-discussedaipa-committee-combat-drug-menace (accessed September 3, 2017).

Chachavalpongpun, Pavin. Is Promoting Human Rights in ASEAN an Impossible Task? January 19, 2018. https://thediplomat.com/2018/01/is-promoting-human-rights-inasean-an-impossible-task/ (accessed January 19, 2018).

Chalermpalanupap, Termsak. No ASEAN Consensus on the South China Sea. July 21, 2016. http://thediplomat.com/2016/07/no-asean-consensus-on-the-south-chinasea/ (accessed October 1, 2016).

Clark, Helen. Why China Should Fear India's Arms Sales to Vietnam (Think South China Sea). January 11, 2017. http://nationalinterest.org/blog/the-buzz/why-chinashould-fear-indias-arms-sales-vietnam-think-south-19025 (accessed January 11, 2017).

Clemens, Walter C. ASEAN and the Logic of Collective Action. July 28, 2016. http://thediplomat.com/2016/07/asean-and-the-logic-of-collective-action/ (accessed September 29, 2016).

-. How to Avoid War in the South China Sea. July 21, 2016. http://thediplomat.com/2016/07/how-to-avoid-war-in-the-south-china-sea/ (accessed October 3, 2016).

Cruz de Castro, Renato. The Philippines is Still Balancing Against China Amid Duterte's Pivot. November 2, 2016. http://thediplomat.com/2016/11/the-philippines-is-stillbalancing-against-china-amid-dutertes-pivot/ (accessed November 2, 2016).

Davies, Mathew. "ASEAN and human rights norms: constructivism, rational choice, and the action-identity gap." International Relations of the Asia-Pacific, 2013: 207231.

Davies, Sara E., Kimberly Nackers, and Sarah Teitt. "Women, Peace and Security as an ASEAN priority." Australian Journal of International Affairs, 2014: 333-355. 
Dillon, Dana R. "Countering Beijing in the South China Sea." Policy Review, 2011: 5167.

Dobell, Graeme. The Biggest Loser in President Rodrigo Duterte's Great China Play Is... October 31, 2016. http://nationalinterest.org/blog/the-buzz/the-biggest-loserpresident-rodrigo-dutertes-great-china-18239 (accessed October 31, 2016).

Doody, Justine. Can ASEAN Economic Integration Succeed? April 2, 2018. https://thediplomat.com/2018/04/can-asean-economic-integration-succeed/ (accessed April 2, 2018).

Doyle, Nicholas. "The ASEAN Human Rights Declaration and the Implications of Recent Southeast Asian Initiatives in Human Rights Institution-Building and Stanrd-Setting." International and Comparative Law Quarterly, 2014: 67-101.

Drysdale, Peter, and Shiro Armstrong. "International and Regional Cooperation: Asia's Role and Responsibilities." Asian Economic Policy Review, 2010: 157-173.

Duffield, John. "Why is there no APTO? Why is there no OSCAP?: Asia-Pacific security institutions in comparative perspective." Contemporary Security Policy, 2010: 6995.

Durando, Jessica. Philippines President Duterte tells Obama 'you can go to hell'. October 4, 2016. http://www.usatoday.com/story/news/world/2016/10/04/duterte-tellsobama-you-can-go-to-hell-/91549588/ (accessed October 4, 2016).

Durbach, Andrea, Catherine Renshaw, and Andrew Byrnes. "'A tongue but no teeth?': The emergence of a regional human rights mechanism in the Asia Pacific region." Sydney Law Review, 2011: 211-238.

Elliott, Lorraine. "ASEAN and environmental governance: rethinking networked." Procedia Social and Behavioral Sciences, 2011: 61-64.

Elliott, Lorraine. "ASEAN and Environmental Governance: Strategies of Regionalismin Southeast Asia ." Global Environmental Politics, 2012: 38-57.

Emmers, Ralf. "Indonesia's role in ASEAN: A case of incomplete and sectorial leadership." The Pacific Review, 2014: 543-562.

Floristella, Angela Pennisi di. The ASEAN Regional Security Partnership: Strengths and Limits of a Cooperative System. Basingstoke: Palgrave Macmillan, 2015.

Foreign Ministers of the Association of Southeast Asian Nations . "Turning Vision into Reality for a Dynamic ASEAN Community." Joint Communique of the 49th ASEAN Foreign Ministers' Meeting. 2016. 1-31.

Ganesan, N. Bilateral Tensions in Post-cold War ASEAN. Singapore: Institute of Southeast Asian Studies, 1999. 
Ganesan, N., and Ramses Amer. International Relations in Southeast Asia. Singapore: ISEAS Publishing, 2010.

Gilley, Bruce. "Beyond the Four Percent Solution: explaining the consequences of China's rise." Journal of Contemporary China, 2011: 795-811.

-. The Nature of Asian Politics. Cambridge: Cambridge University Press, 2014.

-. The Right to Rule: How States Win and Lose Legitimacy. New York City: Columbia University Press, 2013.

Gomez, Jim. ASEAN Summit May Bow to Chinese Pressure on South China Sea. September 5, 2016. http://www.military.com/daily-news/2016/09/05/aseansummit-may-bow-chinese-pressure-south-china-sea.html (accessed September 20, 2016).

Gregson, Wallace C. South China Sea: It's Not Just About the Rocks, It's Also About the Fish. August 1, 2016. http://nationalinterest.org/feature/south-china-sea-its-notjust-about-the-rocks-its-also-about-17206 (accessed August 29, 2016).

Hachigan, Nina. ASEAN's Golden Moment in a Time of Crisis. August 9, 2017. http://foreignpolicy.com/2017/08/09/aseans-golden-moment-trump-north-koreachina-trade/ (accessed August 9, 2017).

Han, David. After Obama, What's Next for ASEAN Centrality? September 27, 2016. http://thediplomat.com/2016/09/after-obama-whats-next-for-asean-centrality/ (accessed September 27, 2016).

Harold, Scott W. Don't Weaken the U.S.-Japan Alliance, Strengthen It. August 12, 2016. http://nationalinterest.org/blog/the-buzz/dont-weaken-the-us\%E2\%80\%93japanalliance-strengthen-it-17330 (accessed October 5, 2016).

Hart, Michael. Is Myanmar on the Path to Genocide? January 18, 2017. http://thediplomat.com/2017/01/is-myanmar-on-the-path-to-genocide/ (accessed January 18, 2017).

Head, Jonathan. BBC reporter in Rakhine: 'A Muslim village was burning'. September 7 , 2017. http://www.bbc.com/news/world-asia-41189564 (accessed September 8, 2017).

Heydarian, Richard Javad. Can China Really Ignore International Law? August 1, 2016. $\mathrm{http}: / /$ nationalinterest.org/feature/can-china-really-ignore-international-law-17211 (accessed September 30, 2016).

Hooi, Khoo Ying. The Indispensible Role of Civil Society in ASEAN. September 15, 2017. https://iapsdialogue.org/2017/09/15/the-indispensable-role-of-civil-societyin-asean/ (accessed November 15, 2017). 
Human Rights Watch. Thailand: Junta Entrenched 3 Years After Coup. May 21, 2017. https://www.hrw.org/news/2017/05/21/thailand-junta-entrenched-3-years-aftercoup (accessed September 3, 2017).

Hunt, Luke. Beware ASEAN's Coming Economic Gloom. February 21, 2016. https://thediplomat.com/2016/02/beware-aseans-coming-economic-gloom/ (accessed November 9, 2017).

-. Does an ASEAN Agreement Mean Progress for RCEP? September 15, 2017. http://thediplomat.com/2017/09/does-an-asean-agreement-mean-progress-forrcep/ (accessed September 17, 2017).

—. Time for an ASEAN Criminal Court? December 16, 2016. http://thediplomat.com/2016/12/time-for-an-asean-criminal-court/ (accessed December 16, 2016).

Hutt, David. Beware Vietnam's Death Machine. April 20, 2017. http://thediplomat.com/2017/04/beware-vietnams-death-machine/ (accessed April 20, 2017).

—. Defending Free Speech in ASEAN. January 23, 2017. http://thediplomat.com/2017/01/defending-free-speech-in-asean/ (accessed January 23, 2017).

Jho, Whasun, and Soo A Chae. "Hegemonic Disputes and the Limits of the ASEAN Regional Forum." Pacific Focus, 2014: 237-259.

Jones, David Martin, and M. L. R. Smith. ASEAN and East Asian International Relations: Regional Delusion. Cheltenham: Edward Elgar Publishing, 2006.

Juego, Bonn. The Political Economy of the ASEAN Regionalisation Process. October 29, 2015. https://www.boell.de/en/2015/10/28/political-economy-aseanregionalisation-process (accessed April 15, 2017).

Kang, David C. "Hierarchy and Legitimacy in International Systems: The Tribute System in Early Modern East Asia." Security Studies, 2010: 591-622.

Kapur, Roshni. Is Timor-Leste Finally Ready to Join ASEAN? October 1, 2016. http://thediplomat.com/2016/10/is-timor-leste-finally-ready-to-join-asean/ (accessed October 5, 2016).

Katsumata, Hiro. "Mimetic adoption and norm diffusion: 'Western' security cooperation in Southeast Asia?" Review of International Studies, April 2011: 557-576.

Katsumata, Hiro. "What explains ASEAN's leadership in East Asian community building?" Pacific Affairs, 2014: 247. 
Khoo, Nicholas. Why ASEAN is in Disarray in the South China Sea. October 7, 2016. http://nationalinterest.org/blog/the-buzz/why-asean-disarray-the-south-china-sea17973 (accessed October 7, 2016).

Kim, Min-hyung. "Thorizing ASEAN Integration." Asian Perspective, 2011: 407-435.

Kinsella, David, Bruce Russet, and Harvey Starr. Wolrd Politics: The Menu for Choice. Boston: Wadsworth, 2013.

Kuo, Mercy A. Regional Security Architectures: Comparing Asia and Europe. June 28, 2017. http://thediplomat.com/2017/06/regional-security-architectures-comparingasia-and-europe/ (accessed June 30, 2017).

—. The Philippines' 'Pivot' to China: View From Singapore. November 16, 2016. http://thediplomat.com/2016/11/the-philippines-pivot-to-china-view-fromsingapore/ (accessed November 16, 2016).

Lee, Yoong Yoong. ASEAN Matters!: Reflecting on the Association of Southeast Asian Nations. Singapore: World Scientific, 2011.

Lewis, Simon. Malaysia calls for ASEAN to coordinate aid for Myanmar's Rohingya. December 19, 2016. http://www.reuters.com/article/us-myanmar-rohingya-aseanmalaysia-idUSKBN1480E1 (accessed December 20, 2016).

Li, Kristoffer Daniel. The Point of ASEAN. July 30, 2016.

http://thediplomat.com/2016/07/the-point-of-asean/ (accessed October 3, 2016).

Limaye, Satu. Why ASEAN Is Here to Stay and What That Means for the US. August 30, 2016. http://thediplomat.com/2016/08/why-asean-is-here-to-stay/ (accessed September 25, 2016).

Ling, Wei. "Rebalancing or De-Balancing: U.S. Pivot and East Asian Order." American Foreign Policy Interests, 2013: 148-154.

Lohman, Walter. Rodrigo Duterte's China Lovefest: What Should America Do? October 20, 2016. http://nationalinterest.org/blog/the-buzz/rodrigo-dutertes-china-lovefestwhat-should-america-do-18118 (accessed October 20, 2016).

Lowenkron, Barry F. "The Essential Role of Non-Governmental Organizations in the Development of Democracy." Remarks to the Senate Foreign Relations Committee. Washongton: United States Department of State, June 6, 2006.

March, James G., and Johan P. Olsen. "The Institutional Dynamics of International Political Orders." International Organization, 1998: 943-969.

Mathur, Sahil. ASEAN and North Korea: Strange Bedfellows? May 3, 2017. http://thediplomat.com/2017/05/asean-and-north-korea-strange-bedfellows/ (accessed May 3, 2017). 
McKinny, Jared. Is Rodrigo Duterte a Fool, a Genius-or Both? October 13, 2016. $\mathrm{http} / / /$ nationalinterest.org/blog/the-skeptics/rodrigo-duterte-foolgenius\%E2\%80\%94or-both-18042 (accessed October 14, 2016).

Miller, Paul D. American Power and Liberal Order. September 14, 2016. http://nationalinterest.org/feature/american-power-liberal-order-17715 (accessed October 3, 2016).

Ministry of Strategy and Finance. "ASEAN + 3 Finance Ministers and Central Bank Governors' Meeting Successfully Concludes." Internet Archive Wayback Machine. May 3, 2010. https://web.archive.org/web/20130430184823/http://english.mosf.go.kr/upload/mi ni/2012/05/FILE_A66G81_20120503182819_1.pdf (accessed October 22, 2017).

Mogato, Manuel, and Aubrey Belford. Dramatic U.S. humanitarian effort in Philippines aids Asia 'pivot'. November 18, 2013. https://www.reuters.com/article/usphilippines-typhoon-pivot/dramatic-u-s-humanitarian-effort-in-philippines-aidsasia-pivot-idUSBRE9AH12L20131118 (accessed March 2, 2018).

Mogato, Manuel, and Kanupriya Kapoor. ASEAN gives Beijing a pass on South China Sea dispute, cites 'improving cooperation'. April 29, 2017. http://www.reuters.com/article/us-asean-summit-idUSKBN17W02E (accessed April 30, 2017).

Mollman, Steve. Maritime Tensions Grow Between Rising China and Rearming Japan. September 23, 2016. http://www.defenseone.com/threats/2016/09/maritimetensions-grow-between-rising-china-and-rearming-japan/131779/?oref=d-river (accessed October 6, 2016).

Mordecai, Aédán. What is the Future of Integration and Inequality in ASEAN? September 15, 2017. http://thediplomat.com/2017/09/what-is-the-future-ofintegration-and-inequality-in-asean/ (accessed September 17, 2017).

Nguyen, Quoc-Thanh. France Unveils Its Defense Strategy in the South China Sea and Beyond. September 27, 2016. http://thediplomat.com/2016/09/france-unveils-itsdefense-strategy-in-the-south-china-sea-and-beyond/ (accessed September 30, 2016).

Oba, Mie. ASEAN's Hedging Strategy. September 29, 2016. http://thediplomat.com/2016/09/aseans-hedging-strategy/ (accessed September 29, 2016).

Olarn, Kocha. Thai protest in Bangkok: 28 injured in explosions. January 20, 2014. http://www.cnn.com/2014/01/19/world/asia/thailand-protests/index.html (accessed September 3, 2017). 
Panda, Aknit. Duterte: No Bargaining With China on South China Sea. October 17, 2016. http://thediplomat.com/2016/10/duterte-no-bargaining-with-china-on-southchina-sea/ (accessed October 17, 2016).

Panda, Ankit. China, ASEAN Come to Agreement on a Framework South China Sea Code of Conduct. May 19, 2017. http://thediplomat.com/2017/05/china-aseancome-to-agreement-on-a-framework-south-china-sea-code-of-conduct/ (accessed may 19, 2017).

Parameswaran, Prashanth. A New ASEAN Trilateral Terrorism 'Task Force'? September 7, 2017. http://thediplomat.com/2017/09/a-new-asean-trilateral-terrorism-taskforce/ (accessed September 13, 2017).

-. ASEAN Steps Up Zika Battle in Special Meeting. September 21, 2016. http://thediplomat.com/2016/09/asean-steps-up-zika-battle-in-special-meeting/ (accessed October 2, 2016).

-. China Blocked ASEAN Defense Meeting Pact Amid South China Sea Fears: US Official. November 4, 2015. http://thediplomat.com/2015/11/china-blocked-asiadefense-meeting-pact-amid-south-china-sea-fears-us-official/ (accessed April 15, 2017).

-. China, Thailand Mull Joint Military Production Facility. December 20, 2016. http://thediplomat.com/2016/12/china-thailand-mull-joint-military-productionfacility/ (accessed December 20, 2016).

-. China-Vietnam South China Sea Spat in the Spotlight. July 25, 2017. http://hediplomat.com/2017/07/china-vietnam-south-china-sea-spat-in-thespotlight/ (accessed July 25, 2017).

-. How Deadly Is ASEAN's Killer Haze? September 21, 2016. http://thediplomat.com/2016/09/how-deadly-is-aseans-killer-haze/ (accessed September 24, 2016).

-. Singapore Unveils New ASEAN Defense Initiatives Ahead of Chairmanship. June 5, 2017. http://thediplomat.com/2017/06/singapore-unveils-new-asean-defenseinitiatives-ahead-of-chairmanship/ (accessed June 5, 2017).

—. Singapore Warns of Rising ASEAN Terror Threat. October 4, 2016. http://thediplomat.com/2016/10/singapore-warns-of-rising-asean-terror-threat/ (accessed October 4, 2016).

—. The Limits of Duterte's US-China Rebalance. October 24, 2016. http://thediplomat.com/2016/10/the-limits-of-dutertes-us-china-rebalance/ (accessed October 24, 2016). 
-. The Real Challenge for US-ASEAN Relations Under Trump. May 5, 2017. http://thediplomat.com/2017/05/the-real-challenge-for-us-asean-relations-undertrump/ (accessed May 5, 2017).

-. US Group to Boost ASEAN Disaster Relief Capabilities. November 22, 2016. http://thediplomat.com/2016/11/us-group-to-boost-asean-disaster-reliefcapabilities/ (accessed November 22, 2016).

-. US Unveils New Maritime Security Initiatives at ASEAN Defense Meeting. October 2, 2016. http://thediplomat.com/2016/10/us-unveils-new-maritime-securityinitiatives-in-us-asean-defense-meeting/ (accessed October 2, 2016).

-. US, Singapore to Launch New Military Exercise in Guam. April 22, 2017. http://thediplomat.com/2017/04/us-singapore-to-launch-new-military-exercise-inguam/ (accessed April 22, 2017).

—. US-ASEAN Defense Ministers' Meeting Kicks Off in Hawaii. October 1, 2016. http://thediplomat.com/2016/10/us-asean-defense-ministers-meeting-kicks-off-inhawaii/ (accessed October 1, 2016).

-. US-Philippines Air Force Cooperation in the Spotlight Amid Exchange. September 2, 2017. http://thediplomat.com/2017/09/us-philippines-air-force-cooperation-in-thespotlight-amid-exchange/ (accessed September 3, 2017).

-. What Did the ASEAN Trilateral Terror Meeting Achieve? June 28, 2017. http://thediplomat.com/2017/06/what-did-the-asean-trilateral-terror-meetingachieve/ (accessed June 30, 2017).

-. Why Vietnam-Philippines South China Sea Confidence-Building Matters. June 27', 2017. http://thediplomat.com/2017/06/why-vietnam-philippines-south-china-seaconfidence-building-matters/ (accessed June 29, 2017).

Parekh, Venessa. Assessing the ASEAN Community Project: Constructivism and the Problem of Inflexible Norms. Student Essay, E-International Relations Students, 2014.

Patag, Kristine Joy. Activist group slams 'violent dispersal of peaceful demonstration'. November 13, 2017. http://www.philstar.com/headlines/2017/11/13/1758534/activist-group-slamsviolent-dispersal-peaceful-demonstration (accessed November 15, 2017).

Paul, T. V. International Relations Theory and Regional Transformation. New York: Cambridge University Press, 2012.

Peace Women. Member States. March 2018. http://www.peacewomen.org/member-states (accessed April 19, 2018). 
Pempel, T.J. "More Pax, Less Americana in Asia ." International Relations of the AsiaPacific, 2010: 465-490.

Petty, Martin, and Karen Lema. SE Asia prioritizes trade pact including China as U.S. rethinks policy. April 26, 2017. https://www.reuters.com/article/us-asean-summittrade/se-asia-prioritizes-trade-pact-including-china-as-u-s-rethinks-policyidUSKBN17S0T2 (accessed February 24, 2018).

Rapp-Hooper, Mira. Here are 5 takeaways from Trump's startling nuclear threats against North Korea. August 21, 2017. https://www.washingtonpost.com/news/monkey-cage/wp/2017/08/21/here-are-5takeaways-from-trumps-startling-nuclear-threats-against-north-korea/ (accessed August 26, 2017).

Rice, Susan E. Susan Rice: American Leadership in the Asia-Pacific Must Continue. November 12, 2016. http://nationalinterest.org/feature/susan-rice-americanleadership-the-asia-pacific-must-18391 (accessed November 13, 2016).

Ritter, Mario. UN: Protectionism Threatens Asia's Economic Growth. May 3, 2017. https://learningenglish.voanews.com/a/un-protectionism-threatens-asia-economicgrowth/3834885.html (accessed October 22, 2017).

Roberts, Christopher B. ASEAN Regionalism. New York: Routledge, 2012.

Roblin, Sebastien. The Philippines' Hothead President Is Crapping All Over His Country's Strongest Ally. October 20, 2016. https://warisboring.com/thephilippines-hothead-president-is-crapping-all-over-his-country-s-strongest-allyb6f6dfe6fa03\#.4oii8jnms (accessed October 20, 2016).

Rüland, Jürgen. "The limits of democratizing interest representation: ASEAN's regional corporatism and normative challenges." European Journal of International Relations, 2014: 237-261.

Ryu, Yongwook, and Maria Ortuoste. "Democratization, regional integration, and human rights: the case of the ASEAN intergovernmental commission on human rights." The Pacific Review, 2014: 357-382.

Sato, Katsunori, and Michael Roy. "Further Limits to Institutional Isomorphism? Introducing the 'Neo-contingency Approach' to the Field of Community-Led Social Ventures." Voluntas: International Journal of Voluntary and Nonprofit Organizations, 2015: 2536-2553.

Shambaugh, David, and Michael Yahuda. International Relations of Asia. Lanham: Rowman \& Littlefield, 2014.

-. International Relations of Asia. Lanham: Rowman \& Littlefield, 2014. 
Sil, Rudra, and Peter J. Katzenstein. Beyond Paradigms: Analytic Eclecticism in the Study of World Politics. Basingstoke: Palgrave Macmillan, 2010.

Simon, Sheldon W. ASEAN and its Security Offspring: Facing New Challenges. Department of the Army, Strategic Studies Institute, 2007.

Slodkowski, Antoni, Wa Lone, Simon Lewis, and Krishna Das. How a two-week army crackdown reignited Myanmar's Rohingya crisis. April 25, 2017. http://www.reuters.com/investigates/special-report/myanmar-rohingya-crisis2/ (accessed November 12, 2017).

Souksavanh, Ounkeo. Lao Civil Society Pressured to Drop Rights Issues From ASEAN Forum. April 22, 2015. http://www.rfa.org/english/news/laos/forum04222015150409.html (accessed November 15, 2017).

Stubbs, Richard. "ASEAN's leadership in East Asian region-building: strength in weakness." The Pacific Review, 2014: 523-541.

Stubbs, Richard, and Sorin Mitrea. "ASEAN At 50: the global political economy's contribution to durability." Contemporary Politics (Rroutledge), 2017: 1-20.

Tadem, Eduardo C. Asean's attitude toward civil society. March 17, 2017. http://opinion.inquirer.net/102490/aseans-attitude-toward-civil-society (accessed November 13, 2017).

—. New Perspectives on Civil Society Engagement with ASEAN. July 12, 2017. https://th.boell.org/en/2017/07/12/new-perspectives-civil-society-engagementasean (accessed November 13, 2017).

Taleb, Nassim Nicholas. Antifragile: Things That Gain from Disorder. New York: Random House, 2012.

Tan, Andrew T.H. East and South-East Asia. New York: Routledge, 2013.

Tan, See Seng. "America the Indispensable: Singapore's View of the United States' Engagement in the Asia-Pacific." Asian Affairs, 2011: 156-171.

The Ministers and Representatives of Asian States. "Final Declaration of the Regional Meeting for Asia of the World Conference on Human Rights." Bangkok: Regional Meeting for Asia of the World Conference on Human Rights, 1993. 1-5.

The Star. Thai junta under fire from allies over Yingluck escape. August 28, 2017. http://www.thestar.com.my/news/regional/2017/08/28/thai-junta-under-fire-fromallies-over-yingluck-escape/ (accessed September 3, 2017).

Tong, Linh. Seeking a Solution to the South China Sea Disputes. July 21, 2016. http://thediplomat.com/2016/07/seeking-a-solution-to-the-south-china-seadisputes/ (accessed October 4, 2016). 
-. The ASEAN Crisis, Part 1: Why the South China Sea Is a Critical Test. December 21, 2016. http://thediplomat.com/2016/12/the-asean-crisis-part-1-why-the-southchina-sea-is-a-critical-test/ (accessed December 21, 2016).

-. The ASEAN Crisis, Part 2: Why Can't ASEAN Agree on the South China Sea? December 22, 2016. http://thediplomat.com/2016/12/the-asean-crisis-part-2-whycant-asean-agree-on-the-south-china-sea/ (accessed December 22, 2016).

-. The ASEAN Crisis, Part 3: What Should ASEAN Do About the South China Sea Dispute? December 23, 2016. http://thediplomat.com/2016/12/the-asean-crisispart-3-what-should-asean-do-about-the-south-china-sea-dispute/ (accessed December 23, 2016).

Tongsopit, Sopitsuda, Noah Kittner, Youngho Chang, and Apinya Aksornkij. "Energy Security in ASEAN: A Quantative Approach for Sustainable Energy Policy." Energy Policy, 2015: 60-72.

Tsjeng, Henrick Z. Time for ASEAN's Defense Ministers Meeting to Put Traditional Security on the Agenda. May 6, 2017. http://thediplomat.com/2017/05/time-foraseans-defense-ministers-meeting-to-put-traditional-security-on-the-agenda/ (accessed May 6, 2017).

U.S. Department of State. Remarks at Press Avaliability. July 23, 2010. http://www.state.gov/secretary/20092013clinton/rm/2010/07/145095.htm (accessed September 30, 2016).

United Nations. "General Assembly Adopts 10 Resolutions Encouraging Stronger Ties between Regional Organizations, United Nations to Address Global Challenges." United Nations - Mettings Coverage and Press Releases. November 21, 2016. https://www.un.org/press/en/2016/ga11859.doc.htm (accessed February 2, 2017).

United Nations. Renewing the United Nations: A Programme for Reform. Report of the Secretary-General, New York: United Nations, 1997.

Wall, Stephen. The Official History of Britain and the European Community, Vol. II: From Rejection to Referendum, 1963-1975. Abingdon: Routledge, 2012.

Watchers, Young China . Chinese Diplomacy in the 21st Century. July 4, 2016. http://thediplomat.com/2016/07/chinese-diplomacy-in-the-21st-century/ (accessed October 1, 2016).

Wey, Adam Leong Kok. Natural disaster management and the future of ASEAN cohesion. Sepetember 23, 2016. http://www.eastasiaforum.org/2016/09/23/natural-disaster-management-and-thefuture-of-asean-cohesion/ (accessed November 13, 2017). 
Yamazawa, Ippei. "The Asian Economic Crisis and Japan." The Developing Economies, September 1998: 332-3515.

Zakheim, Dov S. Think Asia Will Dominate the 21st Century? Think Again. February 13, 2017. http://nationalinterest.org/feature/think-asia-will-dominate-the-21stcentury-think-again-19429 (accessed February 14, 2017). 